\title{
The Impact of Volcker Rule on Bank Profits and Default Probabilities
}

\author{
by \\ Sohhyun Chung \\ A dissertation submitted in partial fulfillment \\ of the requirements for the degree of \\ Doctor of Philosophy \\ (Applied and Interdisciplinary Mathematics) \\ in The University of Michigan \\ 2013
}

Doctoral Committee:

Associate Professor Jussi S. Keppo, Co-Chair

Professor Joseph G. Conlon, Co-Chair

Associate Professor Edward L. Ionides

Professor Haitao Li

Associate Professor Kristen S. Moore 
(c) Sohhyun Chung 2013

All Rights Reserved 
To my father, Kyu-dong Chung, and my mother, Jung-kee Ahn 


\section{ACKNOWLEDGEMENTS}

I would like to express my deepest gratitude to my advisor, Prof. Jussi Keppo, for his excellent guidance, a lot of patience, and always picking me up and pushing me forward every time I struggled with slow research progress or lack of self-motivation. I would also like to thank my co-advisor, Prof. Joseph Conlon, for his generous sharing of his wisdom and experience about research. I also thank my other committee members including Prof. Edward Ionides, Prof. Haitao Li, and Prof. Kristen Moore for their insightful suggestions that were an enormous help to my work.

I would like to acknowledge many others who helped me along the way: my parents for their life-long sacrifices to provide me with the best education and environment to study as well as for their faith in me that I can finish my doctoral studies; my sister Hannah Chung and her husband Ray Cho for their unyielding support and care in all my struggles and frustrations throughout my last 12 years of study abroad in the United States; Pastor Park and my fellow Christian friends whom I have met at Campus Town Church of Ann Arbor for reminding me of the unfailing love of God during my difficult times; the fellow committee members of the Korean Student Association-Graduate at the University of Michigan from year 2009 to 2011, with whom the memories that I had will be perpetually cherished; and all of the students, staff, and faculty members in the Department of Mathematics at the University of Michigan who helped me learn, teach and grow as a researcher, an instructor, and a person throughout the seven years I spent there. 


\section{TABLE OF CONTENTS}

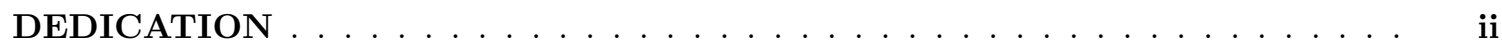

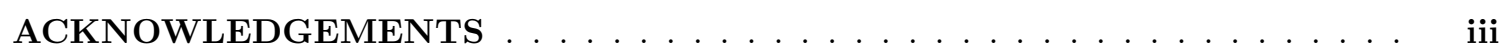

LIST OF FIGURES $\ldots \ldots \ldots \ldots \ldots \ldots \ldots \ldots \ldots \ldots \ldots \ldots \ldots$

\section{CHAPTER}

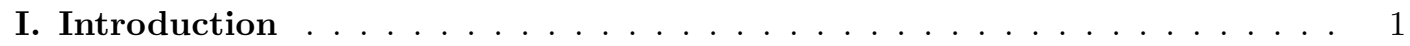

II. A Simple Stochastic Control Model with No Recapitalization . . . . . . . . 5

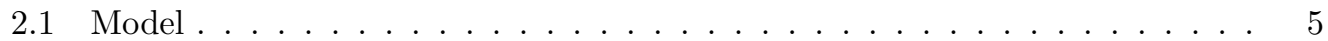

2.2 Characterization of Optimum $\ldots \ldots \ldots \ldots \ldots \ldots$

$2.3 \quad$ Model Calibration . . . . . . . . . . . . . . . . . . . . . . . 16

2.3 .1 Banks . . . . . . . . . . . . . . . . . . 16

$2.3 .2 \quad$ Model Parameters . . . . . . . . . . . . . . . . . . 18

$2.3 .3 \quad$ Cross-sectional Test and Comparative Statics . . . . . . . . . . . 23

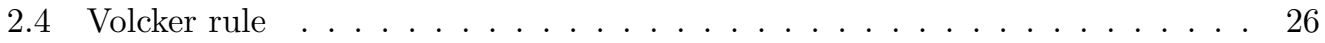

$2.4 .1 \quad$ Loan Prices . . . . . . . . . . . . . . . . . . . . . . . . . . . . . 28

$2.4 .2 \quad$ Default Probabilities . . . . . . . . . . . . . . . . . . . . . 30

$2.5 \quad$ Appendix for Chapter II $\ldots \ldots \ldots \ldots$. . . . . . . . . . . . . . . . . 34

2.5.1 Model under the Objective Measure . . . . . . . . . . . . . . . . 34

2.5.2 Optimal Trading Strategy $\ldots \ldots \ldots$. . . . . . . . . . . . . . . 35

$2.5 .3 \quad$ Model Parameters $\ldots \ldots \ldots$. . . . . . . . . . . . . . . . . 38

2.5 .4 Volcker Rule. . . . . . . . . . . . . . . . . . . . . . . . . . . . . . . 39

2.5.5 $\quad$ Buffer Capital . . . . . . . . . . . . . . . . . . . . . . . . . . . . . 41

$2.5 .6 \quad$ Comparative Statics . . . . . . . . . . . . . . . . . . . 42

2.5 .7 Default Probability . . . . . . . . . . . . . . . . . 45

III. A Stochastic Control Model with Recapitalization . . . . . . . . . . . . . . . 48

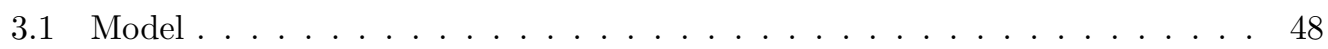

3.1.1 A Model of Bank Capital . . . . . . . . . . . . . . . . . . 50

$3.1 .2 \quad$ A Normalized Model of Bank Capital Ratio . . . . . . . . . . . . . 55

3.2 Characterization of Optimum $\ldots \ldots \ldots \ldots \ldots \ldots$

3.3 Model Calibration . . . . . . . . . . . . . . . . . . . . . . 63

3.3 .1 Banks . . . . . . . . . . . . . . . . . . 63

$3.3 .2 \quad$ Discrete Model for Equity Ratio. . . . . . . . . . . . . . . . . . 65

3.3.3 $\quad$ Model Parameters for Net Income Earnings . . . . . . . . . . . . . 67

3.3 .4 Cross-sectional Test and Comparative Statics . . . . . . . . . . . . 70

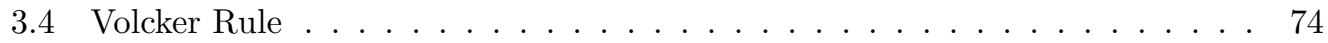

3.4 .1 Bank Value . . . . . . . . . . . . . . . . . . . 75 
3.4 .2 Loan prices . . . . . . . . . . . . . . . . . 76

3.4.3 Default probabilities . . . . . . . . . . . . . . . . . . . . . . . . . . . . . . . . . 8

3.5 Appendix for Chapter III . . . . . . . . . . . . . . . . . . . . . . . . . . . 82

3.5.1 Model under the Objective Measure . . . . . . . . . . . . . . . 82

3.5.2 Optimal Trading Strategy . . . . . . . . . . . . . . . . . . 83

3.5.3 Model Parameters . . . . . . . . . . . . . . . . . . . 86

3.5 .4 Model Value . . . . . . . . . . . . . . . . . . . . . . . . 88

3.5.5 Buffer Capital . . . . . . . . . . . . . . . . . . . . . . . . . . . . . . . . . . . . . . .

3.5.6 Comparative Statics . . . . . . . . . . . . . . . . . . . . . . . . . . . . . . . . . . . 91

3.5.7 Default Probability . . . . . . . . . . . . . . . . 96

IV. Conclusion . . . . . . . . . . . . . . . . . . . . . . . . . 101 


\section{LIST OF FIGURES}

\section{Figure}

\begin{tabular}{|c|c|}
\hline \multirow[t]{10}{*}{2.1} & Actual vs. model buffer capital ratios for the sample banks. This figure \\
\hline & shows mean buffer capital ratios (during 2000 Q1 - 2011 Q4) plotted against the \\
\hline & corresponding model dividend barriers. The filled triangles are with the trading \\
\hline & phas and correlations equal to their estimated values while the empty squares are \\
\hline & with the statistically significant trading alphas and correlations (the non-significant \\
\hline & trading alphas and correlations are zero). Linear regression lines are drawn in \\
\hline & the figure. The numbers in the parentheses are the standard deviations of the \\
\hline & parameters. Without the outlier (ABVA), the regression line for the estimated \\
\hline & parameters is $y=1.344+0.86 x$ and $R^{2}$ is $20 \%$. Thus, then the regression line is \\
\hline & close to the regression line of the significant parameters. $\ldots \ldots \ldots \ldots$ \\
\hline \multirow[t]{7}{*}{2.2} & Comparative Statics. We use the following median parameter values over all the \\
\hline & banks: $\zeta=95 \%, r=2 \%, \delta=2 \%, \sigma_{B}=0.3 \%, \sigma_{T}=4 \%, \rho_{B T}=-0.1, \alpha_{B}=0.4 \%$, \\
\hline & $\alpha_{T}=0.4 \%, \delta=2 \%$, and $x=0.5 \%$. Figures below show how the value function \\
\hline & $(2.7 d)$ and dividend barrier $u$ change with respect to banking proportion $\zeta$, banking \\
\hline & volatility $\sigma_{B}$, trading volatility $\sigma_{T}$, correlation between the banking and trading \\
\hline & earnings $\rho_{B T}$, banking alpha $\alpha_{B}$, trading alpha $\alpha_{T}$, risk-free rate $r$, and wedge \\
\hline & 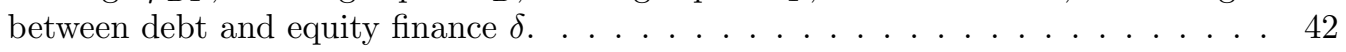 \\
\hline \multirow[t]{9}{*}{2.3} & Default probability changes with varying model parameters for Bank \\
\hline & FHN. We analyze two banks (FHN and MTB) and how their default probability \\
\hline & changes with respect to model parameters. We consider two cases: Case $(i)$ is \\
\hline & without the Volcker rule and case $(\mathrm{ii})$ is under the Volcker rule (no alpha bets). The \\
\hline & first bank is FHN and we use its estimated parameters in Table 2.1 . Figures below \\
\hline & show how the default probability changes with respect to banking proportion $\zeta$, \\
\hline & risk-free rate $r$, correlation between the banking and trading earnings $\rho_{B T}$, wedge \\
\hline & " between debt and equity finance $\delta$, banking volatility $\sigma_{B}$, trading volatility $\sigma_{T}$, \\
\hline & banking alpha $\alpha_{B}$, and trading alpha $\alpha_{T} \cdot \ldots \ldots$. . . . . . . . . . . . . . . . . . \\
\hline \multirow[t]{6}{*}{2.4} & Default probability changes with varying model parameters for Bank \\
\hline & MTB. The second bank is MTB and we use its estimated parameters in Table 2.1. \\
\hline & Figures below show how the default probability changes with respect to banking \\
\hline & proportion $\zeta$, risk-free rate $r$, correlation between the banking and trading earnings \\
\hline & $\rho_{B T}$, wedge between debt and equity finance $\delta$, banking volatility $\sigma_{B}$, trading \\
\hline & volatility $\sigma_{T}$, banking alpha $\alpha_{B}$, and trading alpha $\alpha_{T} \cdot \ldots \ldots$ \\
\hline \multirow[t]{10}{*}{3.1} & Actual vs. model values of banks at the mean out-of-sample equity level. \\
\hline & This figure shows realized market equity level during the out-of-sample period 2010 \\
\hline & Q1 - 2011 Q4 plotted against the model value function evaluated at the mean out-of- \\
\hline & sample equity level. The filled triangles are with the banking and trading alphas and \\
\hline & correlations equal to their estimated values while the empty squares are with the \\
\hline & statistically significant banking and trading alphas and correlations $\rho_{B T}, \rho_{R E}, \rho_{R A}$ \\
\hline & and $\rho_{A E}$ (the non-significant alphas and correlations are zero). Linear regression \\
\hline & lines are drawn in the figure. The numbers in the parentheses are the standard \\
\hline & deviations of the parameters. One asterisk $\left(^{*}\right)$ indicates the significance level of \\
\hline & $5 \%$, and two $(* *)$ indicates $1 \%$. \\
\hline
\end{tabular}


$3.2 \quad$ Actual vs. model buffer capital ratios for the sample banks. This figure shows maximum buffer capital ratios (during 2000 Q1 - 2011 Q4) plotted against the corresponding model dividend barriers. The filled triangles are with the banking and trading alphas and correlations equal to their estimated values while the empty squares are with the statistically significant banking and trading alphas and correlations $\rho_{B T}, \rho_{R E}, \rho_{R A}$ and $\rho_{A E}$ (the non-significant alphas and correlations are zero). Linear regression lines are drawn in the figure. The numbers in the parentheses are the standard deviations of the parameters. $\ldots \ldots \ldots . \ldots 90$

3.3 Comparative Statics. We use the following median parameter values over all the banks: $\zeta=95 \%, r=2 \%, \sigma_{B}=0.5 \%, \sigma_{T}=2 \%, \rho_{B T}=-0.1, \alpha_{B}=0.1 \%$, $\alpha_{T}=3 \%, \delta=18 \%, \mu_{A}=9 \%, \sigma_{A}=7 \%, \rho_{A E}=-0.01, \mu_{R}=0.5 \%, \sigma_{R}=1 \%$, $\rho_{R E}=-0.3, \rho_{R A}=0.4$ and $x=1 \%$. Figures below show how the value function $(3.13 d)$ and dividend barrier $u$ change with respect to banking proportion $\zeta$, banking volatility $\sigma_{B}$, trading volatility $\sigma_{T}$, correlation between the banking and trading earnings $\rho_{B T}$, banking alpha $\alpha_{B}$, trading alpha $\alpha_{T}$, risk-free rate $r$, and wedge between debt and equity finance $\delta$, mean asset growth rate $\mu_{A}$, asset volatility $\sigma_{A}$, correlation between net income earnings and assets growth return $\rho_{A E}$, correlation between assets growth return and net recapitalization earnings $\rho_{R A}$, mean net recapitalization rate $\mu_{R}$, net recapitalization volatility $\sigma_{R}$, and correlation between net income earnings and recapitalization earnings $\rho_{R E} . \ldots \ldots \ldots$. . . . . . . 91

3.4 Default probability changes with varying model parameters for Bank FHN. We analyze two banks (FHN and WFC) and how their default probability changes with respect to model parameters. We consider two cases: case $(i)$ is without the Volcker rule and case (ii) is under the Volcker rule (no alpha bets). The first bank is FHN and we use its estimated parameters in Table 3.2. Figures below show how the default probability changes with respect to banking proportion $\zeta$, risk-free rate $r$, banking volatility $\sigma_{B}$, trading volatility $\sigma_{T}$, banking alpha $\alpha_{B}$, trading alpha $\alpha_{T}$, correlation between the banking and trading earnings $\rho_{B T}$, correlation between net income earnings and net recapitalization earnings $\rho_{R E}$, correlation between assets and net income earnings $\rho_{A E}$, correlation between net recapitalization earnings and assets $\rho_{R A}$, assets growth rate $\mu_{A}$, net recapitalization returns on assets $\mu_{R}$, assets volatility $\sigma_{A}$, net recapitalization volatility $\sigma_{R}$, wedge between debt and equity finance $\delta . \ldots \ldots \ldots \ldots \ldots 6$

3.5 Default probability changes with varying model parameters for Bank WFC. The second bank is WFC and we use its estimated parameters in Table 3.2 Figures below show how the default probability changes with respect to banking proportion $\zeta$, risk-free rate $r$, banking volatility $\sigma_{B}$, trading volatility $\sigma_{T}$, banking alpha $\alpha_{B}$, trading alpha $\alpha_{T}$, correlation between the banking and trading earnings $\rho_{B T}$, correlation between net income earnings and net recapitalization earnings $\rho_{R E}$, correlation between assets and net income earnings $\rho_{A E}$, correlation between net recapitalization earnings and assets $\rho_{R A}$, assets growth rate $\mu_{A}$, net recapitalization returns on assets $\mu_{R}$, assets volatility $\sigma_{A}$, net recapitalization volatility $\sigma_{R}$, wedge between debt and equity finance $\delta . \ldots \ldots \ldots \ldots$. . . . . . . . . 98 


\section{CHAPTER I}

\section{Introduction}

As Brunnermeier, Crockett, Goodhart, Persaud, and Shin (2009) report, the Credit Crunch of 2007-2009 involved a regulatory failure and the solution should not be more regulation per se, but better and different regulation. Today we are certain only about the "different" part since in many countries there are significant regulatory changes $1^{1}$ but we do not know their unintended consequences. In the U.S., Volcker rule represents one of these regulatory changes..$^{2}$ The rule limits banks' proprietary trading that is not at the behest of their clients and caps each bank's ownership in hedge funds and private equity funds at three percent of the assets. Certain activities such as market making, hedging, securitization, and risk management are exempted. Banks have a seven year time frame to become compliant with the regulation.

Reform advocates such as the consumer coalition Americans for Financial Reform think Volcker rule is too weak, and, on the other hand, banks believe it is too costly. ${ }^{3}$ For instance, JPMorgan Chase estimates that the direct costs of the Volcker rule for them will be $\$ 400$ million - $\$ 600$ million annually (see Economist, February 18th

\footnotetext{
${ }^{1}$ See e.g. European recommendations Liikanen $\left.\sqrt{2012}\right)$ and Vickers $(2011)$.

${ }^{2}$ The Volcker rule is section 619 of the Dodd-Frank Wall Street Reform and Consumer Protection Act and it was proposed by former U.S. Federal Reserve Chairman Paul Volcker. For more information: http:// www.sec.gov/rules/proposed/2011/34-65545.pdf http://banking.senate.gov/public/_files/070110_Dodd_Frank_Wall_Street_ Reform_comprehensive_summary_Final.pdf and http://www.sec.gov/about/laws/wallstreetreform-cpa.pdf

${ }^{3}$ See e.g. Reuters, October 11th 2011, "U.S. reveals Volcker rule's murky ban on Wall St bets" by Dave Clarke and Alexandra Alper, Dealbook, New York Times, February 13th 2012, "At Volcker Rule Deadline, a Strong Pushback From Wall St." by Ben Protess and Peter Eavis, and Dealbook, New York Times, February 22nd 2012, "The Volcker Rule, Made Bloated and Weak" by Jesse Eisinger.
} 
2012, "The Dodd-Frank act; Too big not to fail").

Several papers have studied bank capital's role in regulation (see e.g. Hart and Zingales 2011; Acharya, Kulkarni, and Richardson 2010; Kashyap, Rajan, and Stein 2008; Barth, Caprio, and Levine 2004; Bhattacharya, Boot, and Thakor 1998; Dangl and Lehar 2004; Decamps, Rochet, and Roger 2004; Hellmann, Murdock, and Stiglitz 2000; Morrison and White 2005; and Repullo 2004). Some authors have focused specifically on the Volcker rule. Konczal (2012) claims that the Volcker rule will help with the conflicts of interest between banks and their clients and provide for the stability of the economy by removing the "casino" part of the financial system from the core banking parts. Despite the good intentions of the Volcker rule, the rule has also received wide criticism. According to Chatterjee (2011), the rule as proposed is doomed because banks are allowed to continue to trade on behalf of their customers and because it is difficult to separate the client serving activity from proprietary trading. Chow and Surti (2011), Whitehead (2011), and Duffie (2012) argue that the implementation of the Volcker rule would reduce the quality and capacity of market making services that banks provide to U.S. investors. Further, activities identified as too risky for retail banks might migrate to the unregulated parts of the financial system and this could increase systematic risk. Moreover, some authors warn that the regulation may have also other unintended consequences. For instance, Campbell, Ramadorai, and Ranish (2012) present evidence that regulation may contribute to a surge in delinquencies.

The goal of our study is to develop a framework with which we are able to estimate and analyze the impact of the Volcker rule on banks' market equity value and default probability. To achieve this goal, we divide the trading into two parts: alpha bets and hedging of basic banking cash flows. Under this stylized setup we develop two 
models that maximize the bank's expected discounted dividends, i.e., the value of bank market equity equity. In our models presented in Chapter II and III, the state variable is a bank's buffer capital ratio, i.e., accounting equity capital ratio over a minimum capital level. If the buffer capital violates the minimum capital level then the bank is liquidated ${ }^{4}$ We solve the bank's optimal policy (in maximizing the value of the bank) for dividends, liquid asset investments, and the allocation of assets into trading and basic banking business in a single optimization model. This is important since these decisions affect each other and, hence, cannot be analyzed separately. By dynamic programming, the value function satisfies an ordinary differential equation that we solve numerically. We ignore the implementation costs and risks such as differences between federal and state regulators found in Agarwal, Lucca, Seru, and Trebbi (2012).

Several other papers have also modeled banks and other firms' optimal actions with similar stochastic models. The basic theoretical continuous time model of a capital constrained firm is presented in Milne and Robertson (1996). That paper is extended in Milne and Whalley (2001), Milne (2004), and Peura and Keppo (2006) to allow for a recapitalization option. Peura and Keppo also calibrate their model to accounting data on U.S. commercial banks and show that this class of models explains about $40 \%$ of the variation in the buffer capital levels. We confirm this finding in our analysis. Keppo, Kofman, and Meng (2010) consider a model with liquid risky asset investment. In our models in Chapter II and III we extend their framework by considering the proportion of trading assets as a free variable and by including the correlation between banking and trading cash flows to the model. The

\footnotetext{
${ }^{4}$ We model the effect of capital via an elevated survival probability. Holmstrom and Tirole (1997) develop a model in which capital induces the bank to monitor borrowers. This suggests that bank capital has also a positive effect on monitoring. We do not model this effect directly. However, our cross-sectional analysis on the sample of U.S. banks suggests that the model explains a significant part of the variation in the banks' buffer capital ratios.
} 
correlation is an important variable in our analysis since it allows hedging of the banking cash flows. Estrella (2004) uses a variant of the classical inventory or cash management models to study cyclicality of bank capital. Consistent with our model, Mehran and Thakor (2011) find that bank value and its components (the stand-alone values of banks assets and liabilities and the synergies among them) are positively cross-sectionally related to bank capital.

The rest of the paper is organized as follows. Chapter $\Pi$ presents a simple stochastic model with no recapitalization and results. Chapter III presents another stochastic model with recapitalization. Each of Chapter [II and Chapter III includes the calibration results, cross-sectional test, and comparative statics using its respective model. Chapter IV concludes. 


\section{CHAPTER II}

\section{A Simple Stochastic Control Model with No Recapitalization}

\subsection{Model}

We introduce our first model with no recapitalization. Recapitalization activities include issuing or re-purchasing a bank's own stock. In this section we present the used stochastic processes and the objective of the bank under consideration. This model is based on Milne and Robertson (1996) and Keppo et al. (2010). We analyze a single bank that maximizes its expected discounted dividends. Consistent with Basel banking rules (Basel Commitee on Banking Supervision 1996a b c), we divide the bank's assets into banking book and trading book.

The banking book consists of loans that are not marked to market for managerial and accounting purposes. The trading book is a portfolio of different traded instruments (e.g. stocks, bonds, swaps, forward contracts and other derivative instruments) that are usually marked to market daily.

We assume that the bank's total risk-weighted assets $R W(t)^{5}$ grow at a positive risk-free rate $r$, so that

$$
R W(t)=R W(0) e^{r t}
$$

\footnotetext{
${ }^{5}$ Risk-weighted assets are calculated as a weighted sum of a bank's nominal risk exposures, where the weights depend on product type and counterparty sector. According to Peura and Keppo (2006), risk-weighted assets are typically between $65 \%$ and $70 \%$ of total assets.
} 
for some initial positive amount $R W(0)$. This implies that our bank is in a steady state and its total risk-weighted assets grow at a risk-free rate due to new loans and investments $]^{6}$ The bank operates up to liquidation. The liquidation time is defined as the first time when equity hits zero:

$$
\tau=\inf \{t \mid \bar{X}(t) \leq 0\}
$$

where $\tau$ is the liquidation time and $\bar{X}(t)$ is the accounting value of bank equity (bank capital) at time $t$. The credit risk requirement can be modeled by defining $\bar{X}$ as the capital above the minimum capital level (see e.g. Peura and Keppo 2006). We use a minimum capital level in our model calibration and set the minimum level equal to $8 \%$ of the total risk-weighted assets (this is about the minimum capital level in our dataset).

We assume that earnings from the banking book and the trading book are proportional to the bank assets. Banking book equals a fixed proportion of the assets and the rest of the assets are in the trading book. Thus, the bank dedicates certain fixed proportion of its assets to the basic banking business. The trading book consists of a liquid risky asset investment and a risk-free investment. The bank trades the assets in the trading book continuously without any frictions. More specifically, the cumulative earnings processes under the risk-neutral probability measure (see e.g. Bjork 2009) are given by

$$
\begin{aligned}
d E_{B}(t)= & R W(t) \zeta\left(r+\alpha_{B}\right) d t+R W(t) \zeta \sigma_{B} d W_{B}(t), \\
d E_{T}(t)= & R W(t)(1-\zeta) \theta(t)\left(r+\alpha_{T}\right) d t \\
& +R W(t)(1-\zeta) \theta(t) \sigma_{T} d W_{T}(t)+R W(t)(1-\zeta)(1-\theta(t)) r d t \\
= & R W(t)(1-\zeta)\left[r+\theta(t) \alpha_{T}\right] d t+R W(t)(1-\zeta) \theta(t) \sigma_{T} d W(t),
\end{aligned}
$$

\footnotetext{
${ }^{6}$ As pointed out in Keppo et al. (2010), we can justify this in two ways: (1) the growth rate of RWA has only a second order effect on the buffer stock, and (2) RWA fluctuates significantly less than the corresponding market prices due to the definition of RWA.
} 
where $E_{B}(t)$ and $E_{T}(t)$ are the banking and trading book cumulative earnings at time $t, r$ is the risk-free rate, $\zeta$ is the constant proportion of $R W(t)$ in the banking book and $\zeta \in\left[\zeta_{l}, 1\right], \zeta_{l}>0$ is the minimum size of the banking book (so that the firm is still considered as a bank), $\theta(t)$ is the proportion of the trading book invested in the liquid risky asset and $\theta(t) \in[0,1]$ for all $t \geq 0, \alpha_{B}$ and $\alpha_{T}$ are banking book and trading book alphas, $\sigma_{B}$ and $\sigma_{T}$ are banking book and trading book volatilities and $\sigma_{B}, \sigma_{T}>0, W_{B}(t)$ and $W_{T}(t)$ are Wiener processes under the risk-neutral probability measure corresponding to $E_{B}$ and $E_{T}$ and their correlation is $\rho_{B T}$.

If (2.2) is under the risk-neutral measure then it would be natural to assume that $\alpha_{T}=0$ (see e.g. Bjork 2009). However, this implies that a bank engages in trading business only to hedge their risk from banking business (see Corollary 2.12) and this is not what we observe in the market. Therefore, we assume that the bank is able to generate alpha, in which case $\alpha_{T}>0$. This excess return could be, for instance, from market making or it just reflects the bank shareholders' expectation for the future returns. We assume the bank is able to control $\theta(t)$ in continuous time. It can also choose $\zeta$, but this parameter is constant. We do not specify the trading and banking activities that create the alphas (excess returns $\alpha_{B}$ and $\alpha_{T}$ ). In our model they are just alphas of the trading and banking books, and in the model calibration we estimate the parameters from accounting and market data.

By (2.2), the earnings of the bank follow

$$
\begin{aligned}
d E(t)= & d E_{B}(t)+d E_{T}(t) \\
= & R W(t)\left[r+\zeta \alpha_{B}+(1-\zeta) \theta(t) \alpha_{T}\right] d t+ \\
& +R W(t)\left[\zeta \sigma_{B} d W_{B}(t)+(1-\zeta) \theta(t) \sigma_{T} d W_{T}(t)\right]
\end{aligned}
$$

and, thus, the earnings depend on the asset size, the earnings parameters, and 
the bank's trading. As we can see, the earnings volatility depends on the asset quality: The more is invested in trading, the higher the earnings volatility (typically, $\left.\sigma_{T}>\sigma_{B}\right)$. The earnings are added to bank equity, i.e., to the bank's capital.

The bank controls its bank capital also through dividend payments that can be implemented instantaneously without any costs. Formally, a capital control policy $\bar{\pi}$ is a collection $\left(\zeta^{\bar{\pi}},\left\{\theta^{\bar{\pi}}(t), L^{\bar{\pi}}(t)\right\}\right)$, where $\zeta^{\bar{\pi}}$ is the proportion of total risk-weighted assets in the banking book under policy $\bar{\pi}, \theta^{\bar{\pi}}(t)$ is the proportion of trading book in the risky liquid asset at time $t$, and $L^{\bar{\pi}}(t)$ is the cumulative amount of dividends at time $t$. We denote by $\Pi$ the class of admissible policies and they satisfy:

(i) $\zeta^{\bar{\pi}} \in\left[\zeta_{l}, 1\right]$, where $\zeta_{l}>0$, and $\zeta^{\bar{\pi}}$ is constant during the lifetime of the bank

(ii) $\theta^{\bar{\pi}}(t) \in[0,1]$ for all $t \geq 0$ and it is adapted to $F_{t}$, where filtration $\left\{F_{t}\right\}$ is generated by the Wiener processes $W_{B}(t)$ and $W_{T}(t)$

(iii) $L_{t}^{\bar{\pi}}$ is a non-decreasing right-continuous process adapted to $F_{t}$ and $L_{0-}^{\bar{\pi}}=0$.

Condition $(i)$ indicates that the bank cannot change the proportion of the riskweighted assets in the banking book after it has selected that. Thus, the banking business is a long-term investment with long-term commitments. By (ii), short selling is not allowed and the bank cannot invest more than its trading book in the risky asset. Condition (iii) says that dividends cannot be negative.

Bank capital as a function of policy $\bar{\pi}$ is denoted by $\bar{X}^{\bar{\pi}}(t)$ and, by $(2.3)$, it satisfies:

$$
\begin{aligned}
\bar{X}^{\bar{\pi}}(t)= & \bar{X}(0)+\int_{0}^{t} r X^{\pi}(u) d u+\int_{0}^{t} d E^{\bar{\pi}}(u)-L^{\bar{\pi}}(t) \\
= & \bar{X}(0)+\int_{0}^{t} r X^{\pi}(u) d u+\int_{0}^{t} R(u)\left[r+\zeta^{\bar{\pi}} \alpha_{B}+\left(1-\zeta^{\bar{\pi}}\right) \theta^{\bar{\pi}}(u) \alpha_{T}\right] d u \\
& +\int_{0}^{t} R(u)\left[\zeta^{\bar{\pi}} \sigma_{B} d W_{B}(u)+\left(1-\zeta^{\bar{\pi}}\right) \theta^{\bar{\pi}}(u) \sigma_{T} d W_{T}(u)\right]-L^{\bar{\pi}}(t)
\end{aligned}
$$

The integral terms are the gains and losses from the trading and banking books. The last term is the cumulative dividend process. Thus, cumulative profits feed to the 
capital, while dividend payments and cumulative losses represent a leakage from the capital. The first integral term represents that bank capital also earns the risk-free rate 7

By risk-neutral pricing, the market value of bank equity is the expected discounted dividends until liquidation. Thus, the market equity value under policy $\bar{\pi}$ and initial capital $\bar{x}$ (accounting value of equity above the minimum requirement) is given by

$$
\bar{V}_{\bar{\pi}}(\bar{x})=E\left[\int_{0}^{\bar{\tau}_{\bar{\pi}}} e^{-(r+\delta) t} d L^{\bar{\pi}}(t) \mid \bar{X}(0)=\bar{x}\right]
$$

where $E$ is expectation under the risk-neutral probability measure, $\delta$ is a positive constant representing the wedge between debt and equity finance due to capital market frictions such as taxation and agency costs of equity $\left.\right|^{8}$ The wedge satisfies $\delta>\max \left[\alpha_{B}, \alpha_{T}\right]$, which gives $\bar{V}_{\bar{\pi}}(\bar{x})<\infty$. Thus, the excess return in $(2.3)$ and 2.4 is less than the wedge between debt and equity finance.

The problem is to identify the value of an optimally managed bank:

$$
\bar{V}(\bar{x})=\sup _{\bar{\pi} \in \Pi} \bar{V}_{\bar{\pi}}(\bar{x})
$$

and an admissible policy which achieves this value.

\footnotetext{
${ }^{7} \mathrm{As}$ in Peura and Keppo (2006), this assumption can be justified in several ways. We assume that bank capital is explicitly invested in a risk-free asset. Alternatively, we could postulate that any capital the bank has replaces an equivalent of borrowing/deposit funding and that the effective cost of borrowing/deposits to the bank equals the risk-free rate. The latter assumption, in turn, could be justified by the presence of deposit insurance.

${ }^{8}$ As pointed out in Keppo et al. (2010), the parameter $\delta$ should not be interpreted as equity risk premium since it is assumed constant and does not depend on bank leverage. This suggests that our modeling framework is risk-neutral (risk-neutral share holders or risk-neutral probability measure). If the risk-neutral probability measure is used then the drift term of buffer capital process need not coincide with its observed value. In particular, since uncertainty in our model is driven by a Brownian Motion, a change of measure would influence the drift in 2.4, but not the volatility.
} 


\subsection{Characterization of Optimum}

The capital dynamics defined in (2.4) are not time-homogenous, which makes direct solution of the problem (2.6) difficult. However, the problem of capital control can be transformed into a time-homogenous problem of capital ratio control through a simple normalization. The normalized state variable, the bank capital ratio is given by

$$
X(t)=\bar{X}(t) / R W(t)
$$

From Peura and Keppo (2006) we get the following lemma that presents the capital ratio control problem and shows its connection to the capital control problem 2.6.

Lemma II.1. (Capital control problem) Given an admissible policy $\pi \in \Pi$, the capital ratio satisfies

$$
\begin{aligned}
X^{\pi}(t)= & X(0)+\int_{0}^{t}\left[r+\zeta^{\pi} \alpha_{B}+\left(1-\zeta^{\pi}\right) \theta^{\pi}(u) \alpha_{T}\right] d u \\
& +\int_{0}^{t}\left[\zeta^{\pi} \sigma_{B} d W_{B}(u)+\left(1-\zeta^{\pi}\right) \theta^{\pi}(u) \sigma_{T} d W_{T}(u)\right]-L^{\pi}(t) .
\end{aligned}
$$

Define the liquidation time by

$$
\tau_{\pi}=\inf \left\{t \mid X^{\pi}(t) \leq 0\right\}
$$

and the bank equity value as percentage of the total risk-weighted assets under policy $\pi$ by

$$
V_{\pi}(X(0))=E_{X(0)}\left[\int_{0}^{\tau_{\pi}} e^{-\delta t} d L^{\pi}(t)\right]
$$

where the expectation is conditional on the capital ratio dynamics (2.7a). The value function:

$$
V(x)=\sup _{\pi \in \Pi} V_{\pi}(x)
$$


Then (2.6) can be expressed in terms of (2.7d) as

$$
\bar{V}(\bar{X}(0))=R W(0) V(X(0)) .
$$

Further, let $\pi^{*}$ be the policy which achieves the optimum in (2.7d). Then the optimal policy of (2.6), $\bar{\pi}^{*}$, can be expressed in terms of $\pi^{*}$ by

$$
\zeta^{\bar{\pi}^{*}}=\zeta^{\pi^{*}}, \theta^{\bar{\pi}^{*}}(t)=\theta^{\pi^{*}}(t) \text { and } L^{\bar{\pi}^{*}}(t)=\int_{0}^{t} R W(u) d L^{\pi^{*}}(u) .
$$

Thus, when $\pi$ and $\bar{\pi}$ are related through (2.9) then the capital ratio process (2.7a) is the process of $\bar{X}^{\bar{\pi}}(t) / R W(t)$. The proof is based on Ito's lemma and equations (2.1) and (2.3). Equation (2.8) implies that the objective function of the capital ratio control problem, (2.7d), can be interpreted as the market value of bank equity as a percentage of the total risk-weighted assets.

From Højgaard and Taksar (2004) we get the following lemma.

Lemma II.2. (Concavity) The value function in (2.7d) is increasing and concave.

We characterize the value function $(2.7 \mathrm{~d})$ through a set of variational inequalities. For this we define the infinitesimal generator $I$ corresponding to $2.7 \mathrm{a})$ for all sufficiently regular $f$ as follows

$I_{\theta} f(x)=\frac{1}{2}\left[\zeta^{2} \sigma_{B}^{2}+(1-\zeta)^{2} \theta^{2} \sigma_{T}^{2}+2 \zeta \sigma_{B} \rho_{B T}(1-\zeta) \theta \sigma_{T}\right] f^{\prime \prime}(x)+\left[r+\zeta \alpha_{B}+(1-\zeta) \theta \alpha_{T}\right] f^{\prime}(x)$.

Further, let us write the value function corresponding to banking proportion $\zeta \in$ $\left[\zeta_{l}, 1\right]$ as $V^{\zeta}(x)$. That is, $V^{\zeta}(x)$ is the expected discounted dividends in $\left.2.7 \mathrm{c}\right)$ and (2.7d) for given $\zeta$.

Now we get the following proposition. The proof follows from standard arguments (see e.g. Højgaard and Taksar 1999 or Fleming and Soner 2005). 
Proposition II.3. (Value function) The value function corresponding to banking book proportion $\zeta \in\left[\zeta_{l}, 1\right]$ solves

$$
\begin{aligned}
& \text { LIQUIDATION: } \quad V^{\zeta}(0)=0 \\
& \text { OUTSIDE DIVIDENDS: } \delta V^{\zeta}(x)=I_{\theta^{*}} V^{\zeta}(x) \text { for all } x \in(0, u) \\
& \text { DIVIDENDS: } \quad \frac{\partial V^{\zeta}(x)}{\partial x}=1 \text { for all } x \geq u
\end{aligned}
$$

where dividend barrier $u \in(0, \infty)$ and the optimal trading strategy:

$$
\theta^{*}(x)=\max \left\{0, \min \left[1,-\frac{\zeta \sigma_{B} \rho_{B T}}{(1-\zeta) \sigma_{T}}-\frac{\alpha_{T}}{(1-\zeta) \sigma_{T}^{2}} \frac{\partial V^{\zeta}(x)}{\partial x} / \frac{\partial^{2} V^{\zeta}(x)}{\partial x^{2}}\right]\right\}
$$

$\theta^{*}(x)$ is solved in Subsection 2.5.2 for an easy implementation. The optimal policy can be understood as follows. Dividends are paid so as to never let the capital ratio rise above $u$, and between the dividend payments the bank invests actively in the risky financial asset. The optimal trading strategy solves $\max \left(I_{\theta}-\delta\right) V^{\zeta}(x)=0$. Note that, by 2.10 and Lemma II.2. $\left(I_{\theta}-\delta\right) V^{\zeta}(x)$ is concave with respect to $\theta \in[0,1]$ and, thus, the first order condition gives the optimal trading strategy $\theta^{*}$. The term $-\frac{\zeta \sigma_{B} \rho_{B T}}{(1-\zeta) \sigma_{T}}$ in 2.12 is due to (partial) hedging of banking cash flows, and $-\frac{\alpha_{T}}{(1-\zeta) \sigma_{T}^{2}} \frac{\partial V^{\zeta}(x)}{\partial x} / \frac{\partial^{2} V^{\zeta}(x)}{\partial x^{2}}$ is from the alpha of the trading strategy. The hedging term has its maximum value when the correlation equals -1 , and the alpha term is increasing in the alpha of the trading, $\alpha_{T}$. Note that hedging increases value because, by Lemma II.2, the value function is concave and hedging decreases volatility. The max and min functions in 2.12 are due to the trading constraint.

Proposition $\Pi$ II.3 follows from standard dynamic programming arguments applied to the Bellman equation. By 2.11a), when the capital ratio hits zero the bank is liquidated. The slope condition at the dividend barrier (2.11c) and the differential equation between the dividend times (2.11b hold since paying dividends and 
trading are always admissible. We note that the smooth pasting and the super contact conditions are required for $V^{\zeta}$ at the dividend barrier, i.e., $\left.\frac{\partial V^{\zeta}(x)}{\partial x}\right|_{x=u}=1$ and $\left.\frac{\partial^{2} V^{\zeta}(x)}{\partial x^{2}}\right|_{x=u}=0$ (see Dumas 1991$)$.

In case of nonzero correlation between the banking and trading earnings, the value function in Proposition II.3 has to be solved numerically! $!^{9}$ If the correlation is zero, i.e., $\rho_{B T}=0$ then we get the model in Keppo et al. (2010). Further, note that if $\zeta=1$ then the bank invests all the wealth in the banking business and, therefore, the value function is independent of trading since then there are no trading assets. In this case the model equals Peura and Keppo (2006). For $\zeta \in\left[\zeta_{l}, 1\right)$, the smooth pasting and the super contact conditions with Lemma II.2 lead to an explicit formula for the value function (2.11) at the dividend barrier $u$ :

Lemma II.4. (Value at dividend barrier) Let $\tau>0, \alpha_{T}>0, \sigma_{T} \neq 0$, and $\zeta \in\left[\zeta_{l}, 1\right.$ ). Then the value function at the dividend barrier is given by

$$
V^{\zeta}(u)=\frac{r+\zeta \alpha_{B}+(1-\zeta) \alpha_{T}}{\delta}
$$

and $\theta^{*}(u)=1$, i.e., the bank has the maximum position in the liquid risky asset at the barrier. If the above conditions hold, except if we have $\alpha_{T} \leq 0$, then

$$
V^{\zeta}(u)=\frac{r+\zeta \alpha_{B}}{\delta}
$$

Further, if $\alpha_{T}=0$ then $\theta^{*}(u)=\max \left\{0, \min \left[1,-\frac{\zeta \sigma_{B} \rho_{B T}}{(1-\zeta) \sigma_{T}}\right]\right\}$, and if $\alpha_{T}<0$ then $\theta^{*}(u)=0$, i.e., then the bank has the minimum position in the liquid risky asset at the barrier.

Proof: By 2.11b) and the value matching, smooth pasting, and super contact con-

\footnotetext{
${ }^{9}$ We use a standard finite difference approximation method to solve the value function (see e.g. Kushner and Dupuis 2000, Section 5.1) and implemented the method in Matlab.
} 
ditions at $u$, we have

$$
V^{\zeta}(u)=\sup _{\theta \in[0,1]}\left[\left(r+\zeta \alpha_{B}+(1-\zeta) \theta \alpha_{T}\right) / \delta\right]
$$

First, if $\alpha_{T}=0$ then we get 2.14 directly and, by Proposition 2.12, $\theta^{*}(u)$ is as given in the lemma. Second, if $\alpha_{T}>0$ then $\theta^{*}(u)=1$ and 2.13 follows. Finally, if $\alpha_{T}<0$ then $\theta^{*}(u)=0$ and 2.14 follows.

By Lemma II.4, the value function at the dividend time is given by the simple equations (2.13) and 2.14) which do not include the banking and trading volatilities or their correlation. However, the dividend barrier $u$ (solved by the value matching and smooth pasting conditions) and, therefore, also the dividend time depend on the volatilities and the correlation.

From 2.12 we get the following corollary.

Corollary II.5. (Trading) If the trading alpha and the correlation between the banking and trading cash flows are both zero then the bank does not trade. That is, if $\alpha_{T}=0$ and $\rho_{B T}=0$ then $\theta^{*}(x)=0$ for all $x \in[0, u]$.

This result implies that there are two motivations for trading: alpha generating bets and the hedging of banking earnings. When the trading alpha and the correlation are zero then there is no trading. In this case our model is given by Peura and Keppo (2006).

So far we have analyzed the value function with given banking book size $\zeta \in\left[\zeta_{l}, 1\right]$. Next we discuss about the optimal $\zeta$ and for this we define $\Upsilon^{x}(\zeta)=V^{\zeta}(x)$, where $x$ is the buffer capital at time 0 . The optimal $\zeta$ is solved at time 0 and it is constant: $\zeta^{*}=\arg \max _{\zeta \in\left[\zeta_{l}, 1\right]} \Upsilon^{x}(\zeta)$. By the extreme value theorem, $\Upsilon$ attains its maximum on 
$\left[\zeta_{l}, 1\right]$. The maximum value is either at a local maximum in $\left(\zeta_{l}, 1\right)$, or at a boundary ( $\zeta_{l}$ or 1$)$, i.e., at the point where the derivative is zero or at a boundary. We solve $\zeta$ numerically by testing these candidates.

Note that if $\zeta$ was time varying then we would solve that from (2.11b) similarly as $\theta^{*}$ in 2.12). This would give

$\zeta=\max \left\{\zeta_{l}, \min \left[1, \frac{\theta \alpha_{T}-\alpha_{B}}{\sigma_{B}^{2}+\theta^{2} \sigma_{T}^{2}-2 \sigma_{B} \rho_{B T} \theta \sigma_{T}} \frac{\frac{\partial V^{\zeta}(x)}{\partial x}}{\frac{\partial^{2} V^{\zeta}(x)}{\partial x^{2}}}+\frac{\theta \sigma_{T}\left(\theta \sigma_{T}-\sigma_{B} \rho_{B T}\right)}{\sigma_{B}^{2}+\theta^{2} \sigma_{T}^{2}-2 \sigma_{B} \rho_{B T} \theta \sigma_{T}}\right]\right\}$,

where, by Lemma II.2, the first term besides $\theta \alpha_{T}-\alpha_{B}$ is negative. This implies that the higher the banking alpha relative to the trading alpha, the bigger the banking book size is. Since typically $\sigma_{T}>\sigma_{B}$, the last term is positive if $\theta \geq \rho_{B T}$. 


\subsection{Model Calibration}

In this section we calibrate this model to twelve U.S. banks during 2000 Q1 2011 Q4. This period was selected to include the most current period after the repeal of the Glass-Steagall Act of 1933 on late 1999 10 We use the twelve banks because for them we have required accounting data for our analysis over this time period from the Compustat Database. ${ }^{11}$ We also use the banks' risk-weighted assets and tier 1 capital data from the Bank Regulatory Databases for the banks' asset and core capital sizes, the banks' stock price and shares outstanding from CRSP for the market value of shareholders' equity (the shares outstanding are used with the model's market capitalization), the yield on 3-month U.S. treasury bill for the risk-free interest rate, and the S\&P 500 index for the market portfolio.

\subsubsection{Banks}

The banks are introduced in Table 2.1. As we can see, the banks' average total risk-weighted assets during the time period vary from below three billion USD (ABVA, HTLF, and TMP) to over 500 billion USD (BAC, JPM, and WFC). The big banks have smaller buffer capital ratios than the small banks have: The correlation between the buffer capital ratid $[12$ and the risk-weighted asset size is -0.44 . This is consistent with the "too big to fail" concept since if the big banks know that they are so large and so interconnected that their failure would be disastrous to the economy, and which therefore must be supported by government when they face difficulty, then it might be optimal for the big banks to maximize the value of the bailout option by

\footnotetext{
${ }^{10}$ The Glass-Steagall separation of investment and deposit banking was generally repealed by the Gramm-LeachBliley Act of 1999 during the administration of Bill Clinton.

${ }^{11}$ Compustat data variables include: total assets, trading account securities, federal funds sold and securities borrowed or purchased under agreements to resell, interest income and expense on federal funds sold and securities borrowed or purchased under agreements to resell comprehensive income, net gain (loss) from trading securities, tier 1 capital ratio, minority interest, and shareholders' equity.

${ }^{12}$ In this model, we assume a fixed minimum requirement for all banks.
} 
running their business with a low buffer capital ratio ${ }^{13}$ However, given the model parameters (that might, at least partially, be driven by the above discussed moral hazard), seven banks (CBSH, FHN, HTLF, JPM, STT, TMP, and WTFC) have higher mean buffer capital ratios than this model dividend barriers (both under estimated parameters and under the significant parameters, columns under $u$ in Table 2.1). Thus, these banks run their business with higher capital buffers than what is optimal according to this model (the seven banks include both small and big banks) and, therefore, each of these banks has a lower default probability than the corresponding optimally managed bank has. However, the banks might have too high earnings volatility due to the moral hazard problem discussed above and they might have too much leverage because the banks pay low interest rates for their own debt due to the government support (we do not model the government support). Higher earnings volatility and leverage naturally increase the risks of the whole industry.

Most of the bank assets are in the basic banking business, eleven banks have over $90 \%$ of their assets in the banking book. Only JPM has less than $90 \%$ of their assets in the banking book. For all the banks, the banking earnings volatility is lower than their trading volatility. This is consistent with DeYoung and Roland (2001), Stiroh (2004, 2006), and Stiroh and Rumble (2006) who find that movement away from traditional banking activities toward other financial services increases the volatility and market risk. Seven banks had negative correlation between the banking and trading earnings. Negative correlation implies partial hedging of the basic banking business. Seven banks out of twelve had higher trading alpha (excess return) than the banking alpha. Some of the trading alphas are too high for forward looking estimates. However, as explained in Table 2.1, the alphas are bounded above

\footnotetext{
${ }^{13}$ For more on this, see e.g. Haldane and Alessandri (2009) and Miles, Yang, and Marcheggiano (2012).
} 
by a technical condition and this model parameters are the 2000 Q1 - 2011 Q4 sample estimates. We do not know specifically which activities create their trading alphas. For instance, many banks have profitable market making of which return on capital can be high ${ }^{14}$, and during our sample time period many banks placed a lot of assets that looked as a banking book-type into the trading book (e.g. CDO tranches), possibly to take advantage of trading book's lower capital requirements. Further, many high trading alpha banks have high trading volatilities and, by the concavity of the value function (Lemma II.2), this model bank might prefer not to invest in the trading. To understand better the effect of different model parameters, in Subsections 2.5.6 and 2.5.7 we analyze the model behavior with respect to wide ranges of parameter values. For instance, we show in Subsection 2.5.7 that the Volcker rule can raise the default probability of a bank even under a small trading alpha. In the next subsection we explain the parameter estimation.

\subsubsection{Model Parameters}

For bank size $R W_{t}$ we use the total risk-weighted assets. This is consistent with the Basel capital requirements since they are calculated by using the risk-weighted assets (Basel Commitee on Banking Supervision 1996a b c), so they are not directly based on market or accounting equity values. The risk-weighted assets help implementation of the minimum capital level with a simple modification: In this section, capital ratio $2.7 \mathrm{a}$ is the banks' tier 1 capital ratid ${ }^{15}$ (the ratio of tier 1 capital to the total riskweighted assets) in excess of a minimum capital level of $8 \%$. We use $8 \%$ because it is close to the minimum mean buffer capital value of our sample banks ${ }^{16}$

\footnotetext{
${ }^{14}$ For instance, Morgan Stanley posted net trading gains every day during the second quarter of 2007 and Goldman Sachs had only 11 losing days in their trading between April 2009 and April 2010 (see e.g. Bloomberg, May 13th 2010, "Rigged-Market Theory Scores a Perfect Quarter" by Jonathan Weil).

${ }^{15}$ Tier 1 capital is the core measure of a bank's financial strength from a regulator's point of view. It equals shareholders' equity plus minority interests minus portion of perpetual preferred stock and goodwill.

${ }^{16}$ Note that the minimum Basel II capital ratio is $8 \%$, which is close to our minimum level. The U.S. did not fully implement Basel II (see e.g. Verdier (2012)).
} 
Further, as in Peura and Keppo (2006), we use a common estimate for the wedge between debt and equity finance for all the banks and set $\delta=4 \%$. Subsections 2.5.6 and 2.5.7 analyze the impact of these assumptions on the banks' equity value, dividend policy, and default probability.

The total risk-weighted assets are the sum of banking risk-weighted assets $R W A B_{t}$ and trading risk-weighted assets $R W A T_{t}$ :

$$
R W_{t}=R W A B_{t}+R W A T_{t}{ }^{17}
$$

Although the banking proportion $\zeta$ is optimized in this model, we estimate it as the average of the time series for the ratio of the banking assets to the total assets i.e. $\left\{R W A B_{t} / R W_{t}\right\}$, which is $\zeta_{d}$ in Table 2.1. This assumption modifies the constraint on the wedge $\delta$ given in Section 2.1 to $\delta>\zeta_{d} \alpha_{B}+\left(1-\zeta_{d}\right) \alpha_{T}{ }^{18}$ Further, note that $\zeta$ is constant in this model, i.e., the banking asset size is a long term strategic decision and, therefore, the observed $\zeta_{d}$ in Table 2.1 is not the same as the current optimal $\zeta$. As an example, if we set $\zeta_{I}=75 \%$, which is close to the minimum $\zeta_{d}$ in Table 2.1 (JPM), then the model's optimal allocation in the banking business is given by Table 2.1 (columns under $\zeta$ ). Thus, according to this model, in this case the equity value of six banks (ABVA, BAC, JPM, STI, TMP, and WFC; so, all the big banks are in this group) would rise if the size of their trading units was decreased since all these banks have optimal banking proportion higher than their current banking proportion (under both the estimated parameters and the significant ones). This is because all these banks have either a statistically significant negative trading alpha or a statistically significant positive correlation between the trading and banking

\footnotetext{
${ }^{17}$ Risk-weighted banking assets $R W A B_{t}$ and trading assets $R W A T_{t}$ are assumed as: $R W A T_{t}=R W_{t}$. $\frac{\text { trading-related assets }}{\text { total assets }}$, and $R W A B_{t}=R W_{t}-R W A B_{t}$ where trading-related assets include (a) trading account securities and (b) federal funds sold, securities purchased under agreements to resell.

${ }^{18}$ In Table 2.1 diamond symbol $(\diamond)$ indicates trading alpha values which violate the $\delta$-condition, i.e., which do not satisfy $\alpha_{T}<\left(\delta-\zeta \alpha_{B}\right) /(1-\zeta)$. These estimates are set to $\alpha_{T}=\left(\delta-\zeta \alpha_{B}\right) /(1-\zeta)-\epsilon$ where $\epsilon=10^{-4}$ in our analysis.
} 
cash flows, or the trading alpha and the correlation are insignificant and therefore almost zero. That is, they have unprofitable trading or they do not hedge, or both the trading and the hedging are not effective enough. Further, the equity value of only four banks (CBSH, FHN, MTB, and STT) would rise under both the estimated parameters and the significant ones if the trading books were increased. As we will see in Table 2.2 , because of this trading value, the default probability of the four banks rises due to the Volcker rule.

All these four banks have significantly positive trading alphas. Thus, given all the data in Table 2.1, it is not obvious that trading is vital for our sample banks. However, note that here we simply assume that the banking business could keep its profitability when it is expanded, which may not be the case. To avoid this problem, in the next section we assume that if the trading is decreased then that money is invested in a risk-free asset, not in the banking business. That is, the method of the next section represents a more positive trading effect because the banking business generates a positive alpha. Our model's correct trading effect estimate is somewhere between these two estimates.

Similarly as with the assets, total net comprehensive income $N I_{t}$ over period $(t-1, t]$ is the sum of banking net income $N I B_{t}$ and trading net income $N I T_{t}$ over the same period:

$$
N I_{t}=N I B_{t}+N I T_{t}^{19}
$$

However, to get trading net income $\left(N I T_{t}\right)$ from the trading revenues we subtract $50 \%$ for compensation and infrastructure costs from all (positive) gains.20 This

\footnotetext{
${ }^{19}$ Some banks (e.g. Bank of America) define trading-related assets as the sum of: (i) trading account assets; (ii) reverse purchases; (iii) securities borrowed; and (iv) derivative assets. We modify this definition of trading-related assets according to the availability of data in Compustat as the sum of (a) trading account securities and (b) federal funds sold, securities purchased under agreements to resell, and trading revenues as the sum of gain/loss on (a) and interest income on (b) minus interest expense on federal funds purchased and securities sold under repurchase agreements.

${ }^{20}$ I.e., $N I T=\max (0.5 \cdot$ trading revenues, 0$)+\min ($ trading revenues, 0$)$, and $N I B=$ net comprehensive income (including minority interests) - NIT.
} 
is consistent with the compensation at several leading banks.21 We analyze the effect of this assumption in Subsections 2.5.6 and 2.5.7 by varying the trading alpha parameter.

We define banking return on assets, $R O B_{t}$, and trading return on assets, $R O T_{t}$, over period $(t-1, t]$ as follows

$$
R O B_{t}=\frac{N I B_{t}}{R W A B_{t-1}}, \quad R O T_{t}=\frac{N I T_{t}}{R W A T_{t-1}}
$$

In other words, the returns are computed by dividing the net income of year $t$ by the corresponding assets in the previous year $(t-1)$. Volatilities $\sigma_{B}$ and $\sigma_{T}$ are estimated as the annualized standard deviations of the time series $\left\{R O B_{t}\right\}$ and $\left\{R O T_{t}\right\}$, respectively. Parameter $\rho_{B T}$ is the correlation between the time series. Volatilities and correlations are in Table 2.1. Most of the volatilities are less than $5 \%$, but there are three banks with over $50 \%$ annual trading volatility (ABVA, STT, and WTFC). None of these high trading volatility banks are big banks. Seven out of twelve banks have negative correlation between the banking and trading earnings. However, only one of the correlations are statistically significant and there are two other banks in Table 2.1 with significant positive correlations between the earnings. This implies that the hedging story is weak. Further, both big and small banks have positive and negative correlations.

Risk-adjusted excess trading return $\alpha_{T}$ is estimated by Capital Asset Pricing Model:

$$
R O T_{t}-R_{f}=\alpha_{T}+\beta_{T}\left(R_{M}-R_{f}\right)+\epsilon,
$$

where $\beta_{T}$ is the trading beta coefficient, $R_{f}$ is the quarterly 3 -month treasury yield, $R_{M}$ is the quarterly $\mathrm{S} \& \mathrm{P} 500$ index return, and $\epsilon$ is a residual term. Table 2.1 gives

\footnotetext{
${ }^{21}$ See e.g. Boston.com, January 22nd 2010, “Goldman earns record $\$ 4.79$ B in Q4, cuts bonus pool” by Stevenson Jacobs,

http://articles.boston.com/2010-01-22/business/29306629_1_proprietary-trading-bank-financial-crisis
} 
the trading beta and alpha estimates. Nine banks have positive beta estimates and three of the estimates are statistically significant. ${ }^{22}$ Eight banks have positive trading alphas and four of them are statistically significant. On the other hand, there are also two banks with statistically significant negative trading alphas. Both of these negative trading alpha banks are big banks. Clearly, all of our sample banks do not benefit from the trading. Some of the alphas and betas are high, indicating that some of the banks have lucrative activities (e.g. market making) and/or they use leverage and/or derivative instruments. As explained in Table 2.1, the alphas are bounded above by a technical condition (see footnote 18). In Subsections 2.5.6 and 2.5.7 we analyze the model behavior with respect to wide ranges of parameter values. For instance, we show in Subsection 2.5.7 that the Volcker rule can raise the default probability of a bank even under a small trading alpha.

When using the same method in estimating the banking alphas as we did with the trading alphas, we find that all the banking alphas are negative over the time period 2000 Q1 - 2011 Q4. This is not due to the recent global financial crisis because these estimates are similar for the 2000 Q1 - 2007 Q1 period. Note that if a bank's forward looking long-term banking alpha is negative then the bank should be liquidated, unless banking has other purposes (such as collecting free government support that can be utilized e.g. in trading; we do not model this) or a bank brings earnings through recapitalization (we do not model this here but will model this in Chapter III). Since we do not observe voluntary liquidations in our sample, we assume that the forward looking alphas are non-negative. More specifically, we assume that all the banks have the same strictly positive banking alpha. We find the forward looking banking alpha by fitting the model equity value to the realized market equity value

\footnotetext{
${ }^{22}$ Note that we do not need the beta estimates since the expectation in 2.5 is under the risk-neutral probability.
} 
in the asset-weighted least squares sense and obtain $\alpha_{B}=0.38 \%$. We analyze the effect of this assumption on bank value, dividend policy, and default probability in Section 2.5.

\subsubsection{Cross-sectional Test and Comparative Statics}

In Figure 2.1 we show that this model with the significant parameters explains about $32 \%$ of the cross-sectional variation in the banks' buffer capital ratios. Further, the slope of the regression model is significant, indicating significant linear relationship between the model and actual buffer capital levels. This is consistent with Peura and Keppo (2006) who analyze a simpler model but a larger set of banks. Thus, due to our small sample, Figure 2.1 just confirms the finding in that paper. The model with the estimated parameters has a lower explanatory power.

Subsection 2.5.6 gives the comparative statics of the model under the median model parameters. More specifically, figures in Subsection 2.5.6 analyze how the value function $(2.7 d)$ and dividend barrier $u$ change with respect to banking proportion $\zeta$, banking volatility $\sigma_{B}$, trading volatility $\sigma_{T}$, correlation between the banking and trading earnings $\rho_{B T}$, banking alpha $\alpha_{B}$, trading alpha $\alpha_{T}$, risk-free rate $r$, and wedge between debt and equity finance $\delta$.

With these parameter values, the banking business has a higher risk adjusted excess return than the trading business has and, therefore, the bank value rises in the banking proportion (see Figure (2.3.1) . By the lower banking volatility, when banking proportion rises then the earnings risk falls and, therefore, there is less need for the hedging of future losses and the dividend barrier falls in the banking proportion (see Figure (2.3.2) . The effect of banking and trading volatilities can be explained in a similar way, because both of these volatilities increase the earnings volatility. Since, by LemmaII.2, the value function is concave, the higher the earnings 
volatility the lower the value function (see Figures (2.3.3) and (2.3.5). Further, the higher the volatility the more the bank has to hedge its future losses and, thus, the higher the dividend barrier (see Figures (2.3.4) and (2.3.6) . The earnings volatility is the main driver of the dividend barrier: By Table 2.2, the earnings volatility and dividend barrier have a correlation of 1.00 under the estimated parameters and 0.91 under the significant parameters (this is consistent with Peura and Keppo 2006). Thus, our dividend policy is driven by risk management considerations.

The effect of correlation between the banking and trading cash flows is as expected (see Figures (2.3.7) and (2.3.8)). The lower the correlation (and the more negative it is), the higher the value function because then the hedging of banking cash flows is more effective. Thus, in this case the earnings volatility falls and, by Lemma II.2. the value function rises. To understand the effect of correlation on dividend policy, we first note that we have two hedging methods for the banking cash flows. The first is through trading and it requires negative correlation between the banking and trading cash flows. The second is hedging with buffer capital and this is a substitute for the first method. That is, if the bank is not able to hedge the banking cash flows by trading then it raises its buffer capital so that it has more cushion for the future losses. The buffer capital is increased by raising the dividend barrier and, therefore, the dividend barrier rises in the correlation.

As expected, the value function is an increasing function of the banking and trading alphas (see Figures (2.3.9) and (2.3.11)]. However, the effect of the alphas on the dividend barrier is not that straightforward (see Figures (2.3.10) and (2.3.12). This is because the alphas change the shape of the value function (see Figures (2.3.13) and (2.3.14) : The lower the alphas, the more linear the value function. When alphas rise then the value function becomes more concave and, thus, the bank becomes 
more risk averse. This creates the need to hedge more and the dividend barrier rises. However, when alphas are increased even more then their effect on increasing earnings dominates and this decreases the need for hedging and the dividend barrier falls.

The risk-free rate has both positive and negative effects on the equity value. First, by (2.7a), the expected capital ratio rises in the risk-free rate and this increases the equity value (relative to the assets). Second, by (2.7c), the discount rate increases in the risk-free rate and this lowers the equity value. Figure (2.3.15) shows that, similarly as with regular call options (rho of the call), the positive effect is stronger and, thus, the equity value rises. The dividend barrier falls in the risk-free rate (see Figure (2.3.16), because then buffer capital increases faster and discounting is stronger. When buffer capital rises then there is less need for hedging (so, $u$ indeed falls), and when there is more discounting then the value of future dividends decrease and, thus, it is better to pay dividends sooner ( $u$ falls). The effect of the wedge between debt and equity finance can be explained in a similar way. However, the wedge affects only the discounting, not the buffer capital dynamics. Thus, by (2.7b), the wedge has only the negative value effect of the risk-free rate and, therefore, the value falls (see Figure (2.3.17)]. Further, when the wedge rises the company prefers to pay dividends earlier and, hence, the dividend barrier falls (see Figure (2.3.18). 


\subsection{Volcker rule}

By using a sensitivity analysis with the estimated model parameters, we next study our sample banks' trading and estimate the impact of the Volcker rule. In this we utilize Corollary II.5, i.e., if $\alpha_{T}$ and $\rho_{B T}$ are zero then it is optimal for the bank not to trade. More specifically, we measure the value of each bank under four different cases:

(i) Bank equity value without the Volcker rule: Value with the estimated parameter values and with only the statistically significant estimates in Table 2.1. That is, we calculate two bank equity values for this case. In the first, $\alpha_{T}$ and $\rho_{B T}$ are equal to their estimated values, and in the second, each parameter equals its estimated value if the estimate is statistically significant at $5 \%$ significance level and otherwise the parameter is zero. Note that, by Table 2.1, $\alpha_{T}$ and $\rho_{B T}$ are the only parameters in Proposition II.3 that could be zero.

(ii) Bank equity value without trading alpha bets: Value with $\alpha_{T}=0$, i.e., there is no trading due to the excess return and, thus, by Proposition II.3 in this case the banks trade only for hedging. As in $(i)$, we calculate the bank equity values with all the $\rho_{B T}$-estimates and also with only the significant correlations (the insignificant correlations are set to zero).

(iii) Bank equity value without hedging: Value with $\rho_{B T}=0$, i.e., there is no correlation between the trading and banking returns, and, therefore, the banks trade only for the excess return, not for hedging. As in $(i)$, we calculate the bank equity values with all the $\alpha_{T}$-estimates and also with only the significant alphas (the insignificant alphas are set to zero).

(iv) Bank equity without trading: Value with $\alpha_{T}=0$ and $\rho_{B T}=0$, i.e., by 
Corollary II.5 the banks do not trade at all.

In these cases we assume that only $\alpha_{T}$ and $\rho_{B T}$ change and all the other model parameters are constant. Thus, for instance, we assume here that $\zeta$ is constant, i.e., the size of the banking book is independent of $\alpha_{T}$ and $\rho_{B T}$. Further, in this section we assume that if the trading is decreased then that money is invested in the risk-free asset, not in the banking business. Comparing with the effect of optimal banking fraction discussed in Subsection 2.3.2, the method of this section might give a more positive trading effect because in our model the banking business generates a positive alpha, although it is also risky.

The model estimated equity values under the four cases $(i)-(i v)$ are in Table 2.2. The est. column is the bank equity with the estimated $\alpha_{T}$ and $\rho_{B T}$ parameter values in Table 2.1 and the sig. column is with the significant parameters at $5 \%$ significance level (non-significant $\alpha_{T}$ and $\rho_{B T}$ parameters are set to zero). We also report percentage changes from the initial equity value $(i)$ to each of the other equity values $(i i)-(i v)$, and calculate these changes with the estimated parameter values and the significant parameters separately. These changes correspond to the value impacts of the alpha bets, hedging, and trading overall. The difference between the original bank equity value $(i)$ and case (ii) gives the value change due to the alpha bets. Similarly, the difference between $(i)$ and (iii) is the equity value impact of the hedging, and the difference between $(i)$ and $(i v)$ is the total equity value change of trading. Depending on the implementation of the Volcker rule, the differences between $(i)$ and $(i i)$ and between $(i)$ and $(i v)$ give the equity value decrease due to the rule. Therefore, by Table 2.2. Volcker rule decreases on average bank equity value between $14 \%$ (only significant parameters) and 20\% (estimated parameters), and thus about $17 \%$ is our estimate. The effect of banning alpha bets is about the 
same as banning all trading. Thus, the impact of hedging is on average about zero. Further, as in Subsection 2.3.2, the Volcker rule penalizes big banks (BAC, JPM, and WFC) less than typical banks in our sample due to the big banks' unprofitable trading (BAC and JPM, see Table 2.1) or lack of hedging (WFC).

As discussed earlier, in addition to the value changes in Table 2.2, the Volcker rule might create significant compliance costs and we do not consider those in our model.

\subsubsection{Loan Prices}

In this subsection we estimate how much banks should raise their loan rates to compensate for the value decrease due to the Volcker rule. Since the rule prevents banks from collecting trading alpha (or at least makes that harder and costly), banks might focus more on the basic banking business. Therefore, we expect more innovative banking products such as mortgages with insurances for real-estate risk (see e.g. Fabozzi, Shiller, and Tunaru 2010). These products would allow banks to collect higher fees and this way to increase their banking alphas.

We first estimate how much the banks should raise their banking alphas to compensate the value decrease of the Volcker rule. After that we calculate the corresponding increases in the loan rates that would give the new banking alphas if all the other model parameters were fixed ${ }^{23}$ Thus, this is a simple comparative statics of the model. The increases in the loan rates can be viewed as a measure for new innovation and/or cost cutting that the banks need to do to justify the higher banking alphas.

More specifically, we consider three scenarios (the first and the last are for the

\footnotetext{
${ }^{23}$ For instance, we saw this kind of behavior when the U.S. Congress limited the penalties on late payments of credit cards. After the limitation credit card companies started collecting more fees from those people with sterling credit (see e.g. New York Times, May 18th 2009, "Credit Card Industry Aims to Profit From Sterling Payers" by Andrew Martin).
} 
Volcker rule). In the first, we assume that the Volcker rule allows hedging but not the alpha bets. In this case we compare cases $(i)$ and $(i i)$, and find a new banking alpha for case $(i i)$ such that the bank equity value in $(i i)$ equals the equity value in (i). In the second case, hedging is prevented but not the alpha bets. In this case we compare $(i)$ and $($ iii) and estimate a new banking alpha for (iii) that produces the same equity value as in $(i)$. In the last case, we assume that the Volcker rule prevents all trading (hedging and the alpha bets). Thus, in this case we compare $(i)$ and $(i v)$, and calculate a new banking alpha in the same sense as with the other cases. The new banking alphas are reported in Table 2.2. On average, the alpha bets would raise the banking alpha by about 26 basis points (BPS) with the estimated parameters and 22 BPS with the significant parameters, the hedging by 1 BPS with the estimated parameters and 0 BPS with the significant parameters, and total trading by about 26 BPS with the estimated parameters and 22 BPS with the significant parameters. For the Volcker rule effect, we use the impact from the alpha bets and total trading. Thus, by our comparative statics, banks should increase their banking alphas by about 24 BPS to keep their equity value the same as before the rule. Big banks do not need to raise their banking alphas because they are penalized the least by the rule. As mentioned before, to get the higher banking alphas, banks need to create new products and/or to improve their efficiency.

After we have the new banking alphas, we estimate the corresponding bank loan margin changes. For this we analyze banking net income and assume here that each bank's $N I B_{t}$ equals the loan margin after default losses times the banking assets, i.e., $N I B_{t}=m R W A B_{t-1}$, where $m$ is the loan margin and $R W A B_{t-1}$ is the the banking assets at time $t-1$. Thus, return on the banking assets is given by $N I B_{t} / R W A B_{t-1}=m$. On the other hand, if we use the same return model as with 
the trading assets in subsection 2.3.2 then we have

$$
\frac{N I B_{t}}{R W A B_{t-1}}=R_{f}+\alpha_{B}+\beta\left(R_{M}-R_{f}\right)+\epsilon
$$

where $\beta$ is the beta of the banking assets and we assume it is independent of $\alpha_{B}$. Combining the two representations for banking asset returns, we get $m=R_{f}+\alpha_{B}+$ $\beta\left(R_{M}-R_{f}\right)+\epsilon$, which gives $\Delta m=\Delta \alpha_{B}$. That is, the change in the loan margin equals the banking alpha change. Thus, by Table 2.2, if the Volcker rule prevents banks from trading or just from taking alpha bets then the banks should raise their loan margins between zero and $1.62 \%$ (on average 24 BPS) to compensate the value decreases from the Volcker rule. We expect that big banks have least pressure to increase their loan margins; by our comparative statics, they do not need to raise the loan rates at all (but many banks have to decrease their trading operations). Thus, the effect of the Volcker rule on the loan margins is quite small. This is because, based on our model and data, banks do not benefit much from the trading and most of the banks' assets are in the basic banking business. Therefore, a small increase in the loan margins compensates the value fall due to the rule.

\subsubsection{Default Probabilities}

By (2.5), banks maximize their equity value, they do not necessary minimize their default probability. Because banking regulators are in the business of minimizing the default probability, banks and their regulators might have conflicting interests. For instance, in 2008 during the recent financial crisis 21 large banks in the U.S. and Europe paid total over $\$ 400$ billion dividends which represents around one-third of their 2007 market capitalization of $\$ 1.3$ trillion (Acharya, Shin, and Gujral 2009). The dividends lowered the banks' capital and, therefore, their default probability increased. 
In our model, a new regulation (or similarly a new portfolio constraint) cannot increase the banks' value because the rule sets constraints on their behavior. On the other hand, regulation changes can increase or decrease the banks' default probability. Unfortunately, it is not obvious what the effect on the default probability is since banks react to regulation and this can cause positive and negative effects. This is also the case with the Volcker rule.

If trading is profitable then ban on trading lowers the expected earnings and this way also the expected buffer capital level. If also hedging is prevented then earnings risk might increase. Both these effects may increase the default probability. On the other hand, there is also a positive effect: Since Volcker rule prevents trading and, by Table 2.1, trading earnings have a higher volatility than banking earnings have, the total earnings volatility and this way also the default probability might fall. Thus, the total effect on the default probability depends on the magnitude of the negative and positive effects ${ }^{24}$ Table 2.2 gives the effect of Volcker rule on the banks' default probability over 100 years, expected annual earnings, and earnings volatility. The default probabilities are estimated by Monte Carlo simulation with 10,000 paths. By Table 2.2, the change of the default probability from case $(i)$ (i.e. without the Volcker rule) to cases $(i i)-(i v)$ (ban on alpha bets, hedging, and all trading; both estimated and significant parameters) has correlation of -0.77 with the corresponding expected earnings change and 0.05 with the corresponding earnings volatility change. Thus, the expected earnings seem to drive the default probability as its correlation has a higher absolute value. ${ }^{25}$ This implies that the best way to hedge default risk is to run a profitable business. Note that, by Table 2.1, the Volcker rule prevents several

\footnotetext{
${ }^{24}$ Keppo et al. (2010) consider banks' market risk requirement and, according to their model, the requirement has similar effects on the default probability as the Volcker rule.

${ }^{25}$ Default probability does not necessarily increase in earnings volatility. By Figures $(3.4 .4)$ and (3.4.6) in Subsection 2.5.6 the dividend barrier rises in the volatility. Therefore, a low earnings volatility also means a low buffer capital which could increase the default probability.
} 
banks to run their most profitable business.

The effect of Volcker rule on the default probability can be analyzed by comparing the default probability in case $(i)$ (without the rule) with cases (ii) (ban on alpha bets) and (iv) (ban on all the trading). On average the Volcker rule increases the default probability between $0.7 \%$ (with the estimated parameters) and $1.5 \%$ (with the significant parameters) if only alpha bets are prevented, and between $0.8 \%$ (with the estimated parameters) and $1.6 \%$ (with the significant parameters) if all the trading is prevented. Thus, if the banks behave optimally according to our model then the negative default effects of trading alpha and hedging are stronger than the positive effect of a lower earnings volatility. As a result, the default probability of the banks for the next 100 years increases on average by about half (from $2.3 \%$ to $3.4 \%$ ). This effect is mainly driven by four banks (CBSH, FHN, MTB, and STT). Their default probabilities rise due to the Volcker rule under all cases (estimated parameters / significant ones, ban on alpha bets / ban on all trading), and in this sense their effect is robust. By Table 2.1, all the four banks have statistically significant positive trading alphas and their value would rise if their trading operations were expanded. Therefore, when trading is prevented, their expected profits fall (see column $E(\Delta X)$ in Table 2.2 and this lowers the buffer capital of the four banks, which raises the default probability.

We analyze the robustness of these findings in Subsection 2.5.7 by using the estimated parameters of FHN and MTB banks in Table 2.1. By Table 2.2, the default probabilities of FHN and MTB both rise due to the Volcker rule. Within the range of parameter values in the figures of Subsection 2.5.7, FHN has a higher default probability under the Volcker rule as long as its trading alpha is positive and banking volatility is higher than $0.1 \%$. These two parameter scenarios indicate that 
the rule raises FHN's default probability as long as the bank benefits from trading relative to the banking business. Thus, the effect of Volcker rule on FHN's default probability is quite robust and it is not driven by the banks' unusually high trading alpha (it is enough that the alpha is positive). By Subsection 2.5.7. MTB's default probability rises due to the Volcker rule as long as the banking proportion is higher than $98.5 \%$, the correlation between trading and banking cash flows is lower than 0.4 , trading volatility is lower than $2.4 \%$, and trading alpha is over $2.2 \%$. Thus, similarly as with FHN, the parameter ranges for the correlation, trading volatility, and the trading alpha imply that as long as there is enough trading value, the Volcker rule raises the default probability. The parameter scenario of the banking book is more complicated. By Figures (2.3.4) and (2.3.6) in Subsection 2.5.6, the dividend barrier of case $(i i)$ is lower than in case $(i)$ due to the lower earnings volatility of case (ii). When the banking proportion is higher than $98.5 \%$ then, by Figure (2.3.2) in Subsection 2.5.6, the dividend barrier is even lower, raising the default probability - especially in case $(i i)$. This explains the rising default probability due to Volcker rule when $\zeta>98.5 \%$.

We doubt the hedging story and its benefits. By Table 2.2, if the hedging is prevented then the default probability falls by $0.08 \%$ (estimated parameters) and by 0.05\% (significant parameters). This indicates that the banks do not focus on the hedging of their default probability. 


\subsection{Appendix for Chapter II}

\subsubsection{Model under the Objective Measure}

Let us define the market return evolves as the following dynamics under the objective measure $\mathbb{P}$ :

$$
d M(t)=\left(r+\lambda \sigma_{M}\right) M(t) d t+M(t) \sigma_{M} d W_{M}^{\mathbb{P}}(t)
$$

where $W_{M}^{\mathbb{P}}(t)$ is a Wiener process under $\mathbb{P}, \lambda$ is market price of risk and it is constant. We can write this process in terms of $W_{M}(t)$, which is a Wiener process under the risk-neutral probability measure, as follows

$$
d M(t)=M(t)\left[r d t+\sigma_{M} d W_{M}(t)\right]
$$

Thus, we have

$$
W_{M}(t)=\lambda t+W_{M}^{\mathbb{P}}(t)
$$

Under the risk-neutral probability,

$$
d E_{B}(t)=R W(t) \zeta\left(r+\alpha_{B}\right) d t+R W(t) \zeta \sigma_{B} d W_{B}(t)
$$

where $W_{B}(t)=\rho_{B M} W_{M}(t)+\sqrt{1-\rho_{B M}^{2}} \tilde{W}_{B}(t), W_{M}(t)$ and $\tilde{W}_{B}(t)$ are independent Wiener processes, and $\rho_{B M}$ is the correlation between them. By $2.15, W_{B}(t)=$ $\rho_{B M} \lambda t+\rho_{B M} W_{M}^{\mathbb{P}}(t)+\sqrt{1-\rho_{B M}^{2}} \tilde{W}_{B}(t)$ and this gives the following $\mathbb{P}$-dynamics:

$$
d E_{B}(t)=R W(t) \zeta\left(r+\alpha_{B}+\sigma_{B} \lambda \rho_{B M}\right) d t+R W(t) \zeta \sigma_{B} d W_{B}^{\mathbb{P}}(t)
$$

where $W_{B}^{\mathbb{P}}(t)=\rho_{B M} W_{M}^{\mathbb{P}}(t)+\sqrt{1-\rho_{B M}^{2}} \tilde{W}_{B}(t)$. The buffer capital ratio dynamics 2.11a can be written under $\mathbb{P}$ as follows

$$
\begin{aligned}
X^{\pi}(t)= & X(0)+\int_{0}^{t}\left[r+\zeta^{\pi} \alpha_{B}+\left(1-\zeta^{\pi}\right) \theta^{\pi}(u) \alpha_{T}+\zeta^{\pi}\right] d u \\
& +\int_{0}^{t} \lambda\left[\sigma_{B} \rho_{B M}+\left(1-\zeta^{\pi}\right) \theta^{\pi}(u) \sigma_{T} \rho_{T M}\right] d u \\
& +\int_{0}^{t}\left[\zeta^{\pi} \sigma_{B} d W_{B}^{\mathbb{P}}(u)+\left(1-\zeta^{\pi}\right) \theta^{\pi}(u) \sigma_{T} d W_{T}^{\mathbb{P}}(u)\right]-L^{\pi}(t) .
\end{aligned}
$$


where the correlations are estimated by using $\rho_{B M}=\operatorname{Corr}\left[\frac{N I B_{t}}{R W A B_{t}}, \frac{\Delta M_{t}}{M_{t}}\right], \rho_{T M}=$ $\operatorname{Corr}\left[\frac{N I T_{t}}{R W A T_{t}}, \frac{\Delta M_{t}}{M_{t}}\right]$, and the market price of risk from $\lambda=\left(E\left[\frac{\Delta M}{M}\right]-r\right) / \sqrt{\operatorname{Var}\left[\frac{\Delta M}{M}\right] / \Delta t}$.

\subsubsection{Optimal Trading Strategy}

\section{Unconstrained optimal trading strategy}

Let $\tilde{\theta}(x)$ denote an unconstrained optimal trading strategy at buffer capital level $x$ obtained from $2.11 \mathrm{~b}$ by the first order condition i.e.

$$
\tilde{\theta}(x)=-\frac{\zeta \sigma_{B} \rho_{B T}}{(1-\zeta) \sigma_{T}}-\frac{\alpha_{T}}{(1-\zeta) \sigma_{T}^{2}} \frac{V^{\prime}(x)}{V^{\prime \prime}(x)}
$$

If $\alpha_{T}=0$ then $\tilde{\theta}(x)=-\frac{\zeta \sigma_{B} \rho_{B T}}{(1-\zeta) \sigma_{T}}$ and $\theta^{*}(x)=\max \left\{0, \min \left(-\frac{\zeta \sigma_{B} \rho_{B T}}{(1-\zeta) \sigma_{T}}, 1\right)\right\}$. Now assume $\alpha_{T} \neq 0$.

Rearranging 2.16) we get

$$
V^{\prime \prime}(x)=k_{1}(\tilde{\theta}(x)) V^{\prime}(x)
$$

where $k_{1}(\cdot)=-\frac{\alpha_{T}}{(1-\zeta) \sigma_{T}^{2}(\cdot)+\zeta \sigma_{B} \rho_{B T} \sigma_{T}}$.

Inserting 2.17) into 2.11b and then differentiating w.r.t. $x$. we come to

$$
\begin{aligned}
\delta V^{\prime}(x)= & {\left[(1-\zeta)^{2} \tilde{\theta}(x) \sigma_{T}^{2} \tilde{\theta}^{\prime}(x)+\zeta \sigma_{B} \rho_{B T}(1-\zeta) \sigma_{T} \tilde{\theta}^{\prime}(x)\right] k_{1}(\tilde{\theta}(x)) V^{\prime}(x) } \\
& {\left[-\frac{1}{2} \sigma_{\theta}^{2}(1-\zeta) \sigma_{T}^{2} \tilde{\theta}^{\prime}(x) k_{1}(\tilde{\theta}(x))+(1-\zeta) \alpha_{T} \tilde{\theta}^{\prime}(x)\right] V^{\prime}(x) } \\
& +\left[\frac{1}{2} \sigma_{\theta}^{2} k_{1}(\tilde{\theta}(x))+\left(r+\zeta \alpha_{B}+(1-\zeta) \tilde{\theta}^{\prime}(x) \alpha_{T}\right)\right] V^{\prime \prime}(x) .
\end{aligned}
$$

Replacing $V^{\prime \prime}$ by 2.17) into the above equation and solving for $\tilde{\theta}^{\prime}(x)$ we get

$$
\tilde{\theta}^{\prime}(x)=\frac{\delta-\frac{1}{2} \sigma_{\tilde{\theta}}^{2} k_{1}^{2}(\tilde{\theta}(x))-\mu_{\tilde{\theta}} k_{1}(\tilde{\theta}(x))}{\left[(1-\zeta)^{2} \tilde{\theta}(x) \sigma_{T}^{2}+\zeta \sigma_{B} \rho_{B T}(1-\zeta) \sigma_{T}\right] k_{1}(\tilde{\theta}(x))+\left[\frac{\sigma_{\tilde{\theta}}^{2}(1-\zeta) \sigma_{T}^{2}}{2 \alpha_{T}}\right] k_{1}^{2}(\tilde{\theta}(x))+(1-\zeta) \alpha_{T}}
$$


Initial Unconstrained Optimal Trading Weight $\tilde{\theta}(0)$

$\tilde{\theta}(0)$ solves the following system of equations:

$$
\left\{\begin{aligned}
0 \quad= & \frac{1}{2}\left[\zeta^{2} \sigma_{B}^{2}+(1-\zeta)^{2} \tilde{\theta}(0)^{2} \sigma_{T}^{2}+2 \zeta \sigma_{B} \rho_{B T}(1-\zeta) \tilde{\theta}(0) \sigma_{T}\right] V^{\prime \prime}(0) \\
& +\left[r+\zeta \alpha_{B}+(1-\zeta) \tilde{\theta}(0) \alpha_{T}\right] V^{\prime}(0), \\
\tilde{\theta}(0)= & -\frac{\zeta \sigma_{B} \rho_{B T}}{(1-\zeta) \sigma_{T}}-\frac{\alpha_{T}}{(1-\zeta) \sigma_{T}^{2}} \frac{V^{\prime}(0)}{V^{\prime \prime}(0)}
\end{aligned}\right.
$$

The first equation is from 2.11a and 2.11b), and the second equation is 2.16 at $x=0$.

The second equation is equivalent to:

$$
V^{\prime}(0)=-\frac{(1-\zeta) \sigma_{T}^{2} \tilde{\theta}(0)+\zeta \sigma_{B} \sigma_{T} \rho_{B T}}{\alpha_{T}} V^{\prime \prime}(0)
$$

if $\alpha_{T} \neq 0$. Substituting $(2.19)$ into the first equation in the system and letting $\tilde{\theta}_{0}=\tilde{\theta}(0)$, we get

$0=-\alpha_{T}(1-\zeta)^{2} \sigma_{T}^{2} \tilde{\theta}_{0}^{2}-2\left(r+\zeta \alpha_{B}\right)(1-\zeta) \sigma_{T}^{2} \tilde{\theta}_{0}-2\left(r+\zeta \alpha_{B}\right) \zeta \sigma_{B} \sigma_{T} \rho_{B T}+\alpha_{T} \zeta^{2} \sigma_{B}^{2}$

By the quadratic formula and using the fact that if $\rho_{B T}<0$ and $\alpha_{T}>0$ then $\tilde{\theta}_{0}>0$ since $V^{\prime}(0) / V^{\prime \prime}(0)<0$, we get

$$
\tilde{\theta}_{0}=\frac{\left(r+\zeta \alpha_{B}\right) \sigma_{T}-\sqrt{\left(r+\zeta \alpha_{B}\right)^{2} \sigma_{T}^{2}+\left(\alpha_{T} \zeta \sigma_{B}\right)\left(-2\left(r+\zeta \alpha_{B}\right) \sigma_{T} \rho_{B T}+\alpha_{T} \zeta \sigma_{B}\right)}}{-\alpha_{T}(1-\zeta) \sigma_{T}} .
$$

\section{Constrained Optimal Trading Strategy $\theta^{*}(x)$}

By (2.18) and (2.20), we get 


$$
\tilde{\theta}(x)=\tilde{\theta}_{0}+\int_{0}^{x} g(y) d y
$$

where

$$
g(y)=\frac{\delta-\frac{1}{2} \sigma_{\theta}^{2} k_{1}(\tilde{\theta}(y))^{2}-\mu_{\theta} k_{1}(\tilde{\theta}(y))}{\left((1-\zeta)^{2} \tilde{\theta}(y) \sigma_{T}^{2}+\zeta \sigma_{B} \rho_{B T}(1-\zeta) \sigma_{T}\right) k_{1}(\theta(y))-\frac{1}{2} \sigma_{\theta}^{2}(1-\zeta) \sigma_{T}^{2} k_{1}(\theta(y))+(1-\zeta) \alpha_{T}} .
$$

Therefore, the constrained optimal trading strategy $\theta^{*}(x)=\max \{0, \min (\tilde{\theta}(x), 1)\}$, where

$$
\tilde{\theta}(x)= \begin{cases}\tilde{\theta}_{0}+\int_{0}^{x} g(y) d y & \text { if } \alpha_{T} \neq 0 \\ -\frac{\zeta \sigma_{B} \rho_{B T}}{(1-\zeta) \sigma_{T}} & \text { if } \alpha_{T}=0\end{cases}
$$




\subsubsection{Model Parameters}

Table 2.1: Sample Banks and Their Model Parameters over 2000 Q1-2011 Q4 .

\begin{tabular}{|c|c|c|c|c|c|c|c|c|c|c|c|c|c|}
\hline \multirow[t]{2}{*}{ Bank (Ticker) } & \multirow{2}{*}{$\begin{array}{r}\text { Risk-weighted Assets, } \mathrm{m} \$ \\
\text { (standard deviation) }\end{array}$} & \multirow[t]{2}{*}{$\mathrm{BC}, \%$} & \multirow[t]{2}{*}{$V_{d}, \%$} & \multirow{2}{*}{$\begin{array}{r}\zeta_{d}, \% \\
\text { (standard deviation) }\end{array}$} & \multicolumn{2}{|c|}{$\zeta, \%$} & \multirow[t]{2}{*}{$\sigma_{B}, \%$} & \multirow[t]{2}{*}{$\sigma_{T}, \%$} & \multirow{2}{*}{$\begin{array}{r}\rho_{B T} \\
\text { (standard error) }\end{array}$} & \multirow{2}{*}{$\begin{array}{r}\alpha_{T}, \% \\
\text { (standard error) }\end{array}$} & \multirow{2}{*}{$\begin{array}{r}\beta_{T}, \% \\
\text { (standard error) }\end{array}$} & \multicolumn{2}{|c|}{$u, \%$} \\
\hline & & & & & est. & sig. & & & & & & est. & sig. \\
\hline $\begin{array}{l}\text { ALLIANCE BANKSHARES } \\
\text { (ABVA) }\end{array}$ & $\begin{array}{r}390 \\
(50)\end{array}$ & 5.73 & 11.19 & $\begin{array}{r}91.90 \\
(17.11)\end{array}$ & 99.59 & 100.00 & 0.60 & 192.43 & $\begin{array}{r}-0.43 \\
(0.18)\end{array}$ & $\begin{array}{c}615.81 \diamond \\
(620.74)\end{array}$ & $\begin{array}{r}-775.52 \\
(1851.08)\end{array}$ & 78.78 & 3.08 \\
\hline $\begin{array}{l}\text { BANK OF AMERICA } \\
\text { (BAC) }\end{array}$ & $\begin{array}{r}874,187 \\
(486,145)\end{array}$ & 0.94 & 15.82 & $\begin{array}{r}90.98 \\
(2.22)\end{array}$ & 100.00 & 100.00 & 0.42 & 1.48 & $\begin{array}{r}-0.24 \\
(0.14)\end{array}$ & $\begin{array}{r}-1.50^{* *} \\
(0.47)\end{array}$ & $\begin{array}{r}4.92^{* *} \\
(1.67)\end{array}$ & 1.83 & 1.83 \\
\hline $\begin{array}{l}\text { COMMERCE BANCSHARES } \\
\text { (CBSH) }\end{array}$ & $\begin{array}{r}13,011 \\
(632)\end{array}$ & 4.23 & 23.05 & $\begin{array}{l}99.88 \\
(0.12)\end{array}$ & 97.05 & 75.00 & 0.14 & 12.47 & $\begin{array}{r}-0.47^{* *} \\
(0.12)\end{array}$ & $\begin{array}{r}55.36^{* *} \\
(6.12)\end{array}$ & $\begin{array}{r}25.49 \\
(21.75)\end{array}$ & 0.27 & 0.27 \\
\hline $\begin{array}{l}\text { FIRST HORIZON } \\
\text { (FHN) }\end{array}$ & $\begin{array}{l}22,559 \\
(5,652)\end{array}$ & 2.73 & 17.20 & $\begin{array}{l}95.91 \\
(2.64)\end{array}$ & 91.92 & 75.00 & 0.58 & 5.99 & $\begin{array}{l}-0.08 \\
(0.14)\end{array}$ & $\begin{array}{r}21.02^{* *} \\
(2.26)\end{array}$ & $\begin{array}{r}5.85 \\
(7.97)\end{array}$ & 1.70 & 1.79 \\
\hline $\begin{array}{l}\text { HEARTLAND FINANCIAL } \\
\text { (HTLF) }\end{array}$ & $\begin{array}{l}2,132 \\
(644)\end{array}$ & 2.00 & 14.72 & $\begin{array}{r}99.96 \\
(0.05)\end{array}$ & 99.68 & 100.00 & 0.18 & 29.81 & $\begin{array}{r}0.05 \\
(0.15)\end{array}$ & $\begin{array}{r}1.86 \\
(10.62)\end{array}$ & $\begin{array}{r}110.92^{* *} \\
(36.34)\end{array}$ & 0.53 & 0.53 \\
\hline $\begin{array}{l}\text { JPMORGAN CHASE } \\
(\mathrm{JPM})\end{array}$ & $\begin{array}{r}827,965 \\
(319,811)\end{array}$ & 1.37 & 14.83 & $\begin{array}{l}74.17 \\
(9.72)\end{array}$ & 100.00 & 100.00 & 0.26 & 0.76 & $\begin{array}{r}-0.23 \\
(0.14)\end{array}$ & $\begin{array}{r}-1.23 * * \\
(0.24)\end{array}$ & $\begin{array}{r}2.41^{* *} \\
(0.84)\end{array}$ & 0.72 & 0.72 \\
\hline $\begin{array}{l}\text { M \& T BANK } \\
\text { (MTB) }\end{array}$ & $\begin{array}{r}46,239 \\
(14,500)\end{array}$ & 0.09 & 19.89 & $\begin{array}{l}99.54 \\
(0.84)\end{array}$ & 83.75 & 83.75 & 0.17 & 1.89 & $\begin{array}{l}0.31^{*} \\
(0.13)\end{array}$ & $\begin{array}{r}2.94^{* *} \\
(0.56)\end{array}$ & $\begin{array}{r}3.85 \\
(1.98)\end{array}$ & 0.49 & 0.49 \\
\hline $\begin{array}{l}\text { STATE STREET } \\
\text { (STT) }\end{array}$ & $\begin{array}{r}53,943 \\
(13,739)\end{array}$ & 6.80 & 35.27 & $\begin{array}{r}99.27 \\
(1.33)\end{array}$ & 98.77 & 98.53 & 0.95 & 63.35 & $\begin{array}{r}0.17 \\
(0.17)\end{array}$ & $\begin{array}{r}264.73^{* *}, \diamond \\
(88.86)\end{array}$ & $\begin{array}{r}68.80 \\
(312.78)\end{array}$ & 3.56 & 3.21 \\
\hline $\begin{array}{l}\text { SUNTRUST BANKS } \\
\text { (STI) }\end{array}$ & $\begin{array}{l}133,965 \\
(26,138)\end{array}$ & 0.81 & 13.88 & $\begin{array}{r}97.16 \\
(4.27)\end{array}$ & 100.00 & 100.00 & 0.36 & 1.88 & $\begin{array}{r}0.23 \\
(0.14)\end{array}$ & $\begin{array}{r}-0.55 \\
(0.57)\end{array}$ & $\begin{array}{r}1.31 \\
(2.02)\end{array}$ & 1.54 & 1.54 \\
\hline $\begin{array}{l}\text { TOMPKINS FINANCIAL } \\
\text { (TMP) }\end{array}$ & $\begin{array}{l}1,472 \\
(427)\end{array}$ & 3.94 & 25.11 & $\begin{array}{r}98.63 \\
(1.56)\end{array}$ & 100.00 & 100.00 & 0.14 & 1.28 & $\begin{array}{r}-0.16 \\
(0.22)\end{array}$ & $\begin{array}{r}-1.18 \\
(0.76)\end{array}$ & $\begin{array}{r}-0.66 \\
(2.25)\end{array}$ & 0.32 & 0.32 \\
\hline $\begin{array}{l}\text { WELLS FARGO } \\
(\text { WFC) }\end{array}$ & $\begin{array}{r}526,377 \\
(333,883)\end{array}$ & 1.18 & 19.89 & $\begin{array}{l}97.34 \\
(2.62)\end{array}$ & 100.00 & 100.00 & 0.31 & 2.37 & $\begin{array}{r}0.70^{* *} \\
(0.09)\end{array}$ & $\begin{array}{r}0.34 \\
(0.75)\end{array}$ & $\begin{array}{r}3.98 \\
(2.63)\end{array}$ & 1.53 & 1.24 \\
\hline $\begin{array}{l}\text { WINTRUST FINANCIAL } \\
\text { (WTFC) }\end{array}$ & $\begin{array}{r}6,252 \\
(3,193)\end{array}$ & 1.63 & 12.45 & $\begin{array}{r}99.92 \\
(0.17)\end{array}$ & 99.65 & 99.95 & 0.15 & 111.98 & $\begin{array}{r}-0.28 \\
(0.15)\end{array}$ & $\begin{array}{r}467.18 \\
(231.90)\end{array}$ & $\begin{array}{r}-1323.96 \\
(791.79)\end{array}$ & 0.23 & 0.37 \\
\hline
\end{tabular}

Risk-weighted assets column is the average total risk-weighted asset size during the period in terms of million USD. BC denotes the mean buffer capital ratio. $V_{d}$ is the average market capitalization during the time period divided by the average risk-weighted asset during the time period (subscript $d$ is for data, distincting from the model estimated value). Parameter $\zeta_{d}$ is the time-series average of the ratio of banking assets to total assets, and $\zeta$ is the corresponding model optimal ratio (the lower bound $\zeta_{I}$ is $75 \%$ ). The column under est. is calculated with the trading alphas and correlations equal to their estimated values (the estimates are in this same table) while the column under sig. is calculated with only the statistically significant trading alphas and correlations (the non-significant trading alphas and correlations are zero). Each bank's estimated $\sigma_{B}$ and $\sigma_{T}$ are the time-series annualized standard deviation of the banking and trading returns, and $\rho_{B T}$ is the correlation between the banking and trading returns. One asterisk $\left.{ }^{*}\right)$ indicates the significance level of $5 \%$, and two $\left({ }^{* *}\right)$ indicates $1 \%$. Each bank's $\alpha_{T}$ and $\beta_{T}$ are the bank's trading alpha (excess return) and trading beta coefficient. Diamond symbol $(\diamond)$ indicates the trading alpha values which violate the $\delta$-condition in Subsection 2.3 .2 (footnote 18), i.e., which have $\alpha_{T} \geq\left(\delta-\zeta \alpha_{B}\right) /(1-\zeta)$. We set these estimates equal to $\alpha_{T}=\left(\delta-\zeta \alpha_{B}\right) /(1-\zeta)-\epsilon$ where $\epsilon=10^{-4}$. Therefore, we use the trading alpha value of $20.36 \%$ for ABVA and $222.72 \%$ for STT. $u$ denotes the model estimated dividend barrier. We find the forward looking banking alpha by fitting the model equity value to the realized market equity value in the asset-weighted least squares sense and obtain $\alpha_{B}=0.38 \%$ ( $\alpha_{B}$ is the model implied value and it is the same for all the banks). 


\subsubsection{Volcker Rule}

Table 2.2: Effects of trading. $(i)$ Base case is with the estimated parameters; $(i i)$ is the case with trading alpha $\alpha_{T}=0$; case $(i i i)$ is with $\rho_{B T}=0$, i.e., zero correlation between the banking and trading earnings; case $(i v)$ is with zero $\rho_{B T}$ and $\alpha_{T} . V$ is the model bank equity value in terms of the risk weighted assets. $\Delta V / V$ is the value change relative to the base case value. $\alpha_{B}$ is a (new) banking alpha that gives the same bank equity value as in the base case. $\Delta \alpha_{B}$ is the difference between the base case $\alpha_{B}$ and the new $\alpha_{B}$. $D P$ denotes the default probability during the next 100 years (by Monte Carlo simulation with 10,000 paths and time discretization $\Delta t=1 / 365$ a year). $E(\Delta X)$ and $\operatorname{Std}(\Delta X)$ are the annualized average and standard deviation of $\Delta X$, respectively. $u$ denotes the model estimated dividend barrier. The columns under est. are calculated with the trading alphas and correlations equal to their estimated values in Table 2.1 while the columns under sig. are calculated with only the statistically significant trading alphas and correlations (the non-significant trading alphas and correlations are zero).

\begin{tabular}{|c|c|c|c|c|c|c|c|c|c|c|c|c|c|c|c|c|c|}
\hline \multirow[t]{2}{*}{ Bank } & \multirow[t]{2}{*}{ Cases } & \multicolumn{2}{|c|}{$V, \%$} & \multicolumn{2}{|c|}{$\Delta V / V, \%$} & \multicolumn{2}{|c|}{$D P, \%$} & \multicolumn{2}{|c|}{$E(\Delta X), \%$} & \multicolumn{2}{|c|}{$\operatorname{Std}(\Delta X), \%$} & \multicolumn{2}{|c|}{$\alpha_{B}, \%$} & \multicolumn{2}{|c|}{$\Delta \alpha_{B}, \%$} & \multicolumn{2}{|c|}{$u, \%$} \\
\hline & & est. & sig. & est. & sig. & est. & sig. & est. & sig. & est. & sig. & est. & sig. & est. & sig. & est. & sig. \\
\hline \multirow[t]{4}{*}{ ABVA } & (i) Base case & 27.50 & 20.11 & & & 14.17 & 5.12 & 1.07 & 0.35 & 8.88 & 0.55 & 0.38 & 0.38 & & & 78.78 & 3.08 \\
\hline & (ii) $\alpha_{T}=0$ & 20.52 & 20.11 & -25.38 & 0.00 & 4.17 & 5.12 & 0.35 & 0.35 & 0.50 & 0.55 & 0.52 & 0.38 & 0.14 & 0.00 & 2.67 & 3.08 \\
\hline & (iii) $\rho_{B T}=0$ & 26.10 & 20.11 & -5.09 & 0.00 & 14.07 & 5.12 & 1.07 & 0.35 & 8.86 & 0.55 & 0.48 & 0.38 & 0.10 & 0.00 & 79.27 & 3.08 \\
\hline & (iv) $\alpha_{T}, \rho_{B T}=0$ & 20.11 & 20.11 & -26.87 & 0.00 & 5.12 & 5.12 & 0.35 & 0.35 & 0.55 & 0.55 & 0.53 & 0.38 & 0.15 & 0.00 & 3.08 & 3.08 \\
\hline \multirow[t]{4}{*}{$\mathrm{BAC}$} & (i) Base case & 16.26 & 16.26 & & & 3.16 & 3.16 & 0.35 & 0.35 & 0.38 & 0.38 & 0.38 & 0.38 & & & 1.83 & 1.83 \\
\hline & (ii) $\alpha_{T}=0$ & 16.38 & 16.26 & 0.71 & 0.00 & 2.77 & 3.16 & 0.35 & 0.35 & 0.37 & 0.38 & 0.38 & 0.38 & 0.00 & 0.00 & 1.75 & 1.83 \\
\hline & (iii) $\rho_{B T}=0$ & 16.26 & 16.26 & 0.00 & 0.00 & 3.16 & 3.16 & 0.35 & 0.35 & 0.38 & 0.38 & 0.38 & 0.38 & 0.00 & 0.00 & 1.83 & 1.83 \\
\hline & $(i v) \alpha_{T}, \rho_{B T}=0$ & 16.26 & 16.26 & 0.00 & 0.00 & 3.16 & 3.16 & 0.35 & 0.35 & 0.38 & 0.38 & 0.38 & 0.38 & 0.00 & 0.00 & 1.83 & 1.83 \\
\hline \multirow[t]{4}{*}{$\mathrm{CBSH}$} & (i) Base case & 26.28 & 26.28 & & & 0.06 & 0.06 & 0.45 & 0.45 & 0.13 & 0.13 & 0.38 & 0.38 & & & 0.27 & 0.27 \\
\hline & (ii) $\alpha_{T}=0$ & 22.91 & 22.91 & -12.84 & -12.84 & 0.12 & 0.12 & 0.38 & 0.38 & 0.13 & 0.13 & 0.45 & 0.45 & 0.07 & 0.07 & 0.30 & 0.30 \\
\hline & (iii) $\rho_{B T}=0$ & 26.26 & 26.26 & -0.10 & -0.10 & 0.06 & 0.06 & 0.45 & 0.45 & 0.14 & 0.14 & 0.38 & 0.38 & 0.00 & 0.00 & 0.29 & 0.29 \\
\hline & $(i v) \alpha_{T}, \rho_{B T}=0$ & 22.88 & 22.88 & -12.94 & -12.94 & 0.14 & 0.14 & 0.38 & 0.38 & 0.14 & 0.14 & 0.45 & 0.45 & 0.07 & 0.07 & 0.33 & 0.33 \\
\hline \multirow[t]{4}{*}{ FHN } & (i) Base case & 62.20 & 62.11 & & & 0.41 & 0.44 & 1.22 & 1.22 & 0.59 & 0.60 & 0.38 & 0.38 & & & 1.70 & 1.79 \\
\hline & $(i i) \alpha_{T}=0$ & 17.91 & 17.90 & -71.21 & -71.19 & 4.61 & 4.68 & 0.36 & 0.36 & 0.55 & 0.55 & 1.27 & 1.27 & 0.89 & 0.89 & 3.04 & 3.06 \\
\hline & (iii) $\rho_{B T}=0$ & 62.11 & 62.11 & -0.15 & 0.00 & 0.44 & 0.44 & 1.22 & 1.22 & 0.60 & 0.60 & 0.38 & 0.38 & 0.00 & 0.00 & 1.79 & 1.79 \\
\hline & $(i v) \alpha_{T}, \rho_{B T}=0$ & 17.90 & 17.90 & -71.23 & -71.19 & 4.68 & 4.68 & 0.36 & 0.36 & 0.55 & 0.55 & 1.27 & 1.27 & 0.89 & 0.89 & 3.06 & 3.06 \\
\hline \multirow[t]{4}{*}{ HTLF } & (i) Base case & 20.49 & 20.46 & & & 0.29 & 0.27 & 0.38 & 0.38 & 0.18 & 0.18 & 0.38 & 0.38 & & & 0.53 & 0.53 \\
\hline & (ii) $\alpha_{T}=0$ & 20.46 & 20.46 & -0.15 & 0.00 & 0.27 & 0.27 & 0.38 & 0.38 & 0.18 & 0.18 & 0.38 & 0.38 & 0.00 & 0.00 & 0.53 & 0.53 \\
\hline & (iii) $\rho_{B T}=0$ & 20.50 & 20.46 & 0.01 & 0.00 & 0.29 & 0.27 & 0.38 & 0.38 & 0.18 & 0.18 & 0.38 & 0.38 & 0.00 & 0.00 & 0.53 & 0.53 \\
\hline & (iv) $\alpha_{T}, \rho_{B T}=0$ & 20.46 & 20.46 & -0.15 & 0.00 & 0.27 & 0.27 & 0.38 & 0.38 & 0.18 & 0.18 & 0.38 & 0.38 & 0.00 & 0.00 & 0.53 & 0.53 \\
\hline
\end{tabular}




\begin{tabular}{|c|c|c|c|c|c|c|c|c|c|c|c|c|c|c|c|c|c|}
\hline \multirow[t]{2}{*}{ Bank } & \multirow[t]{2}{*}{ Cases } & \multicolumn{2}{|c|}{$V, \%$} & \multicolumn{2}{|c|}{$\Delta V / V, \%$} & \multicolumn{2}{|c|}{$D P, \%$} & \multicolumn{2}{|c|}{$E(\Delta X), \%$} & \multicolumn{2}{|c|}{$\operatorname{Std}(\Delta X), \%$} & \multicolumn{2}{|c|}{$\alpha_{B}, \%$} & \multicolumn{2}{|c|}{$\Delta \alpha_{B}, \%$} & \multicolumn{2}{|c|}{$u, \%$} \\
\hline & & est. & sig. & est. & sig. & est. & sig. & est. & sig. & est. & sig. & est. & sig. & est. & sig. & est. & sig. \\
\hline \multirow[t]{4}{*}{ JPM } & (i) Base case & 14.75 & 14.75 & & & 0.68 & 0.68 & 0.28 & 0.28 & 0.20 & 0.20 & 0.38 & 0.38 & & & 0.72 & 0.72 \\
\hline & (ii) $\alpha_{T}=0$ & 14.78 & 14.75 & 0.22 & 0.00 & 0.79 & 0.68 & 0.28 & 0.28 & 0.19 & 0.20 & 0.38 & 0.38 & 0.00 & 0.00 & 0.69 & 0.72 \\
\hline & (iii) $\rho_{B T}=0$ & 14.75 & 14.75 & 0.00 & 0.00 & 0.68 & 0.68 & 0.28 & 0.28 & 0.20 & 0.20 & 0.38 & 0.38 & 0.00 & 0.00 & 0.72 & 0.72 \\
\hline & (iv) $\alpha_{T}, \rho_{B T}=0$ & 14.75 & 14.75 & 0.00 & 0.00 & 0.68 & 0.68 & 0.28 & 0.28 & 0.20 & 0.20 & 0.38 & 0.38 & 0.00 & 0.00 & 0.72 & 0.72 \\
\hline \multirow[t]{4}{*}{ MTB } & (i) Base case & 17.32 & 17.32 & & & 8.83 & 8.83 & 0.39 & 0.39 & 0.18 & 0.18 & 0.38 & 0.38 & & & 0.49 & 0.49 \\
\hline & (ii) $\alpha_{T}=0$ & 16.70 & 16.70 & -3.56 & -3.56 & 9.04 & 9.04 & 0.38 & 0.38 & 0.17 & 0.17 & 0.39 & 0.39 & 0.01 & 0.01 & 0.48 & 0.48 \\
\hline & (iii) $\rho_{B T}=0$ & 17.46 & 17.46 & 0.82 & 0.82 & 8.24 & 8.24 & 0.39 & 0.39 & 0.17 & 0.17 & 0.38 & 0.38 & 0.00 & 0.00 & 0.47 & 0.47 \\
\hline & (iv) $\alpha_{T}, \rho_{B T}=0$ & 16.70 & 16.70 & -3.56 & -3.56 & 9.04 & 9.04 & 0.38 & 0.38 & 0.17 & 0.17 & 0.39 & 0.39 & 0.01 & 0.01 & 0.48 & 0.48 \\
\hline \multirow[t]{4}{*}{ STT } & (i) Base case & 103.24 & 103.59 & & & 0.51 & 0.47 & 2.00 & 2.00 & 1.11 & 1.05 & 0.38 & 0.38 & & & 3.56 & 3.21 \\
\hline & (ii) $\alpha_{T}=0$ & 19.61 & 19.61 & -81.01 & -81.07 & 14.49 & 14.49 & 0.38 & 0.38 & 0.94 & 0.94 & 2.00 & 2.00 & 1.62 & 1.62 & 6.06 & 6.06 \\
\hline & (iii) $\rho_{B T}=0$ & 103.59 & 103.59 & 0.34 & 0.00 & 0.47 & 0.47 & 2.00 & 2.00 & 1.05 & 1.05 & 0.37 & 0.38 & -0.01 & 0.00 & 3.21 & 3.21 \\
\hline & (iv) $\alpha_{T}, \rho_{B T}=0$ & 19.61 & 19.61 & -81.01 & -81.07 & 14.49 & 14.49 & 0.38 & 0.38 & 0.94 & 0.94 & 2.00 & 2.00 & 1.62 & 1.62 & 6.06 & 6.06 \\
\hline \multirow[t]{4}{*}{ STI } & (i) Base case & 17.63 & 17.63 & & & 2.13 & 2.13 & 0.37 & 0.37 & 0.35 & 0.35 & 0.38 & 0.38 & & & 1.54 & 1.54 \\
\hline & $(i i) \alpha_{T}=0$ & 17.63 & 17.63 & 0.00 & 0.00 & 2.13 & 2.13 & 0.37 & 0.37 & 0.35 & 0.35 & 0.38 & 0.38 & 0.00 & 0.00 & 1.54 & 1.54 \\
\hline & (iii) $\rho_{B T}=0$ & 17.63 & 17.63 & 0.00 & 0.00 & 2.13 & 2.13 & 0.37 & 0.37 & 0.35 & 0.35 & 0.38 & 0.38 & 0.00 & 0.00 & 1.54 & 1.54 \\
\hline & (iv) $\alpha_{T}, \rho_{B T}=0$ & 17.63 & 17.63 & 0.00 & 0.00 & 2.13 & 2.13 & 0.37 & 0.37 & 0.35 & 0.35 & 0.38 & 0.38 & 0.00 & 0.00 & 1.54 & 1.54 \\
\hline \multirow[t]{4}{*}{ TMP } & (i) Base case & 22.36 & 22.36 & & & 0.14 & 0.14 & 0.37 & 0.37 & 0.13 & 0.13 & 0.38 & 0.38 & & & 0.32 & 0.32 \\
\hline & (ii) $\alpha_{T}=0$ & 22.36 & 22.36 & 0.03 & 0.00 & 0.14 & 0.14 & 0.37 & 0.37 & 0.13 & 0.13 & 0.38 & 0.38 & 0.00 & 0.00 & 0.31 & 0.32 \\
\hline & (iii) $\rho_{B T}=0$ & 22.36 & 22.36 & 0.00 & 0.00 & 0.14 & 0.14 & 0.37 & 0.37 & 0.13 & 0.13 & 0.38 & 0.38 & 0.00 & 0.00 & 0.32 & 0.32 \\
\hline & (iv) $\alpha_{T}, \rho_{B T}=0$ & 22.36 & 22.36 & 0.00 & 0.00 & 0.14 & 0.14 & 0.37 & 0.37 & 0.13 & 0.13 & 0.38 & 0.38 & 0.00 & 0.00 & 0.32 & 0.32 \\
\hline \multirow[t]{4}{*}{ WFC } & (i) Base case & 18.58 & 18.43 & & & 1.43 & 1.09 & 0.38 & 0.37 & 0.35 & 0.30 & 0.38 & 0.38 & & & 1.53 & 1.24 \\
\hline & (ii) $\alpha_{T}=0$ & 18.43 & 18.43 & -0.81 & 0.00 & 1.09 & 1.09 & 0.37 & 0.37 & 0.30 & 0.30 & 0.38 & 0.38 & 0.00 & 0.00 & 1.24 & 1.24 \\
\hline & (iii) $\rho_{B T}=0$ & 18.86 & 18.43 & 1.46 & 0.00 & 1.18 & 1.09 & 0.38 & 0.37 & 0.31 & 0.30 & 0.37 & 0.38 & -0.01 & 0.00 & 1.26 & 1.24 \\
\hline & (iv) $\alpha_{T}, \rho_{B T}=0$ & 18.43 & 18.43 & -0.81 & 0.00 & 1.09 & 1.09 & 0.37 & 0.37 & 0.30 & 0.30 & 0.38 & 0.38 & 0.00 & 0.00 & 1.24 & 1.24 \\
\hline \multirow[t]{4}{*}{ WTFC } & (i) Base case & 39.75 & 20.24 & & & 0.06 & 0.15 & 0.77 & 0.38 & 0.15 & 0.15 & 0.38 & 0.38 & & & 0.23 & 0.37 \\
\hline & (ii) $\alpha_{T}=0$ & 20.27 & 20.24 & -49.01 & 0.00 & 0.17 & 0.15 & 0.38 & 0.38 & 0.14 & 0.15 & 0.77 & 0.38 & 0.39 & 0.00 & 0.35 & 0.37 \\
\hline & (iii) $\rho_{B T}=0$ & 39.68 & 20.24 & -0.17 & 0.00 & 0.07 & 0.15 & 0.77 & 0.38 & 0.17 & 0.15 & 0.38 & 0.38 & 0.00 & 0.00 & 0.30 & 0.37 \\
\hline & (iv) $\alpha_{T}, \rho_{B T}=0$ & 20.24 & 20.24 & -49.07 & 0.00 & 0.15 & 0.15 & 0.38 & 0.38 & 0.15 & 0.15 & 0.77 & 0.38 & 0.39 & 0.00 & 0.37 & 0.37 \\
\hline
\end{tabular}




\subsubsection{Buffer Capital}

In this subsection, we illustrate how our model explains cross-sectional variation in the banks' buffer capital ratios (equity capital ratios above the minimum capital level) before the Volcker rule. Figure 2.1 represents the actual capital buffer ratio against the model predicted capital level taken to be the dividend barrier $u$ in Table 2.1. This plot uses banks' mean capital buffer ratios over 2000 Q1 - 2011 Q4 as the measure of the actual buffer ratios.

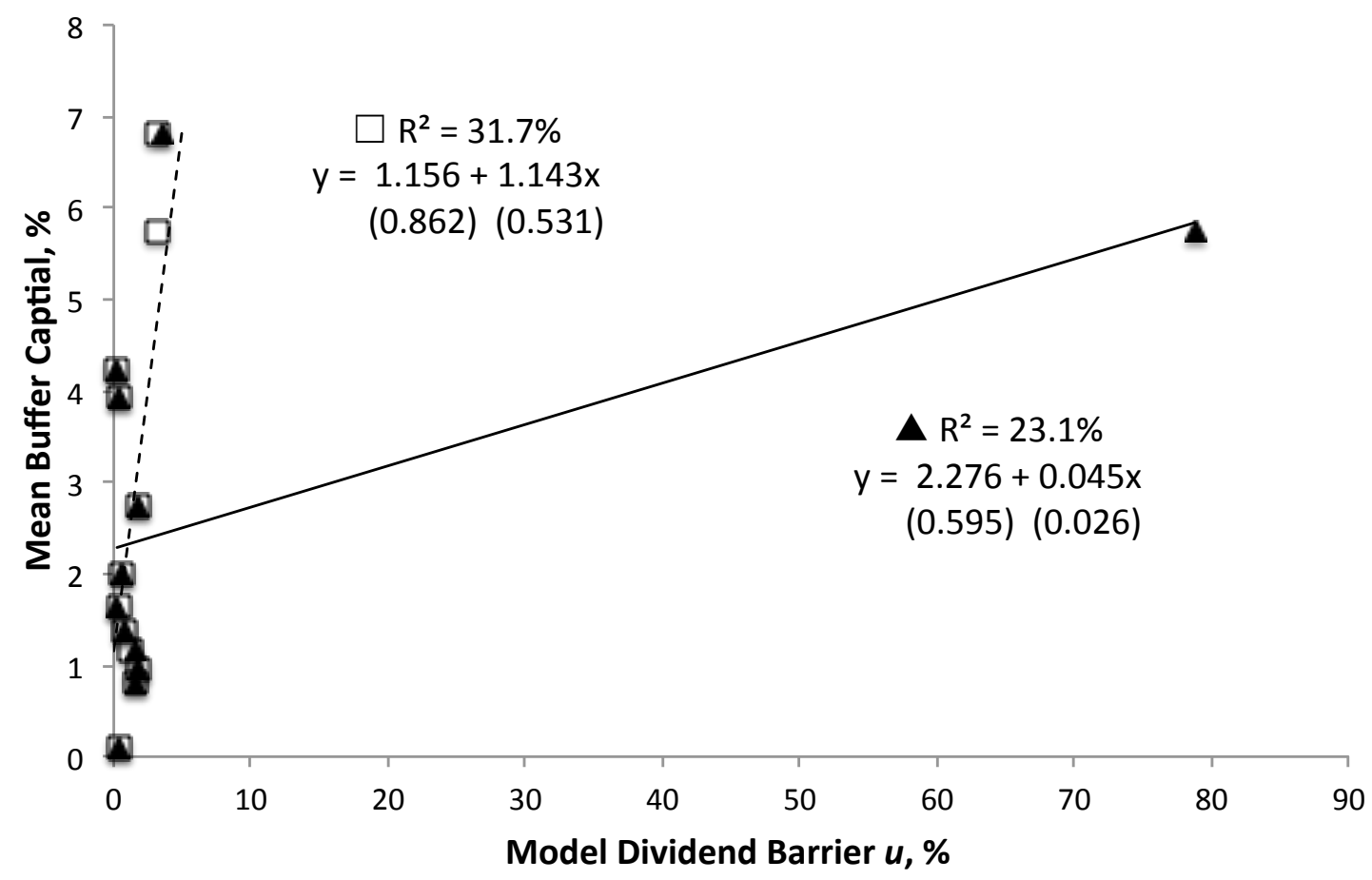

Figure 2.1: Actual vs. model buffer capital ratios for the sample banks. This figure shows mean buffer capital ratios (during 2000 Q1 - 2011 Q4) plotted against the corresponding model dividend barriers. The filled triangles are with the trading alphas and correlations equal to their estimated values while the empty squares are with the statistically significant trading alphas and correlations (the non-significant trading alphas and correlations are zero). Linear regression lines are drawn in the figure. The numbers in the parentheses are the standard deviations of the parameters. Without the outlier (ABVA), the regression line for the estimated parameters is $y=1.344+0.86 x$ and $R^{2}$ is $20 \%$. Thus, then the regression line is close to the regression line of the significant parameters. 


\subsubsection{Comparative Statics}

Figure 2.2: Comparative Statics. We use the following median parameter values over all the banks: $\zeta=95 \%, r=2 \%, \delta=2 \%, \sigma_{B}=0.3 \%, \sigma_{T}=4 \%, \rho_{B T}=-0.1, \alpha_{B}=0.4 \%, \alpha_{T}=0.4 \%$, $\delta=2 \%$, and $x=0.5 \%$. Figures below show how the value function $(2.7 d)$ and dividend barrier $u$ change with respect to banking proportion $\zeta$, banking volatility $\sigma_{B}$, trading volatility $\sigma_{T}$, correlation between the banking and trading earnings $\rho_{B T}$, banking alpha $\alpha_{B}$, trading alpha $\alpha_{T}$, risk-free rate $r$, and wedge between debt and equity finance $\delta$.

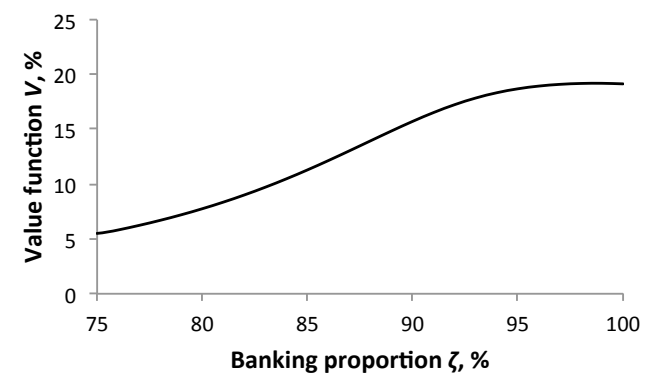

(2.3.1) Value function vs. banking proportion

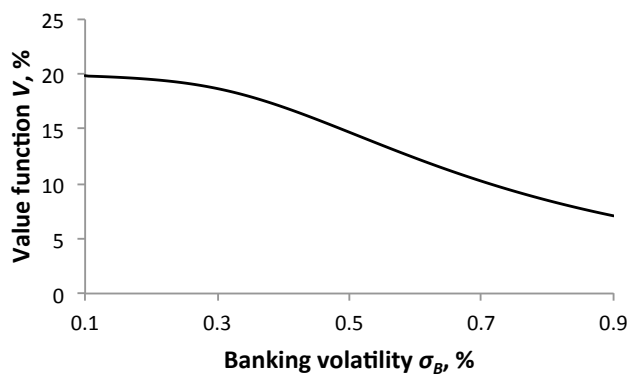

(2.3.3) Value function vs. banking volatility

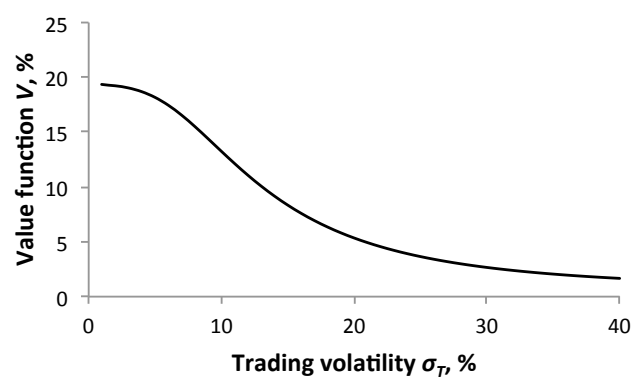

(2.3.5) Value function vs. trading volatility

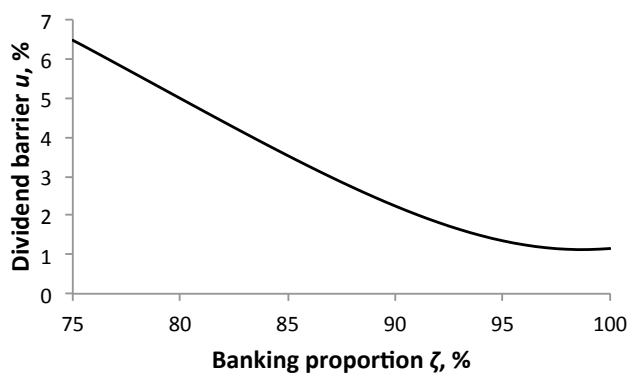

(2.3.2) Dividend barrier vs. banking proportion

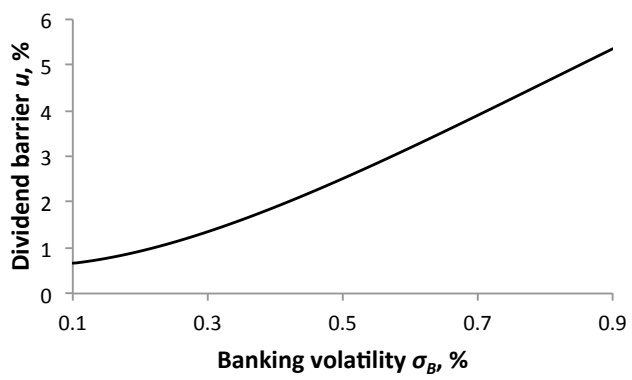

(2.3.4) Dividend barrier vs. banking volatility

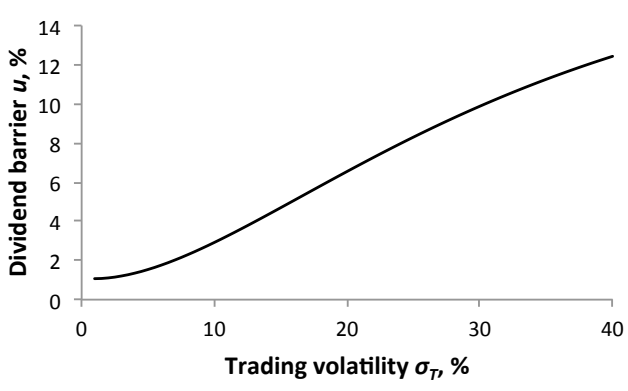

(2.3.6) Dividend barrier vs. trading volatility 


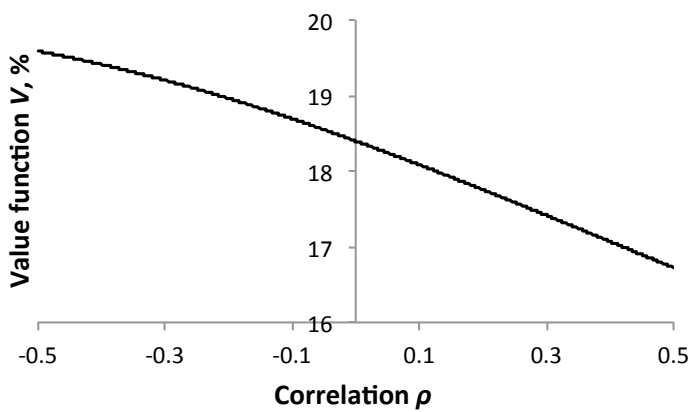

(2.3.7) Value function vs. correlation

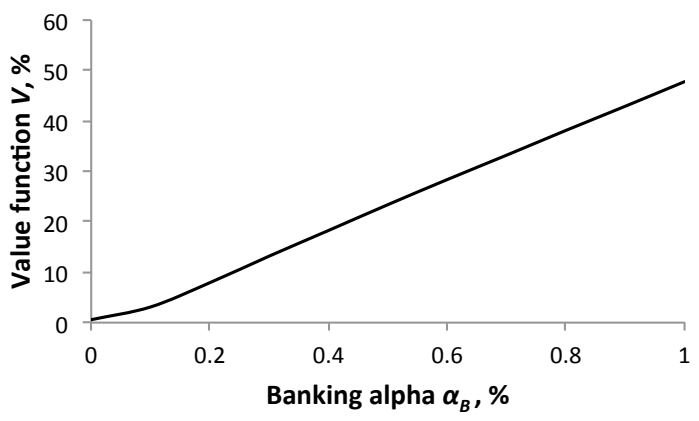

(2.3.9) Value function vs. banking alpha

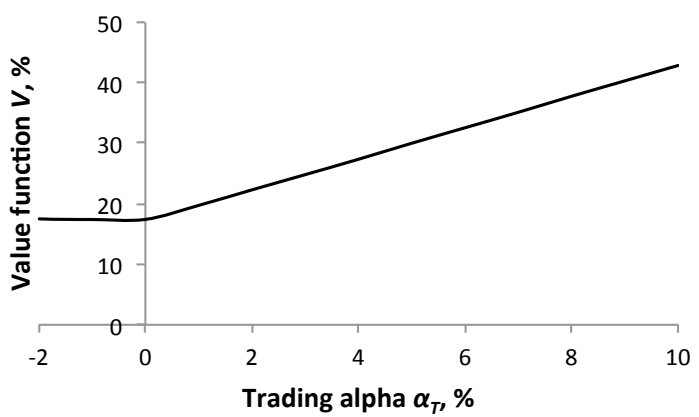

(2.3.11) Value function vs. trading alpha

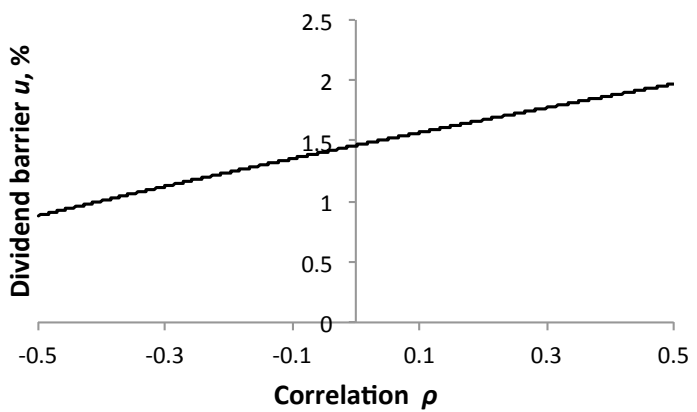

(2.3.8) Dividend barrier vs. correlation

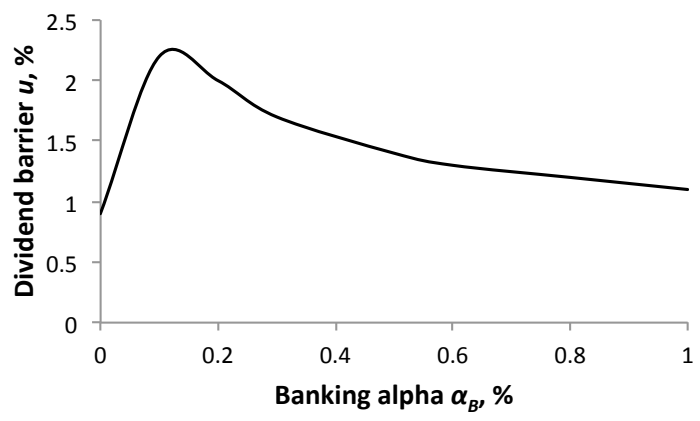

(2.3.10) Dividend barrier vs. banking alpha

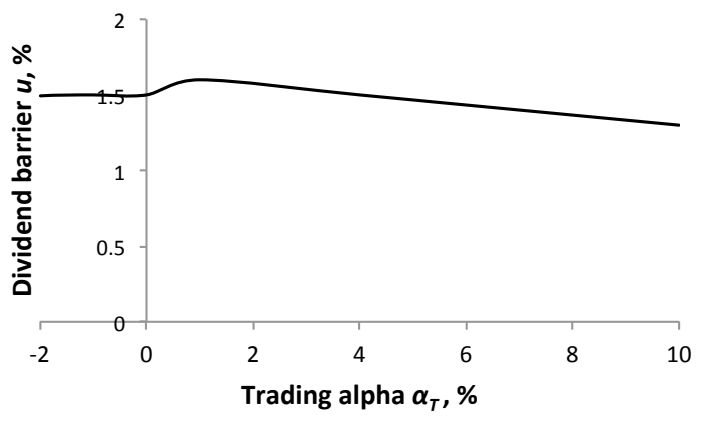

(2.3.12) Dividend barrier vs. trading alpha 


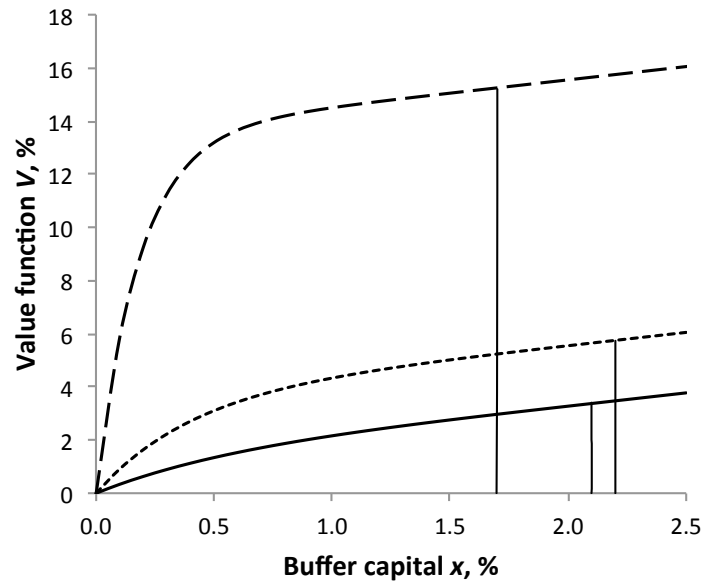

(2.3.13) Value function and dividend barrier vs. buffer capital under three banking alphas: $0.05 \%$ (lowest), $0.1 \%$ (middle), and $0.3 \%$ (highest). The dotted vertical lines are dividend barriers. This explains (j).

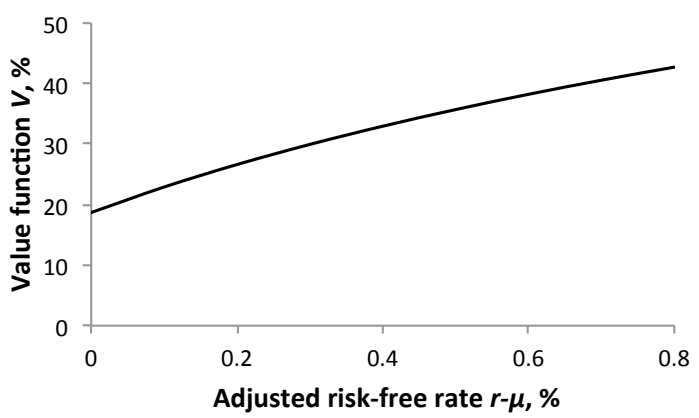

(2.3.15) Value function vs. adjusted risk-free rate

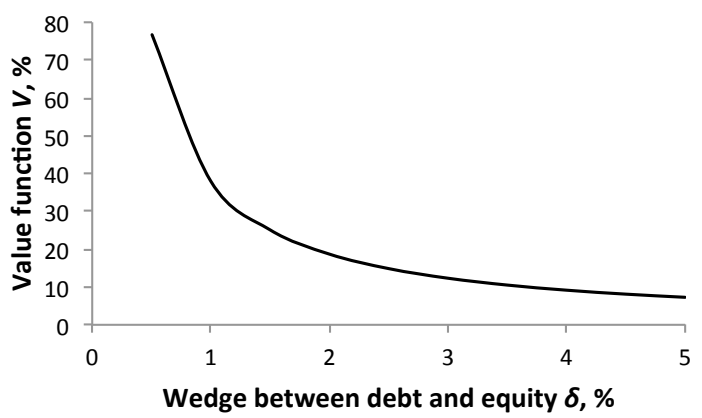

(2.3.17) Value function vs. wedge between debt and equity

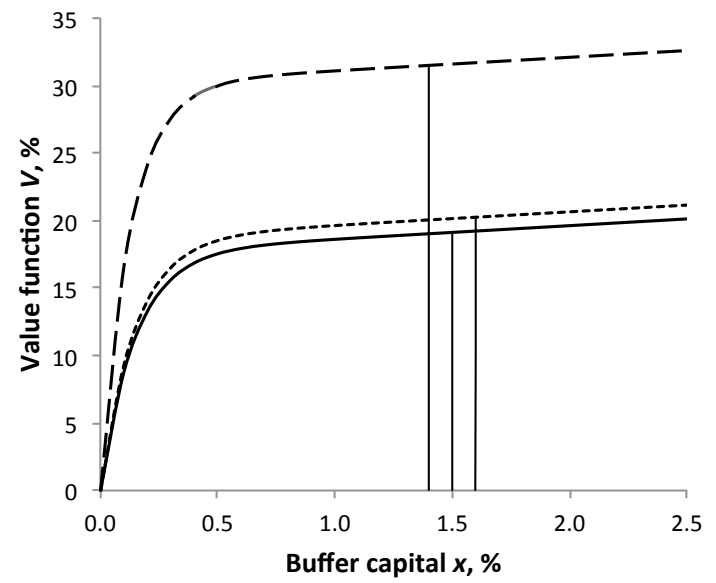

(2.3.14) Value function and dividend barrier vs. buffer capital under three trading alphas: $0.05 \%$ (lowest), $0.5 \%$ (middle), and 5\% (highest). The dotted vertical lines are dividend barriers. This figure explains (1).

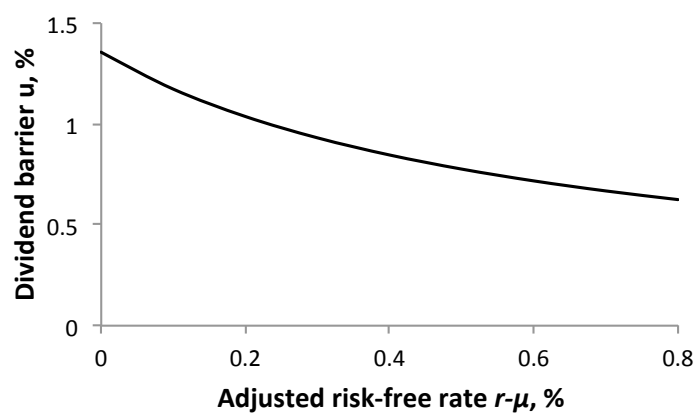

(2.3.16) Dividend barrier vs. adjusted risk-free rate

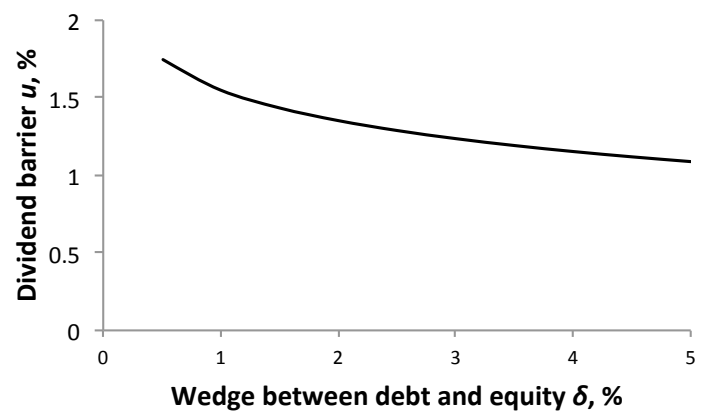

(2.3.18) Dividend barrier vs. wedge between debt and equity 


\subsubsection{Default Probability}

Figure 2.3: Default probability changes with varying model parameters for Bank FHN. We analyze two banks (FHN and MTB) and how their default probability changes with respect to model parameters. We consider two cases: Case $(i)$ is without the Volcker rule and case $(i i)$ is under the Volcker rule (no alpha bets). The first bank is FHN and we use its estimated parameters in Table 2.1. Figures below show how the default probability changes with respect to banking proportion $\zeta$, risk-free rate $r$, correlation between the banking and trading earnings $\rho_{B T}$, wedge between debt and equity finance $\delta$, banking volatility $\sigma_{B}$, trading volatility $\sigma_{T}$, banking alpha $\alpha_{B}$, and trading alpha $\alpha_{T}$.

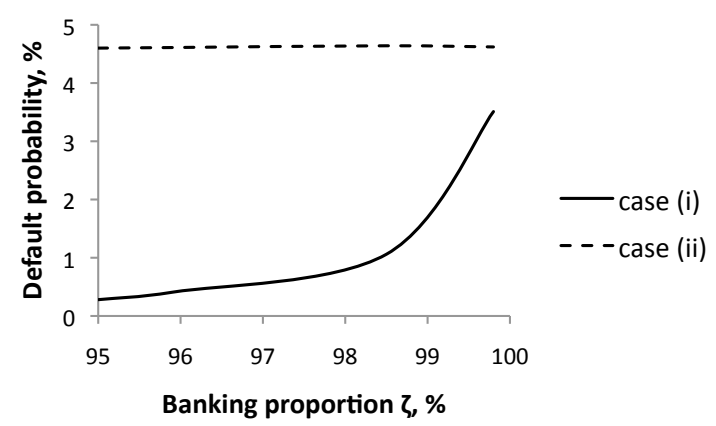

(2.4.1) Default probability vs. banking proportion

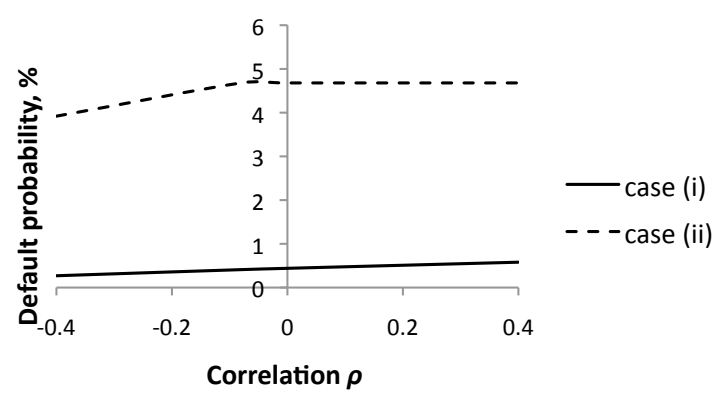

(2.4.3) Default probability vs. correlation

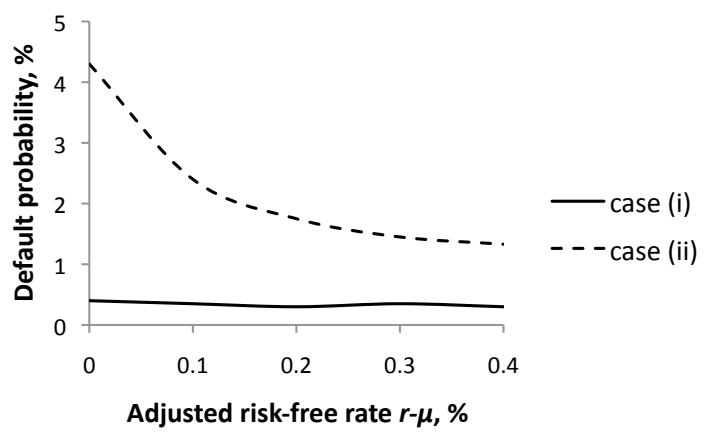

(2.4.2) Default probability vs. adjusted risk-free rate

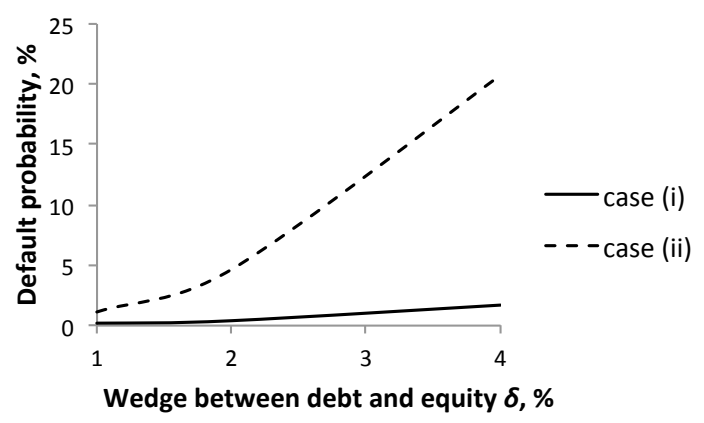

(2.4.4) Default probability vs. wedge between debt and equity 


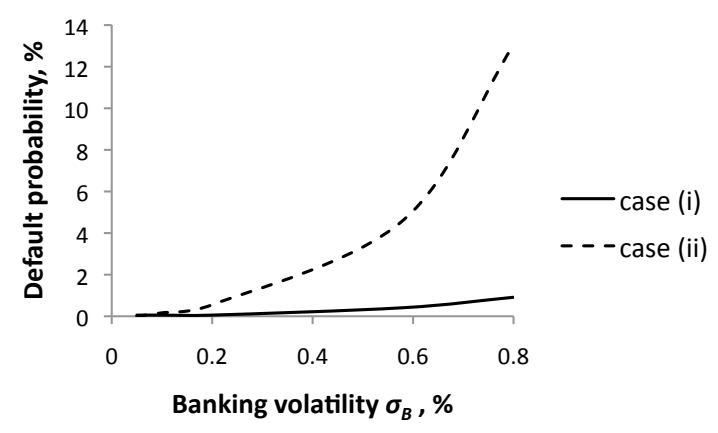

(2.4.5) Default probability vs. banking volatility

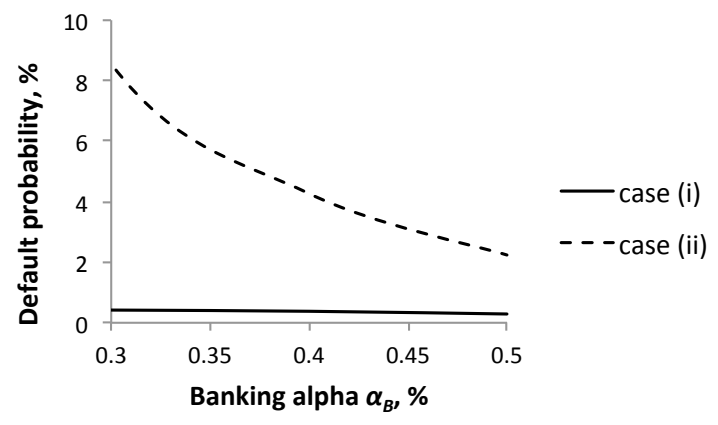

(2.4.7) Default probability vs. banking alpha

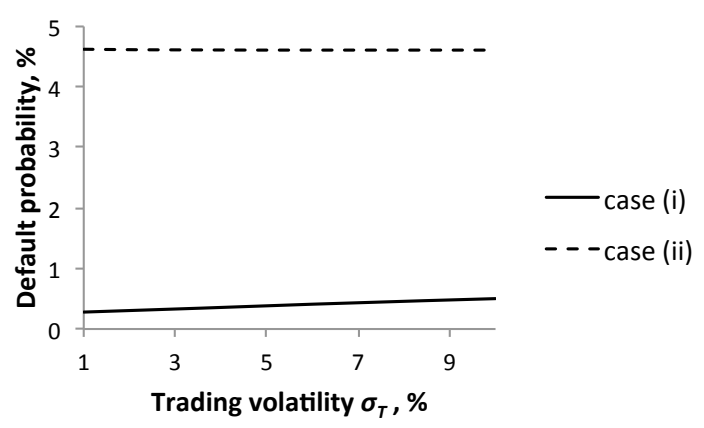

(2.4.6) Default probability vs. trading volatility

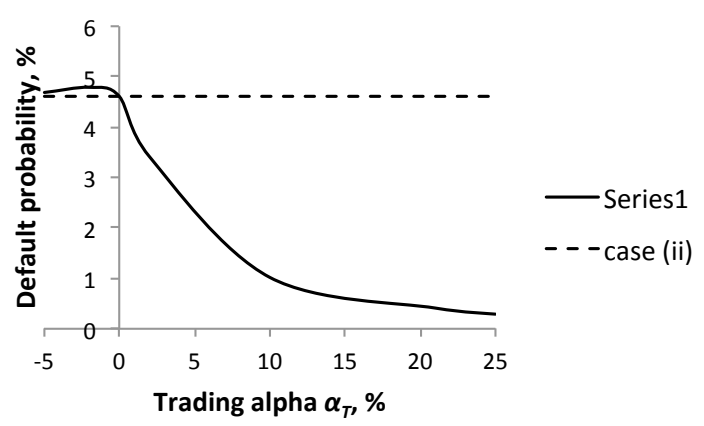

(2.4.8) Default probability vs. trading alpha

Figure 2.4: Default probability changes with varying model parameters for Bank MTB. The second bank is MTB and we use its estimated parameters in Table 2.1. Figures below show how the default probability changes with respect to banking proportion $\zeta$, risk-free rate $r$, correlation between the banking and trading earnings $\rho_{B T}$, wedge between debt and equity finance $\delta$, banking volatility $\sigma_{B}$, trading volatility $\sigma_{T}$, banking alpha $\alpha_{B}$, and trading alpha $\alpha_{T}$.

(2.4.1) Default probability vs. banking proportion

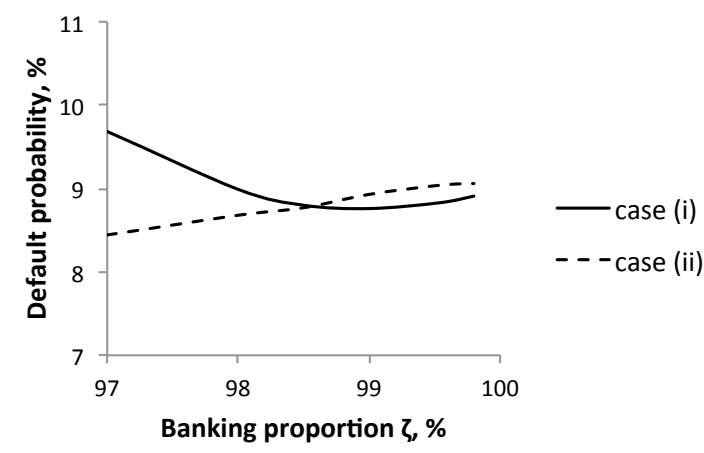

(2.4.2) Default probability vs. adjusted risk-free rate

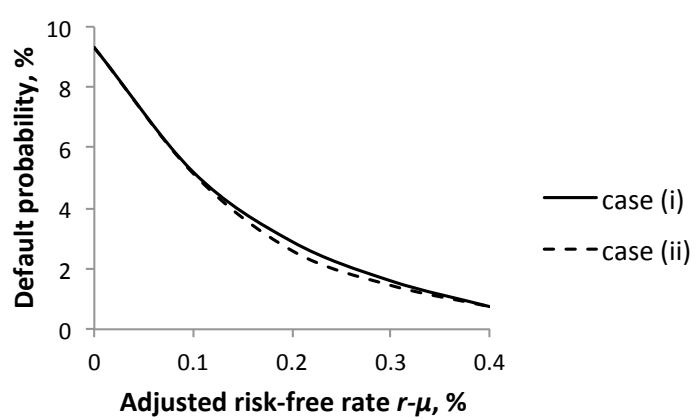




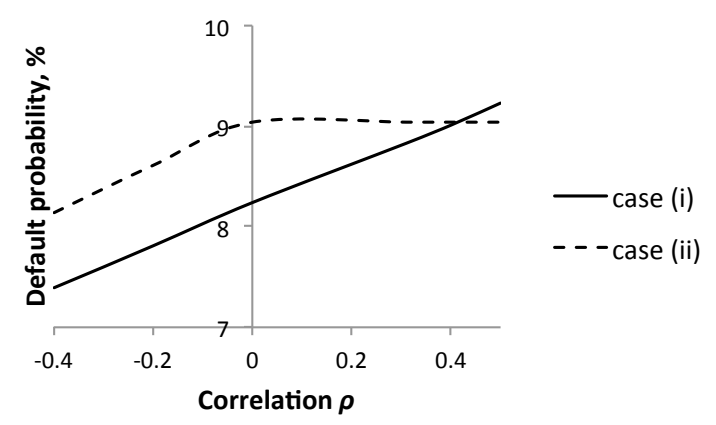

(2.5.3) Default probability vs. correlation

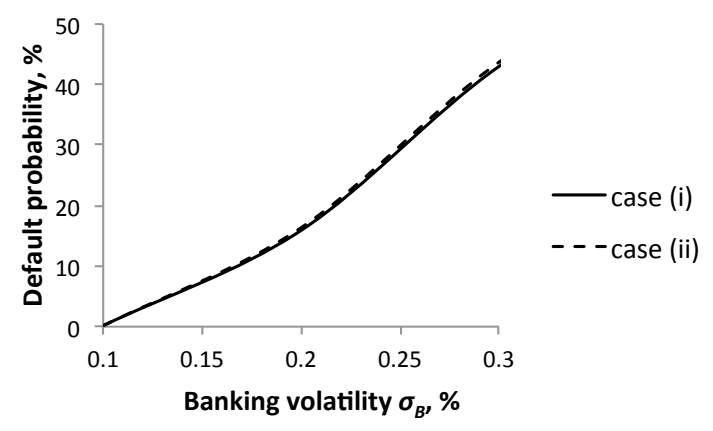

(2.5.5) Default probability vs. banking volatility

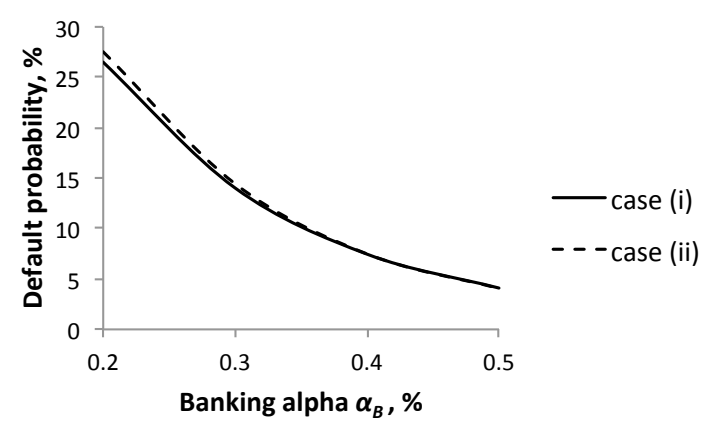

(2.5.7) Default probability vs. banking alpha

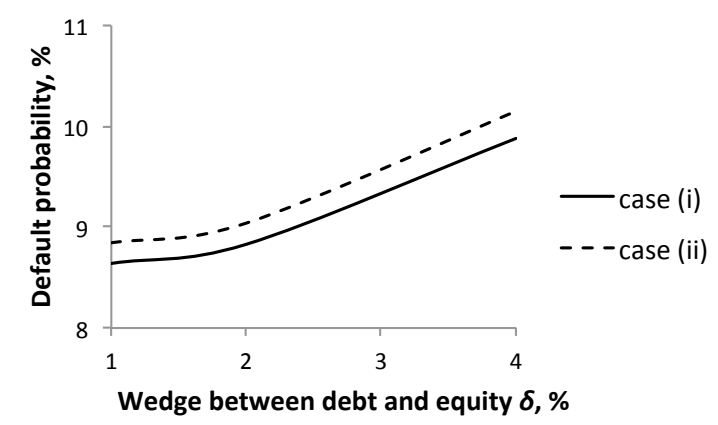

(2.5.4) Default probability vs. wedge between debt and equity

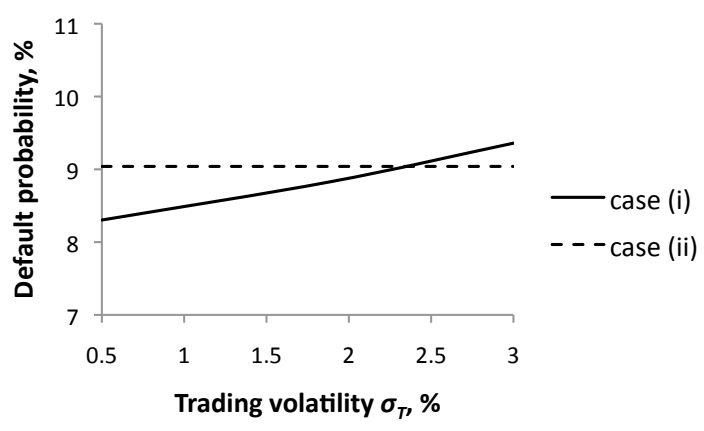

(2.5.6) Default probability vs. trading volatility

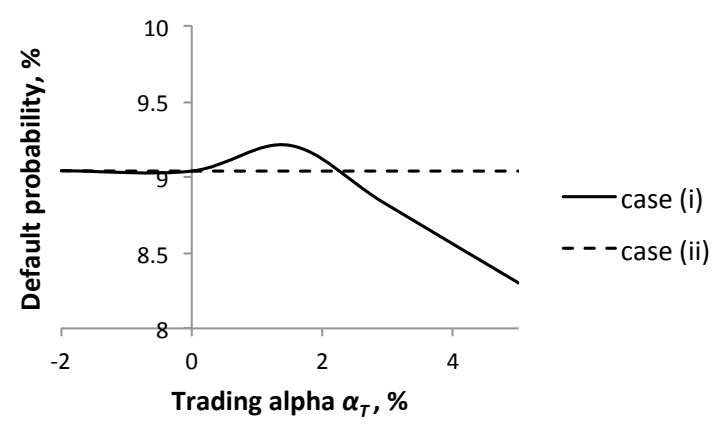

(2.5.8) Default probability vs. trading alpha 


\section{CHAPTER III}

\section{A Stochastic Control Model with Recapitalization}

\subsection{Model}

We introduce a new model which considers a bank's recapitalization process ${ }^{26}$ Similar to our model presented in Chapter II], the new model is based on Milne and Robertson (1996) and Keppo et al. (2010). The main differences between the two models are as follows:

- Assets dynamics:

- In Chapter 3.1, we model total assets instead of risk-weighted asset: 27 as in Chapter 2.1. This has some advantages and disadvantages. One of the advantages is that we have reliable quarterly data for total assets from the Compustat database while the data of risk-weighted assets are not available in the same database. In addition, the method of applying different weights to different types of assets in computing risk-weighted assets is unclear and complicated to model. One disadvantage against using total assets may be that it is not as informative as the risk-weighted assets.

- Although the assumption in Chapter 2.1 that the risk-weighted assets grows

\footnotetext{
${ }^{26} \mathrm{~A}$ bank has a motivation to buy back their shares when their prices decline considerably below their own estimation in the market to increase the bank's per-share earnings. Buybacks are under regulation by the Federal Reserve since they can lower their buffer capital (see e.g. Wall Street Journal "Fed Wary of Bank Stock Buybacks.") ${ }^{27}$ See footnote 5
} 
at risk-free rate has an advantage of making the model simple to implement numerically ${ }^{28}$, it lacks evidence supported by banks' data. It is well-known that assets equals shareholders' equity plus debt. If we assume that assets grows at a fixed rate while equity evolves stochastically, then we inevitably and unwillingly make the assumption that this debt evolves stochastically. Therefore, it is realistic to model assets as a stochastic variable of which movement is correlated with that of the equity. Thus, we model assets by a geometric brownian motion that has a correlation with the dynamics of the shareholders' equity in Chapter 3.1 .

- A bank's sources of earnings:

- In Chapter 2, a bank may collect earnings from net comprehensive income i.e. earnings from banking and trading business as well as from interests income on bank capital re-invested at a risk-free rate. However, we removed the assumption that a bank earns interests on the bank capital as in Chapter 3.1, and we assume that the net income earnings are strictly divided into earnings from bank's investments in banking assets and earnings from trading.

- In Chapter 3.1, we incorporate a bank's recapitalization (issuing and buying a bank's own stock) into our model while we did not in Chapter 2.1. Therefore, in the new model, a bank may have earnings not only from net comprehensive income but also from recapitalization. This can be justified by Table 3.2 as the estimates of net comprehensive recapitalization return are positive for most banks. We assume that earnings through recapitaliza-

\footnotetext{
${ }^{28}$ This assumption enables us to obtain the ODE for the value function outside dividends in $2.11 \mathrm{~b}$ of which coefficients do not depend on $x$, which makes solutions easily attainable.
} 
tion is proportion to the size of the bank i.e. total assets.

Besides these differences, our model in Chapter 2.1 takes a similar approach with the previous model to solve the same optimization problem for banks.

\subsubsection{A Model of Bank Capital}

The bank operates up to liquidation. The liquidation time is defined as the first time when equity hits minimum capital level:

$$
\tau=\inf \{t \mid \bar{X}(t) \leq 0\}
$$

where $\tau$ is the liquidation time and $\bar{X}(t)$ is the accounting shareholders' equity above the minimum level $K \cdot A(t), K$ is a fixed ratio, e.g., the minimum capital requirement of Basel regulation (see e.g. Peura and Keppo 2006). We use a minimum capital level in our model calibration and set $K$ equal to the minimum equity capital ratio in our dataset.

We assume that earnings from the banking book and the trading book are proportional to bank assets $A(t)$. Banking book equals a fixed proportion of the assets and the rest of the assets are in the trading book. Thus, the bank dedicates a certain fixed proportion of its assets to the basic banking business. We also assume that the bank's interest payments on its debt are deducted from the banking book. The trading book consists of a liquid risky asset investment and a risk-free investment. The bank trades the assets in the trading book continuously without any frictions. More specifically, the cumulative earnings processes under the risk-neutral probability measure (see e.g. Bjork 2009) are given by 


$$
\begin{aligned}
d E_{B}(t)= & {\left[A(t) \zeta\left(r+\alpha_{B}\right) d t+A(t) \zeta \sigma_{B} d W_{B}(t)\right]-r[A(t)-(\bar{X}(t)+K A(t))] d t } \\
= & A(t)\left[\zeta\left(r+\alpha_{B}\right)-r(1-K)\right] d t+r \bar{X}(t) d t+A(t) \zeta \sigma_{B} d W_{B}(t) \\
d E_{T}(t)= & A(t)(1-\zeta) \theta(t)\left(r+\alpha_{T}\right) d t+A(t)(1-\zeta) \theta(t) \sigma_{T} d W_{T}(t) \\
& +A(t)(1-\zeta)(1-\theta(t)) r d t \\
= & A(t)(1-\zeta)\left[r+\theta(t) \alpha_{T}\right] d t+A(t)(1-\zeta) \theta(t) \sigma_{T} d W_{T}(t)
\end{aligned}
$$

where $E_{B}(t)$ and $E_{T}(t)$ are the banking and trading book cumulative earnings at time $t, A(t)$ is the bank's assets at time $t, r$ is the risk-free rate, $\zeta$ is the constant proportion of $A(t)$ in the banking book and $\zeta \in\left[\zeta_{l}, 1\right], \zeta_{l}>0$ is the minimum size of the banking book (so that the firm is still considered as a bank), $\theta(t)$ is the proportion of the trading book invested in the liquid risky asset and $\theta(t) \in[0,1]$ for all $t \geq 0$, $\alpha_{B}$ and $\alpha_{T}$ are banking book and trading book alphas, $\sigma_{B}$ and $\sigma_{T}$ are banking book and trading book volatilities and $\sigma_{B}, \sigma_{T}>0, W_{B}(t)$ and $W_{T}(t)$ are Wiener processes under the risk-neutral probability measure corresponding to $E_{B}$ and $E_{T}$ and their correlation is $\rho_{B T}$.

Net banking income equals net banking earnings before interest payments on debt minus the interest payments. The net banking earnings before the interest payments are represented by the first two terms in $(3.2)$, and the interests payments are represented by the last term. Thus, we assume that the bank pays risk-free rate for its debt 29 and its banking business can earn excess return $\alpha_{B}$. The parameter $\alpha_{B}$ corresponds to high loan margins and returns on the bank's loan portfolio. Note that $\alpha_{T}$ in 3.3 implies that the banks might be able to generate trading alpha. This

\footnotetext{
${ }^{29}$ By Compustat data, our sample banks' (introduced in Section 3) pay about risk-free interest rate on their debt: The interest rate on their debt and 3-month treasury bill rate have a correlation of 0.9 between 2000 and 2011 . Further, the average interest rate in that period is about $2 \%$ which is about the 3 -month treasury bill rate over the same time period.
} 
excess return could be, for instance, from market making or it just reflects the bank shareholders' expectation for the future returns.

We define a Wiener process $W_{E}(t)$ under the risk-neutral probability measure and volatility $\sigma_{\theta(t)}$ corresponding to the total earnings of the bank as follows

$$
\sigma_{\theta(t)} d W_{E}(t)=\zeta \sigma_{B} d W_{B}(t)+(1-\zeta) \theta(t) \sigma_{T} d W_{T}(t)
$$

where

$$
\sigma_{\theta(t)}=\sqrt{\zeta^{2} \sigma_{B}^{2}+2 \zeta \sigma_{B} \rho_{B T}(1-\zeta) \theta(t) \sigma_{T}+(1-\zeta)^{2} \theta(t)^{2} \sigma_{T}^{2}}
$$

and $\sigma_{\theta(t)}$ represents the volatility of the bank's earnings. As we can see, the earnings volatility depends on the asset quality: The more is invested in trading, the higher the earnings volatility (typically, $\sigma_{T}>\sigma_{B}$ ). We assume the bank is able to control $\theta(t)$ in continuous time. It can also choose $\zeta$, but this parameter is constant. We do not specify the trading and banking activities that create the alphas (excess returns $\alpha_{B}$ and $\alpha_{T}$. In our model they are just alphas of the trading and banking books, and in the model calibration we estimate the parameters from accounting and market data.

By 3.2 - 3.4, the earnings of the bank follow

$d E(t)=d E_{B}(t)+d E_{T}(t)=A(t)\left[\mu_{\theta}-r(1-K)+r \frac{\bar{X}(t)}{A(t)}\right] d t+A(t) \sigma_{\theta(t)} d W_{E}(t)$

where

$$
\mu_{\theta(t)}=r+\zeta \alpha_{B}+(1-\zeta) \theta(t) \alpha_{T}
$$

Drift term $\mu_{\theta(t)}$ represents proportional net income before interest payments on the bank's debt. Thus, the earnings depend on the asset size, the earnings parameters, and the bank's trading. The earnings are added to $\bar{X}(t)$, i.e., to the bank's equity capital above the minimum level. 
We assume that the bank's total assets follow a geometric Brownian motion given by

$$
A(t)=A(0) e^{\left(\mu_{A}-\frac{1}{2} \sigma_{A}^{2}\right) t+\sigma_{A} W_{A}(t)}
$$

for some initial positive amount $A(0)$, where $\mu_{A}$ is the constant percentage drift, $\sigma_{A}$ is the constant percentage volatility and $\sigma_{A}>0, W_{A}(t)$ is a standard Wiener process under the risk-neutral probability measure, and the correlation between $W_{A}(t)$ and $W_{E}(t)$ is $\rho_{A E}$.

The bank's capital also changes due to equity issuances and stock buybacks. For this we define net recapitalization as equity issuance minus stock buybacks. We assume that the cumulative net recapitalization follows

$$
d R(t)=A(t)\left[\mu_{R} d t+\sigma_{R} d W_{R}(t)\right]
$$

where $\sigma_{R}>0$ and $W_{R}(t)$ is a Wiener process under $\mathbb{Q}$ and it has correlations: $d W_{R}(t) d W_{A}(t)=\rho_{R A} d t$ and $d W_{R}(t) d W_{E}(t)=\rho_{R E} d t$. Thus, asset dynamics and net recapitalization processes are correlated (parameter $\rho_{R A}$ ) because changes in equity due to the net recapitalization also changes the asset size. Parameter $\rho_{R E}$ is due to the fact that earnings process might tricker recapitalization and stock repurchases. As expected, in our data (see Table 3.2) we have $\rho_{R A}>0$ and $\rho_{R E}<0$ (both of them are significant at $5 \%$ level), i.e., when there is recapitalization then the asset size rises and when earnings are low, banks sell equity. Equation 3.8 differs from the model in Keppo et al. (2010) who do not consider stock buybacks but only equity issuances when bank capital level is low. Since the correlation between recapitalization and equity level is insignificant, we do not use the model in Keppo et al. (2010) in the present paper. Naturally, the net recapitalization depends on many factors such as taxes, equity level, earnings, bond market prices, and market liquidity, and we do 
not model here. Instead we use directly (3.8) and fit the net recapitalization process to our data.

In addition to banking book size and trading risk, the bank controls its bank capital through dividend payments that can be implemented instantaneously without any costs. Formally, a capital control policy $\bar{\pi}$ is a collection $\left(\zeta^{\bar{\pi}},\left\{\theta^{\bar{\pi}}(t), L^{\bar{\pi}}(t)\right\}\right)$, where $\zeta^{\bar{\pi}}$ is the proportion of total assets in the banking book under policy $\bar{\pi}, \theta^{\bar{\pi}}(t)$ is the proportion of trading book in the risky liquid asset at time $t$, and $L^{\bar{\pi}}(t)$ is the cumulative amount of dividends at time $t$. We denote by $\Pi$ the class of admissible policies and they satisfy:

(i) $\zeta^{\bar{\pi}} \in\left[\zeta_{l}, 1\right]$, where $\zeta_{l}>0$, and $\zeta^{\bar{\pi}}$ is constant during the lifetime of the bank

(ii) $\theta^{\bar{\pi}}(t) \in[0,1]$ for all $t \geq 0$ and it is adapted to $F_{t}$, where filtration $\left\{F_{t}\right\}$ is generated by the Wiener processes $W_{A}(t), W_{E}(t)$, and $W_{R}(t)$.

(iii) $L_{t}^{\bar{\pi}}$ is a non-decreasing right-continuous process adapted to $F_{t}$ and $L_{0-}^{\bar{\pi}}=0$.

Condition $(i)$ indicates that the bank cannot change the proportion of the assets in the banking book after it has selected that. Thus, the banking business is a longterm investment with long-term commitments. By $(i i)$, short selling is not allowed and the bank cannot invest more than its trading book in the risky asset. Condition (iii) says that dividends cannot be negative.

Bank capital as a function of policy $\bar{\pi}$ is denoted by $\bar{X}^{\bar{\pi}}(t)$ and, by 3.5 and 3.8 , it satisfies:

$$
\begin{aligned}
\bar{X}^{\bar{\pi}}(t)= & \bar{X}(0)-K(A(t)-A(0))+\int_{0}^{t} d E^{\bar{\pi}}(u)+\int_{0}^{t} d R(u)-L^{\bar{\pi}}(t) \\
= & \bar{X}(0)-K(A(t)-A(0))+\int_{0}^{t} A(u)\left[\mu_{\theta(t)}-r(1-K)+r \frac{\bar{X}(t)}{A(t)}\right] d u \\
& +A(u) \sigma_{\theta(u)} d W_{E}(u)+\int_{0}^{t} A(u)\left[\mu_{R} d u+\sigma_{R} d W_{R}(u)\right]-L^{\bar{\pi}}(t) .
\end{aligned}
$$

The integral terms are the gains and losses from the trading and banking books and 
the changes of equity due to the net recapitalization. The last term is the cumulative dividend process. Thus, cumulative profits and equity issuances feed to the capital, while dividend payments, cumulative losses, and stock buybacks represent a leakage from the capital.

By risk-neutral pricing, the market value of bank equity is the expected discounted dividends until liquidation. Thus, the equity value under policy $\bar{\pi}$ and initial accounting buffer capital $\bar{x}$ is given by

$$
\bar{V}_{\overline{\bar{\pi}}}(\bar{x})=E\left[\int_{0}^{\bar{\tau}_{\bar{\pi}}} e^{-(r+\delta) t} d L^{\bar{\pi}}(t) \mid \bar{X}(0)=\bar{x}\right],
$$

where $E$ is expectation under the risk-neutral probability measure, $\delta$ is a positive constant representing the wedge between debt and equity finance due to capital market frictions such as taxation and agency costs of equity ${ }^{30}$ The wedge satisfies $\delta>\max \left[\alpha_{B}, \alpha_{T}, \mu_{R}-r\right]$, which gives $\bar{V}_{\bar{\pi}}(\bar{x})<\infty$. Thus, the wedge $\delta$ should be greater than any of the returns from banking, trading, or net recapitalization in excess of risk-free rate. The problem is to identify the value of an optimally managed bank:

$$
\bar{V}(\bar{x})=\sup _{\bar{\pi} \in \Pi} \bar{V}_{\bar{\pi}}(\bar{x})
$$

and an admissible policy which achieves this value.

\subsubsection{A Normalized Model of Bank Capital Ratio}

The capital dynamics defined in (3.9) are not time-homogenous, which makes direct solution of the problem (3.11) difficult. However, the problem of capital control can be transformed into a time-homogenous problem of capital ratio control through a simple normalization. The normalized state variable, the bank capital ratio is given by

$$
X(t)=\bar{X}(t) / A(t) .
$$

\footnotetext{
${ }^{30}$ Since our modeling framework is under the risk-neutral probability measure $\delta$ should not be interpreted as an equity risk premium.
} 
From Peura and Keppo (2006) we get the following lemma that presents the capital ratio control problem and shows its connection to the capital control problem (3.11).

Lemma III.1. (Capital control problem) Given an admissible policy $\pi \in \Pi$, the capital ratio satisfies

$$
\begin{aligned}
X^{\pi}(t)= & X(0)+\int_{0}^{t}\left[\left(\mu_{\theta^{\pi}(u)}-r\left(1-K-X^{\pi}(t)\right)-\sigma_{A} \sigma_{\theta(u)} \rho_{A E}\right) d u+\sigma_{\theta^{\pi}(u)} d W_{E}(u)\right] \\
& +\int_{0}^{t}\left[\left(\mu_{R}-\sigma_{A} \rho_{R A} \sigma_{R}\right) d u+\sigma_{R} d W_{R}(u)\right]-L^{\pi}(t) \\
& -\int_{0}^{t}\left[X^{\pi}(u)+K\right]\left[\left(\mu_{A}-\sigma_{A}^{2}\right) d u+\sigma_{A} d W_{A}(u)\right] .
\end{aligned}
$$

Define the liquidation time by

$$
\tau_{\pi}=\inf \left\{t \mid X^{\pi}(t) \leq 0\right\}
$$

and the bank equity value as percentage of the total assets under policy $\pi$ by

$$
V_{\pi}(X(0))=E_{X(0)}\left[\int_{0}^{\tau_{\pi}} e^{-\left(r+\delta-\mu_{A}+\frac{1}{2} \sigma_{A}^{2}\right) t+\sigma_{A} W_{A}(t)} d L^{\pi}(t)\right]
$$

where the expectation is conditional on the capital ratio dynamics (3.13a). The value function:

$$
V(x)=\sup _{\pi \in \Pi} V_{\pi}(x)
$$

Then (3.11) can be expressed in terms of (3.13d) as

$$
\bar{V}(\bar{X}(0))=A(0) V(X(0))
$$

Further, let $\pi^{*}$ be the policy which achieves the optimum in (3.13d). Then the optimal policy of (3.11), $\bar{\pi}^{*}$, can be expressed in terms of $\pi^{*}$ by

$$
\zeta^{\bar{\pi}^{*}}=\zeta^{\pi^{*}}, \theta^{\bar{\pi}^{*}}(t)=\theta^{\pi^{*}}(t), \text { and } L^{\bar{\pi}^{*}}(t)=\int_{0}^{t} A(u) d L^{\pi^{*}}(u) \text {. }
$$


Hence, when $\pi$ and $\bar{\pi}$ are related through 3.15 then the capital ratio process (3.13a is the process of $\bar{X}^{\bar{\pi}}(t) / A(t)$. The proof is based on Ito's lemma and equations (3.5) and (3.7). Equation (3.14) implies that the objective function of the capital ratio control problem, $(3.13 \mathrm{~d})$, can be interpreted as the market value of bank equity as a percentage of the total assets.

From Højgaard and Taksar (2004) we get the following lemma.

Lemma III.2. (Concavity) The value function in (3.13d) is increasing and concave. 


\subsection{Characterization of Optimum}

We characterize the value function (3.13d) through a set of variational inequalities. For this purpose we define the infinitesimal generator $\mathcal{A}$ corresponding to $3.13 \mathrm{a})$ for all sufficiently regular $f$ as follows

$$
\begin{aligned}
\mathcal{A}_{\theta} f(x)= & \frac{1}{2}\left[\sigma_{\theta}^{2}+\sigma_{R}^{2}+2 \sigma_{\theta} \sigma_{R} \rho_{R E}+(x+K)^{2} \sigma_{A}^{2}\right] f^{\prime \prime}(x) \\
& -(x+K) \sigma_{A}\left(\sigma_{R} \rho_{R A}+\sigma_{\theta} \rho_{A E}\right) f^{\prime \prime}(x) \\
& +\left[\mu_{\theta}-r+\mu_{R}-(x+K)\left(\mu_{A}-r\right)\right] f^{\prime}(x) .
\end{aligned}
$$

Further, let us write the value function corresponding to banking proportion $\zeta \in$ $\left[\zeta_{l}, 1\right]$ as $V^{\zeta}(x)$. That is, $V^{\zeta}(x)$ is the expected discounted dividends in (3.13c) and (3.13d) for given $\zeta$.

Now we get the following proposition. The proof follows from standard arguments (see e.g. Højgaard and Taksar 1999 or Fleming and Soner 2005).

Proposition III.3. (Value function) The value function corresponding to banking book proportion $\zeta \in\left[\zeta_{l}, 1\right]$ solves

$$
\text { LIQUIDATION: } \quad V^{\zeta}(0)=0
$$

$$
\text { LIQUID ASSET INVESTMENT: } \quad \max _{\theta \in[0,1]}\left(\mathcal{A}_{\theta}-\lambda\right) V^{\zeta}(x)=0 \text { for all } x \in(0, u)
$$

$$
\text { DIVIDENDS: } \quad \frac{\partial V^{\zeta}(x)}{\partial x}=1 \text { for all } x \geq u
$$

where $\lambda=r-\mu_{A}+\delta$ and the optimal trading strategy $\theta^{*}(x)=\max \{0, \min [1, \hat{\theta}(x)]\}$, where $\hat{\theta}(x)$ solves:

$$
\hat{\theta}(x)=-\frac{\zeta \sigma_{B} \rho}{(1-\zeta) \sigma_{T}}-\frac{\alpha_{T}}{(1-\zeta) \sigma_{T}^{2}\left[1+\left(\sigma_{R} \rho_{R E}-(x+K) \rho_{A E} \sigma_{A}\right) / \sigma_{\hat{\theta}(x)}\right]} \frac{\frac{\partial V^{\zeta}(x)}{\partial x}}{\frac{\partial^{2} V^{\zeta}(x)}{\partial x^{2}}} .
$$


For each buffer capital ratio $x$, one of the inequalities (3.17b) - (3.17c) is tight.

The numerical solution for 3.18 is given in Appendix 3.5.2. The optimal policy can be understood as follows. Dividends are paid so as to never let the capital ratio rise above $u$, and between the dividend payments the bank invests actively in the risky financial asset. The optimal trading strategy solves $\max \left(\mathcal{A}_{\theta}-\lambda\right) V^{\zeta}(x)=0$. Note that, by (3.16) and Lemma III.2, $\left(\mathcal{A}_{\theta}-\lambda\right) V^{\zeta}(x)$ is concave with respect to $\theta \in[0,1]$ and, thus, the first order condition gives the optimal trading strategy $\theta^{*}$. The term $-\frac{\zeta \sigma_{B} \rho}{(1-\zeta) \sigma_{T}}$ in 3.18 is due to (partial) hedging of banking cash flows, and $-\frac{\alpha_{T}}{(1-\zeta) \sigma_{T}^{2}\left[1+\left(\sigma_{R} \rho_{R E}-(x+K) \rho_{A E} \sigma_{A}\right) / \sigma_{\hat{\theta}(x)}\right]} \frac{\partial V^{\zeta}(x)}{\partial x} / \frac{\partial^{2} V^{\zeta}(x)}{\partial x^{2}}$ is from the alpha of the trading strategy. The hedging term has its maximum value when the correlation equals -1 , and the alpha term is increasing in the alpha of the trading, $\alpha_{T}$. Note that hedging increases value because, by Lemma III.2, the value function is concave and hedging decreases volatility. The max and min functions in the equation for $\theta^{*}(x)$ are due to the trading constraint.

Proposition III.3 follows from standard dynamic programming arguments applied to the Bellman equation. By (3.17a), when the capital ratio hits zero the bank is liquidated. The slope condition at the dividend barrier $(3.17 \mathrm{c}$ ) and the differential equation between the dividend times $3.17 \mathrm{~b}$ hold since paying dividends and trading are always admissible. We note that the smooth pasting and the super contact conditions are required for $V^{\zeta}$ at the dividend barrier, i.e., $\left.\frac{\partial V^{\zeta}(x)}{\partial x}\right|_{x=u}=1$ and $\left.\frac{\partial^{2} V^{\zeta}(x)}{\partial x^{2}}\right|_{x=u}=0$ (see Dumas 1991$)$.

In case of nonzero correlation between the banking and trading earnings, the value function in Proposition III.3 has to be solved numerically ${ }^{31}$ If the correlation is zero, i.e., $\rho=0$ then we get the model in Keppo et al. (2010). Further, note that if $\zeta=1$

\footnotetext{
${ }^{31}$ We use a standard finite difference approximation method to solve the value function (see e.g. Kushner and Dupuis 2000. Section 5.1) and implemented the method in Matlab.
} 
then the bank invests all the wealth in the banking business and, therefore, the value function is independent of trading since then there are no trading assets. In this case the model equals Peura and Keppo (2006). For $\zeta \in\left[\zeta_{l}, 1\right)$, the smooth pasting and the super contact conditions with Lemma III.2 lead to an explicit formula for the value function (3.17) at the dividend barrier $u$ :

Lemma III.4. (Value at dividend barrier) Let $\tau>0, \alpha_{T}>0, \sigma_{T} \neq 0$, and $\zeta \in\left[\zeta_{l}, 1\right)$. Then the value function at the dividend barrier is given by

$$
V^{\zeta}(u)=\frac{\zeta \alpha_{B}+(1-\zeta) \alpha_{T}+\mu_{R}-(u+K)\left(\mu_{A}-r\right)}{\lambda}
$$

and $\theta^{*}(u)=1$, i.e., the bank has the maximum position in the liquid risky asset at the barrier. If the above conditions hold, except if we have $\alpha_{T} \leq 0$, then

$$
V^{\zeta}(u)=\frac{\zeta \alpha_{B}+\mu_{R}-(u+K)\left(\mu_{A}-r\right)}{\lambda}
$$

Further, if $\alpha_{T}=0$ then $\theta^{*}(u)=\max \left\{0, \min \left[1,-\frac{\zeta \sigma_{B} \rho}{(1-\zeta) \sigma_{T}}\right]\right\}$, and if $\alpha_{T}<0$ then $\theta^{*}(u)=0$, i.e., then the bank has the minimum position in the liquid risky asset at the barrier.

Proof: By (3.17b and the value matching, smooth pasting, and super contact conditions at $u_{D}$, we have

$$
V^{\zeta}(u)=\sup _{\theta(u) \in[0,1]}\left[\left(\zeta \alpha_{B}+(1-\zeta) \theta(u) \alpha_{T}+\mu_{R}-(u+K)\left(\mu_{A}-r\right)\right) / \lambda\right]
$$

First, if $\alpha_{T}=0$ then we get $(3.20)$ directly and, by Proposition III.3, $\theta^{*}(u)=$ $\max \left\{0, \min \left[1,-\frac{\zeta \sigma_{B} \rho}{(1-\zeta) \sigma_{T}}\right]\right\}$. Second, if $\alpha_{T}>0$ then $\theta^{*}(u)=1$ and 3.19 follows. Finally, if $\alpha_{T}<0$ then $\theta^{*}(u)=0$ and 3.20 follows. 
By Lemma III.4, the value function at the dividend time is given by the simple equations 3.19 and 3.20 which do not include any volatilities or correlations. However, the dividend barrier $u$ (solved by the value matching and smooth pasting conditions) and, therefore, also the dividend time depend on the volatilities and the correlations.

From (3.18) we get the following corollary.

Corollary III.5. (Trading) If the trading alpha and the correlation between the banking and trading cash flows are both zero then the bank does not trade. That is, if $\alpha_{T}=0$ and $\rho=0$ then $\theta^{*}(x)=0$ for all $x \in(0, u]$.

This result implies that there are two motivations for trading: alpha generating bets and the hedging of banking earnings. When the trading alpha and the correlation are zero then there is no trading. In this case our model is given by Peura and Keppo (2006).

So far we have analyzed the value function with given banking book size $\zeta \in\left[\zeta_{l}, 1\right]$. Next we discuss about the optimal $\zeta$ and for this we define $\Upsilon^{x}(\zeta)=V^{\zeta}(x)$, where $x$ is the buffer capital at time 0 . The optimal $\zeta$ is solved at time 0 and it is constant: $\zeta^{*}=\arg \max _{\zeta \in\left[\zeta_{l}, 1\right]} \Upsilon^{x}(\zeta)$. By the extreme value theorem, $\Upsilon$ attains its maximum on $\left[\zeta_{l}, 1\right]$. The maximum value is either at a local maximum in $\left(\zeta_{l}, 1\right)$, or at a boundary $\left(\zeta_{l}\right.$ or 1$)$, i.e., at the point where the derivative is zero or at a boundary. We solve $\zeta$ numerically by testing these candidates.

Note that if $\zeta$ was time varying then we would solve that from $(3.17 \mathrm{~b})$ similarly as $\theta^{*}$ in Proposition III.3. This would give $\zeta=\max \left(\zeta_{l}, \min (1, \hat{\zeta})\right)$ where $\hat{\zeta}=\frac{\left(\theta \alpha_{T}-\alpha_{B}\right) \sigma_{\theta}}{\left(\sigma_{\theta}+\sigma_{R} \rho_{R E}-(x+K) \sigma_{A} \rho_{A E}\right)\left(\sigma_{B}^{2}+\theta^{2} \sigma_{T}^{2}-2 \sigma_{B} \rho \theta \sigma_{T}\right)} \frac{\frac{\partial V^{\zeta}(x)}{\partial x}}{\frac{\partial^{2} V^{\zeta}(x)}{\partial x^{2}}}+\frac{\theta \sigma_{T}\left(\theta \sigma_{T}-\sigma_{B} \rho\right)}{\sigma_{B}^{2}+\theta^{2} \sigma_{T}^{2}-2 \sigma_{B} \rho \theta \sigma_{T}}$, where, by Lemma III.2, the first term besides $\theta \alpha_{T}-\alpha_{B}$ and $\left(\sigma_{\theta}+\sigma_{R} \rho_{R E}-(x+\right.$ 
$\left.K) \sigma_{A} \rho_{A E}\right)$ is negative. This implies that the higher the banking alpha relative to the trading alpha, the bigger the banking book size is. Since typically $\sigma_{T}>\sigma_{B}$, the last term is positive if $\theta \geq \rho$. 


\subsection{Model Calibration}

In this section we calibrate our model to twelve U.S. banks during 2000 Q1 2011 Q4. This period was selected to include the most current period after the repeal of the Glass-Steagall Act on late 1999 We use the twelve banks because for them we have required accounting data for our analysis over this time period from the Compustat Database ${ }^{33}$ We estimate the model parameters by using the in-sample data on the banks. The period is divided into in-sample and out-of-sample periods: 2000 Q1 - 2009 Q4 is the in-sample period and 2010 Q1- 2011 Q4 is the out-of-sample period. We also use the banks' stock price and shares outstanding from CRSP for the market value of shareholders' equity (the shares outstanding are used with the model's market capitalization), the yield on 3-month U.S. treasury bill for the risk-free interest rate, and the S\&P 500 index for the market portfolio.

\subsubsection{Banks}

The banks are introduced in Table 3.1. As we can see, the banks' average total assets during the time period vary from below three billion USD (ABVA, HTLF, and TMP) to over 500 billion USD (BAC, JPM, and WFC). The big banks have smaller buffer capital ratios than the small banks have: The correlation between the mean buffer capital ratio and the mean asset size is -0.10 . This is consistent with the "too big to fail" concept since if the big banks know that they are so large and so interconnected that their failure would be disastrous to the economy, and which therefore must be supported by government when they face difficulty, then it might be optimal for the big banks to maximize the value of the bailout option by running

\footnotetext{
${ }^{32}$ Glass-Steagall Act limited commercial banks' security activities and affiliations between commercial banks and securities firms.

${ }^{33}$ Compustat data variables include: total assets, trading account securities, federal funds sold and securities borrowed or purchased under agreements to resell, interest income and expense on federal funds sold and securities borrowed or purchased under agreements to resell comprehensive income, net gain (loss) from trading securities, tier 1 capital ratio, and shareholders' equity.
} 
their business with a low buffer capital ratio ${ }^{34}$ However, given the model parameters (that might, at least partially, be driven by the above discussed moral hazard), seven banks (CBSH, FHN, HTLF, JPM, STT, TMP, and WTFC) have higher mean buffer capital ratios than our model dividend barriers (both under estimated parameters and under the significant parameters, columns under $u$ in Table 3.1.). Thus, these banks run their business with higher capital buffers than what is optimal according to our model (the seven banks include both small and big banks) and, therefore, each of these banks has a lower default probability than the corresponding optimally managed bank has. However, the banks might have too high earnings volatility due to the moral hazard problem discussed above and they might have too much leverage because the banks pay low interest rates for their own debt due to the government support (we do not model the government support). Higher earnings volatility and leverage naturally increase the risks of the whole industry.

Most of the bank assets are in the basic banking business, eleven banks have over $90 \%$ of their assets in the banking book. Only JPM has less than $80 \%$ of their assets in the banking book. For all the banks, the banking earnings volatility is lower than their trading volatility. This is consistent with DeYoung and Roland (2001), Stiroh (2004, 2006), and Stiroh and Rumble (2006) who find that movement away from traditional banking activities toward other financial services increases the volatility and market risk. Seven banks had negative correlation between the banking and trading earnings. Negative correlation implies partial hedging of the basic banking business. Seven banks out of twelve had higher trading alpha (excess return) than the banking alpha. Some of the trading alphas are too high for forward looking estimates. However, as explained in Table 3.1, the alphas are bounded above by a ${ }^{34}$ For more on this, see e.g. Haldane and Alessandri (2009) and Miles et al. (2012). 
technical condition and our model parameters are the 2000 Q1 - 2011 Q4 sample estimates. We do not know specifically which activities create their trading alphas. For instance, many banks have profitable market making of which return on capital can be high ${ }^{35}$, and during our sample time period many banks placed a lot of assets that looked as a banking book-type into the trading book (e.g. CDO tranches), possibly to take advantage of trading book's lower capital requirements. Further, many high trading alpha banks have high trading volatilities and, by the concavity of the value function (Lemma III.2), our model bank might prefer not to invest in the trading. To understand better the effect of different model parameters, in Subsections 3.5.6 and 3.5.7 we analyze the model behavior with respect to wide ranges of parameter values. For instance, we show in Subsection 3.5.7 that the Volcker rule can raise the default probability of a bank even under a small trading alpha. In the next subsection we explain the parameter estimation.

\subsubsection{Discrete Model for Equity Ratio}

In this subsection, we estimate parameters by comparing our continuous model with the corresponding discrete model and matching their first and second moments. For this, we need to write our model under the objective measure $\mathbb{P}$ to estimate parameters from real data. This is done in Subsection 3.5.1.

The accounting identity that governs the evolution of bank's shareholders' equity is of the form

$$
C_{t}=C_{t-1}+N I_{t}-D_{t}+S_{t}
$$

where $C_{t}$ is bank's shareholders' equity at time $t, N I_{t}$ is net (comprehensive) income over period $(t-1, t), D_{t}$ is total dividend payments over period $(t-1, t)$, each payment

\footnotetext{
${ }^{35}$ For instance, Morgan Stanley posted net trading gains every day during the second quarter of 2007 and Goldman Sachs had only 11 losing days in their trading between April 2009 and April 2010 (see e.g. Bloomberg, May 13th 2010, "Rigged-Market Theory Scores a Perfect Quarter" by Jonathan Weil).
} 
made at discrete finite times, and $S_{t}$ is net recapitalization over period $(t-1, t)$. For the net recapitalization, we use the change in the sum of common and preferred capital plus capital surplus/share premium minus treasury capital. Note that (3.21) is consistent with our continuous time model (3.9).

Let $B_{t}$ denote the bank's shareholders' equity above the minimum capital requirement $K \cdot A_{t}$ at time $t$ i.e. $B_{t}=C_{t}-K \cdot A_{t}$, and $X_{t}=B_{t} / A_{t}$ the bank buffer equity ratio, where $A_{t}$ is the total assets at time $t$. Then, the discrete dynamics of $X_{t}$ follows

$$
\begin{aligned}
\Delta X_{t} & =\frac{B_{t}}{A_{t}}-\frac{B_{t-1}}{A_{t-1}}=\frac{C_{t}}{A_{t}}-\frac{C_{t-1}}{A_{t-1}}=\left(\frac{C_{t}}{A_{t}}-\frac{C_{t-1}}{A_{t}}\right)+\left(\frac{C_{t-1}}{A_{t}}-\frac{C_{t-1}}{A_{t-1}}\right) \\
& =\frac{C_{t}-C_{t-1}}{A_{t}}+\frac{C_{t-1}}{A_{t-1}}\left(\frac{A_{t-1}-A_{t}}{A_{t}}\right) \\
& =\left(\frac{N I_{t}}{A_{t}}-\frac{D_{t}}{A_{t}}+\frac{S_{t}}{A_{t}}\right)-\left(\frac{\Delta A_{t}}{A_{t}}\right)\left[X_{t-1}+K\right] .
\end{aligned}
$$

Then, the expectation and variance of change in equity ratio can be written:

$$
\begin{aligned}
E\left[\Delta X_{t}\right]= & E\left[\frac{N I_{t}}{A_{t}}\right]-E\left[\frac{D_{t}}{A_{t}}\right]+E\left[\frac{S_{t}}{A_{t}}\right]-E\left[\frac{\Delta A_{t}}{A_{t}}\left(X_{t-1}+K\right)\right], \\
\operatorname{Var}\left[\Delta X_{t}\right]= & \operatorname{Var}\left[\frac{N I_{t}}{A_{t}}\right]+\operatorname{Var}\left[\frac{D_{t}}{A_{t}}\right]+\operatorname{Var}\left[\frac{S_{t}}{A_{t}}\right]+\operatorname{Var}\left[\frac{\Delta A_{t}}{A_{t}}\left(X_{t-1}+K\right)\right] \\
& +2 \operatorname{Cov}\left[\frac{N I_{t}}{A_{t}}, \frac{S_{t}}{A_{t}}\right]-2 \operatorname{Cov}\left[\frac{N I_{t}}{A_{t}}, \frac{\Delta A_{t}}{A_{t}}\left(X_{t-1}+K\right)\right] \\
& -2 \operatorname{Cov}\left[\frac{S_{t}}{A_{t}},\left(\frac{\Delta A_{t}}{A_{t}}\right)\left(X_{t-1}+K\right)\right] .
\end{aligned}
$$

Similarly, we obtain the expectation and variance of $d X$ under the objective measure $\mathbb{P}$ according to 3.25 as follows:

$$
\begin{aligned}
E[d X]= & {\left[\mu_{\theta}-\sigma_{\theta}\left(\sigma_{A} \rho_{A E}-\lambda \rho_{M}\right)-r(1-(K+E[X])] d t-E[d \tilde{L}]\right.} \\
& +\left[\mu_{R}-\sigma_{R}\left(\sigma_{A} \rho_{R A}-\lambda \rho_{S M}\right)\right] d t-(E[X]+K)\left(\mu_{A}-\sigma_{A}^{2}+\lambda \sigma_{A} \rho_{A M}\right) d t \\
\operatorname{Var}[d X]= & \sigma_{\theta}^{2} d t+\operatorname{Var}[d \tilde{L}]+\sigma_{R}^{2} d t+\sigma_{A}^{2}\left((E[X]+K)^{2}+\operatorname{Var}[X]\right) d t \\
& +2 \sigma_{\theta} \sigma_{R} \rho_{R E} d t-2 \sigma_{\theta} \sigma_{A}(E[X]+K) \rho_{A E} d t \\
& -2 \sigma_{R} \sigma_{A}(E[X]+K) \rho_{R A} d t
\end{aligned}
$$


In comparison between $(3.22)$ and 3.22 , we estimate parameters in the continuous model using correspondence:

$$
\begin{aligned}
& \sigma_{\theta}=\sqrt{\frac{1}{\Delta t} \operatorname{Var}\left[\frac{N I_{t}}{A_{t}}\right]}, \sigma_{R}=\sqrt{\frac{1}{\Delta t} \operatorname{Var}\left[\frac{S_{t}}{A_{t}}\right]}, \sigma_{A}=\sqrt{\frac{\operatorname{Var}\left[\left(\frac{\Delta A_{t}}{A_{t}}\right)\left(X_{t-1}+K\right)\right]}{\left((E[X]+K)^{2}+\operatorname{Var}[X]\right) \Delta t},} \\
& \rho_{R E}=\frac{\operatorname{Cov}\left[\frac{N I_{t}}{A_{t}}, \frac{S_{t}}{A_{t}}\right]}{\sigma_{\theta} \sigma_{R} \Delta t}, \quad \rho_{A E}=\frac{\operatorname{Cov}\left[\frac{N I_{t}}{A_{t}}, \frac{\Delta A_{t}}{A_{t}}\left(X_{t-1}+K\right)\right]}{\sigma_{\theta} \sigma_{A}(E[X]+K) \Delta t}, \\
& \rho_{R A}=\frac{\operatorname{Cov}\left[\frac{S_{t}}{A_{t}}, \frac{\Delta A_{t}}{A_{t}}\left(X_{t-1}+K\right)\right]}{\sigma_{R} \sigma_{A}(E[X]+K) \Delta t}, \\
& \mu_{\theta}=\frac{1}{\Delta t} E\left[\frac{N I_{t}}{A_{t}}\right]+\sigma_{\theta}\left[\sigma_{A} \rho_{A E}-\lambda \rho_{M}\right]+r(1-K-E[X]) \\
& \mu_{R}=\frac{1}{\Delta t} E\left[\frac{S_{t}}{A_{t}}\right]+\sigma_{R}\left[\sigma_{A} \rho_{R A}-\lambda \rho_{S M}\right] \\
& \mu_{A}=\frac{1}{\Delta t(E[X]+K)} E\left[\frac{\Delta A_{t}}{A_{t}}\left(X_{t-1}+K\right)\right]+\sigma_{A}^{2}-\lambda \sigma_{A} \rho_{A M} .
\end{aligned}
$$

The estimates for $\lambda, \rho_{A M}, \rho_{S M}, \rho_{M}$ are given in Table 3.1 .

\subsubsection{Model Parameters for Net Income Earnings}

Now we estimate the parameters for the dynamics of net (comprehensive) income earnings. The total assets $A_{t}$ is the sum of banking assets $A B_{t}$ and trading assets $A T_{t}$ :

$$
A_{t}=A B_{t}+A T_{t}
$$

Similarly as with the assets, total net comprehensive income $N I_{t}$ over period $(t-1, t]$ is the sum of banking net comprehensive income $N I B_{t}$ and trading net comprehensive income $N I T_{t}$ over the same period:

$$
N I_{t}=N I B_{t}+N I T_{t}
$$

For the trading revenues we use the gain (loss) of trading/dealing securities in Compustat. However, to get trading net income $\left(N I T_{t}\right)$ from the trading revenues we subtract $50 \%$ for compensation and infrastructure costs from all (positive) gains. 
This is consistent with the compensation at several leading banks ${ }^{36}$ We analyze the effect of this assumption in Subsections 3.5.6 and 3.5.7 by varying the trading alpha parameter. For the banking net income $\left(N I B_{t}\right)$ we use Compustat's net income $\left(N I_{t}\right)$ minus the trading net income $\left(N I T_{t}\right)$.

We define banking return on assets, $R O B_{t}$, and trading return on assets, $R O T_{t}$, over period $(t-1, t]$ as follows

$$
R O B_{t}=\frac{N I B_{t}}{A B_{t-1}}, \quad R O T_{t}=\frac{N I T_{t}}{A T_{t-1}}
$$

In other words, the returns are computed by dividing the net income of year $t$ by the corresponding assets in the previous year $(t-1){ }^{37}$

Volatilities $\sigma_{B}$ and $\sigma_{T}$ are estimated as the annualized standard deviations of the time series $\left\{R O B_{t}\right\}$ and $\left\{R O T_{t}\right\}$, respectively. Parameter $\rho_{B T}$ is the correlation between the time series $\left\{\frac{N I B_{t}}{A_{t-1}}\right\}$ and $\left\{\frac{N I T_{t}}{A_{t-1}}\right\}$. Volatilities and correlations are in Table 3.1. Most of the volatilities are less than $5 \%$, but there are four banks with over $5 \%$ annual trading volatility (FHN, HTLF, JPM, and WTFC). Ten out of twelve banks have negative correlation between the banking and trading earnings. However, only two of the correlations are statistically significant and there is another bank in Table 3.2 with significant positive correlations between the earnings. This implies that the hedging story is weak. Further, both big and small banks have positive and negative correlations.

Risk-adjusted excess trading return $\alpha_{T}$ is estimated by Capital Asset Pricing Model:

$$
R O T_{t}-R_{f}=\alpha_{T}+\beta_{T}\left(R_{M}-R_{f}\right)+\epsilon,
$$

\footnotetext{
${ }^{36}$ See e.g. Boston.com, January 22nd 2010, "Goldman earns record $\$ 4.79 B$ in Q4, cuts bonus pool" by Stevenson Jacobs,

http://articles.boston.com/2010-01-22/business/29306629_1_proprietary-trading-bank-financial-crisis

${ }^{7}$ We use Compustat variables as follows: $A T=$ trading securities, $A B=$ total assets $-\mathrm{AT}, N I T=\max \left(0.5^{*}\right.$ net gain in trading, 0$)+\min ($ net gain in trading, 0$)$, and $N I B=$ net income - NIT.
} 
where $\beta_{T}$ is the trading beta coefficient, $R_{f}$ is the quarterly 3 -month treasury yield, $R_{M}$ is the quarterly $\mathrm{S} \& \mathrm{P} 500$ index return, and $\epsilon$ is a residual term. Table 3.2 gives the trading alpha and beta estimates. Nine banks have positive beta estimates and two of the estimates are statistically significant ${ }^{38}$ Five banks have positive trading alphas and four of them are statistically significant. On the other hand, there are also seven other banks with statistically significant negative trading alphas. Clearly, all of our sample banks do not benefit from the trading. Some of the alphas and betas are high, indicating that some of the banks have lucrative activities (e.g. market making) and/or they use leverage and/or derivative instruments. As we will see in Section 3.4, the Volcker rule can raise the default probability of a bank even under a small trading alpha.

When using the same method in estimating the banking alphas, i.e. banking excess return prior to the interest payments on debt, as we did with the trading alphas, we use the time series for banking return $R O B_{t}$ plus the time series for the interest payments divided by total assets $I_{t}$ minus on debt minus the risk-free return on the RHS as follows

$$
\left(R O B_{t}+I_{t}\right)-R_{f}=\alpha_{B}+\beta_{T}\left(R_{M}-R_{f}\right)+\epsilon
$$

where $\beta_{B}$ is the banking beta coefficient. Table 3.2 gives the banking alpha and beta estimates. we find that all the banking alphas are negative over the time period 2000 Q1 - 2011 Q4. This is not due to the recent global financial crisis because these estimates are similar for the 2000 Q1 - 2007 Q1 period. In theory, a bank should be liquidated if a bank's banking alpha is negative, which is not the case in reality. That means, all sample banks rely on their earnings from trading business or net recapitalization. Not surprisingly, nine banks have positive net recapitalization

\footnotetext{
${ }^{38}$ Note that we do not need the beta estimates since the expectation in (6) is under the risk-neutral probability.
} 
return on assets.

We estimate the wedge between debt and equity finance, $\delta$ as the implied solution by fitting the model equity ratio value to the realized market equity ratio. We compute such $\delta$ once with estimated parameters or once with significant parameters 39

Although the banking proportion $\zeta$ is optimized in our model, we also estimate it from our data. We find the best-fitting implied $\zeta$ for the equations (3.6) and (3.4) by using the estimates of $\sigma_{\theta}$ and $\mu_{\theta}$ computed as in (3.23). We assume that $r=2 \%$ as it is close to the average of risk-free rate over our sample period. We denote the solution of the system above by $\zeta_{d}$, which is given in Table 3.1. Note that $\theta(t)=1$ for convenience above. Using $\zeta_{d}$ requires us to modify the constraint on the wedge $\delta$ given in Section 1 to $\delta>\max \left[\zeta_{d} \alpha_{B}+\left(1-\zeta_{d}\right) \alpha_{T}, \mu_{R}\right]$. None of our sample banks have parameter estimates which violate this constraint. Further, note that $\zeta$ is constant in our model, i.e., the banking asset size is a long term strategic decision and, therefore, the observed $\zeta_{d}$ in Table 3.1 is not the same as the current optimal $\zeta$. In fact, If we set $\zeta_{I}=75 \%$, which is close to the minimum $\zeta_{d}$ in Table 3.1 (JPM), the model's optimal allocation in the banking business is at $75 \%$ or the minimum banking proportion possible. In other words, according to our model, the equity value of all sample banks would rise if the size of their trading units was increased. However, note that here we simply assume that the trading business could keep its profitability when it is expanded, which may not be the case.

\subsubsection{Cross-sectional Test and Comparative Statics}

In Figure 3.2 we show that our model explains about $34 \%$ of the cross-sectional variation in the banks' maximum buffer capital ratios. Further, the slope of the regression model is significant, indicating significant linear relationship between the

\footnotetext{
${ }^{39}$ See columns under $\delta$ in Table 3.1
} 
model and actual buffer capital levels. This is consistent with Peura and Keppo (2006) who analyze a simpler model but a larger set of banks. Thus, due to our small sample, Figure 3.2 just confirms the finding in that paper.

Subsection 3.5 .6 gives the comparative statics of the model under the median model parameters. More specifically, figures in Subsection 3.5.6 analyze how the value function $(3.13 d)$ and dividend barrier $u$ change with respect to banking proportion $\zeta$, banking volatility $\sigma_{B}$, trading volatility $\sigma_{T}$, correlation between the banking and trading earnings $\rho_{B T}$, banking alpha $\alpha_{B}$, trading alpha $\alpha_{T}$, risk-free rate $r$, and wedge between debt and equity finance $\delta$.

With these parameter values, the banking business has a higher risk adjusted excess return than the trading business has and, therefore, the bank value rises in the banking proportion (see Figure (3.4.1) in Subsection 3.5.6. By the lower banking volatility, when banking proportion rises then the earnings risk falls and, therefore, there is less need for the hedging of future losses and the dividend barrier falls in the banking proportion (see Figure (3.4.2). The effect of banking and trading volatilities can be explained in a similar way, because both of these volatilities increase the earnings volatility. Since, by Lemma III.2, the value function is concave, the higher the earnings volatility the lower the value function (see Figures (3.4.3) and (3.4.5) . Further, the higher the volatility the more the bank has to hedge its future losses and, thus, the higher the dividend barrier (see Figures (3.4.4) and (3.4.6). The earnings volatility is the main driver of the dividend barrier: By Table 3.2, the earnings volatility and dividend barrier have a correlation of 1.00 under the estimated parameters and 0.91 under the significant parameters (this is consistent with Peura and Keppo (2006)). Thus, our dividend policy is driven by risk management considerations. 
The effect of correlation between the banking and trading cash flows is as expected (see Figures (3.4.7) and (3.4.8)). The lower the correlation (and the more negative it is), the higher the value function because then the hedging of banking cash flows is more effective. Thus, in this case the earnings volatility falls and, by Lemma III.2, the value function rises. To understand the effect of correlation on dividend policy, we first note that we have two hedging methods for the banking cash flows. The first is through trading and it requires negative correlation between the banking and trading cash flows. The second is hedging with buffer capital and this is a substitute for the first method. That is, if the bank is not able to hedge the banking cash flows by trading then it raises its buffer capital so that it has more cushion for the future losses. The buffer capital is increased by raising the dividend barrier and, therefore, the dividend barrier rises in the correlation.

As expected, the value function is an increasing function of the banking and trading alphas (see Figures (3.4.9) and (3.4.11)]. However, the effect of the alphas on the dividend barrier is not that straightforward (see Figures (3.4.10) and (3.4.12). This is because the alphas change the shape of the value function (see Figures (3.4.13) and (3.4.14) : The lower the alphas, the more linear the value function. When alphas rise then the value function becomes more concave and, thus, the bank becomes more risk averse. This creates the need to hedge more and the dividend barrier rises. However, when alphas are increased even more then their effect on increasing earnings dominates and this decreases the need for hedging and the dividend barrier falls.

The adjusted risk-free rate has both positive and negative effects on the equity value. First, by (3.13a), the expected capital ratio rises in the adjusted risk-free rate and this increases the equity value (relative to the assets). Second, by (3.13c), the 
discount rate increases in the adjusted risk-free rate and this lowers the equity value. Figure (3.4.13) shows that, similarly as with regular call options (rho of the call), the positive effect is stronger and, thus, the equity value rises. The dividend barrier falls in the adjusted risk-free rate (see Figure (3.4.14), because then buffer capital increases faster and discounting is stronger. When buffer capital rises then there is less need for hedging (so, $u$ indeed falls), and when there is more discounting then the value of future dividends decrease and, thus, it is better to pay dividends sooner $(u$ falls). The effect of the wedge between debt and equity finance can be explained in a similar way. However, the wedge affects only the discounting, not the buffer capital dynamics. Thus, by (3.13b), the wedge has only the negative value effect of the adjusted risk-free rate and, therefore, the value falls (see Figure (3.4.15). Further, when the wedge rises the company prefers to pay dividends earlier and, hence, the dividend barrier falls (see Figure (3.4.16)). 


\subsection{Volcker Rule}

By using a sensitivity analysis with the estimated model parameters, we next study our sample banks' trading and estimate the impact of the Volcker rule. In this we utilize Corollary III.5, i.e., if $\alpha_{T}$ and $\rho_{B T}$ are zero then it is optimal for the bank not to trade. More specifically, we measure the value of each bank under four different cases:

(i) Bank equity value without the Volcker rule: Value with the estimated parameter values and with only the statistically significant estimates in Table 3.2. That is, we calculate two bank equity values for this case. In the first, $\alpha_{T}$ and $\rho_{B T}$ are equal to their estimated values, and in the second, each parameter equals its estimated value if the estimate is statistically significant at $5 \%$ significance level and otherwise the parameter is zero. Note that, by Table 3.1, $\alpha_{T}$ and $\rho_{B T}$ are the only parameters in Proposition III.3 that could be zero.

(ii) Bank equity value without trading alpha bets: Value with $\alpha_{T}=0$, i.e., there is no trading due to the excess return and, thus, by Proposition III.3 in this case the banks trade only for hedging. As in $(i)$, we calculate the bank equity values with all the $\rho_{B T}$-estimates and also with only the significant correlations (the insignificant correlations are set to zero).

(iii) Bank equity value without hedging: Value with $\rho_{B T}=0$, i.e., there is no correlation between the trading and banking returns, and, therefore, the banks trade only for the excess return, not for hedging. As in $(i)$, we calculate the bank equity values with all the $\alpha_{T}$-estimates and also with only the significant alphas (the insignificant alphas are set to zero).

(iv) Bank equity without trading: Value with $\alpha_{T}=0$ and $\rho_{B T}=0$, i.e., by 
Corollary III.5 the banks do not trade at all.

In these cases we assume that only $\alpha_{T}$ and $\rho_{B T}$ change and all the other model parameters are constant. Thus, for instance, we assume here that $\zeta$ is constant, i.e., the size of the banking book is independent of $\alpha_{T}$ and $\rho_{B T}$. Further, in this section we assume that if the trading is decreased then that money is invested in the risk-free asset, not in the banking business.

\subsubsection{Bank Value}

The model estimated equity values under the four cases $(i)-(i v)$ are in Table 3.3 . We also report percentage changes from the initial equity value $(i)$ to each of the other equity values $(i i)-(i v)$. These changes correspond to the value impacts of the alpha bets, hedging, and trading overall. The difference between the original bank equity value ( $i$ ) and case (ii) gives the value change due to the alpha bets. Similarly, the difference between $(i)$ and $(i i i)$ is the equity value impact of the hedging, and the difference between $(i)$ and $(i v)$ is the total equity value change of trading. Depending on the implementation of the Volcker rule, the differences between $(i)$ and (ii) and between $(i)$ and $(i v)$ give the equity value decrease due to the rule.

By Table 3.3 , Volcker rule decreases on average bank equity value by $1 \%$ in the assets-weighted sense. The effect of banning alpha bets is about the same as banning all trading. Thus, the impact of hedging is on average about zero.

To analyze the robustness of our results further, we create a fictitious bank with trading model parameters as follows: $r=3 \%, \alpha_{T}=3.5 \%$ and $\sigma_{T}=3.03 \%$. These parameter values are consistent with the hedge fund parameter estimates in Ang, Gorovyy, and van Inwegen (2011), Cremers and Petajisto (2009), Getmansky, Lo, and Makarov (2004), Wermers (2003), Daniel, Grinblatt, Titman, and Wermers (1997), Carhart (1997), Chen, Hong, Huang, and Kubik (2004), and Kosowski, 
Naik, and Teo (2007). The other model parameters are equal to the median estimates of the corresponding parameters in our sample data: $\zeta=98 \%, \sigma_{B}=0.65 \%$, $\rho_{B T}=-0.09, m u_{A}=11.69 \%, \sigma_{A}=10.75 \%, \rho_{A E}=0.01, \mu_{R}=0.68 \%, \alpha_{B}=$ $0.56 \%, \rho_{R A}=0.48, \rho_{R E}=-0.35$, and $\delta=16.78 \%$. Thus, this fictitious bank has trading operations that correspond to hedge funds in the empirical papers. We find that preventing alpha bets decreases the fictitious bank's equity value by $11.6 \%$ and preventing hedging decreases the bank equity value by $0.4 \%$. Thus, consistent with the results of our sample banks, hedging has only a small impact on the fictitious bank. If all trading is banned then the bank's equity value falls by $12 \%$.

As discussed earlier, in addition to the value changes in Table 3.3, the Volcker rule might create significant compliance costs and we do not consider those in our model.

\subsubsection{Loan prices}

In this subsection we estimate how much banks should raise their loan rates to compensate for the value decrease due to the Volcker rule. Since the rule prevents banks from collecting trading alpha (or at least makes that harder and costly), banks might focus more on the basic banking business. Therefore, we expect more innovative banking products such as mortgages with insurances for real-estate risk (see e.g. Fabozzi et al. 2010). These products would allow banks to collect higher fees and this way to increase their banking alphas.

We first estimate how much the banks should raise their banking alphas to compensate the value decrease of the Volcker rule. After that we calculate the corresponding increases in the loan rates that would give the new banking alphas if all the other model parameters were fixed 40 Thus, this is a simple comparative statics

\footnotetext{
${ }^{40}$ For instance, we saw this kind of behavior when the U.S. Congress limited the penalties on late payments of
} 
of the model. The increases in the loan rates can be viewed as a measure for new innovation and/or cost cutting that the banks need to do to justify the higher banking alphas.

More specifically, we consider three scenarios (the first and the last are for the Volcker rule). In the first, we assume that the Volcker rule allows hedging but not the alpha bets. In this case we compare cases $(i)$ and $(i i)$, and find a new banking alpha for case $(i i)$ such that the bank equity value in $(i i)$ equals the equity value in (i). In the second case, hedging is prevented but not the alpha bets. In this case we compare $(i)$ and $($ iii $)$ and estimate a new banking alpha for (iii) that produces the same equity value as in $(i)$. In the last case, we assume that the Volcker rule prevents all trading (hedging and the alpha bets). Thus, in this case we compare $(i)$ and $(i v)$, and calculate a new banking alpha in the same sense as with the other cases. The new banking alphas are reported in Table 3.3. On average, the alpha bets would raise the banking alpha by about 1 basis point (BP), the hedging by almost 0 BPS, and total trading by about $1 \mathrm{BP}$.

For the Volcker rule effect, we use the impact from the alpha bets and total trading. Thus, by our comparative statics, banks should increase their banking alphas by about 9.5 BPS to keep their equity value the same as before the rule. As mentioned before, to get the higher banking alphas, banks need to create new products and/or to improve their efficiency.

After we have the new banking alphas, we estimate the corresponding bank loan margin changes. For this we analyze banking net income and assume here that each bank's $N I B_{t}$ equals the loan margin after default losses times the banking assets, i.e., $N I B_{t}=m A B_{t-1}$, where $m$ is the loan margin and $A B_{t-1}$ is the the banking assets credit cards. After the limitation credit card companies started collecting more fees from those people with sterling credit (see e.g. New York Times, May 18th 2009, "Credit Card Industry Aims to Profit From Sterling Payers" by Andrew Martin). 
at time $t-1$. Thus, return on the banking assets is given by $N I B_{t} / A B_{t-1}=m$. On the other hand, if we use the same return model as with the trading assets in subsection 3.3 .3 then we have

$$
\frac{N I B_{t}}{A B_{t-1}}=R_{f}+\alpha_{B}+\beta\left(R_{M}-R_{f}\right)+\epsilon
$$

where $\beta$ is the beta of the banking assets and we assume it is independent of $\alpha_{B}$. Combining the two representations for banking asset returns, we get $m=R_{f}+\alpha_{B}+$ $\beta\left(R_{M}-R_{f}\right)+\epsilon$, which gives $\Delta m=\Delta \alpha_{B}$. That is, the change in the loan margin equals the banking alpha change. Thus, by Table 3.2 , if the Volcker rule prevents banks from trading or just from taking alpha bets then the banks should raise their loan margins between zero and $47 \mathrm{BPS}$ (on average $1 \mathrm{BP}$ ) to compensate the value decreases from the Volcker rule. We expect that big banks have least pressure to increase their loan margins; by our comparative statics, they do not need to raise the loan rates at all (but many banks have to decrease their trading operations). Thus, the effect of the Volcker rule on the loan margins is quite small. This is because, based on our model and data, banks do not benefit much from the trading and most of the banks' assets are in the basic banking business. Therefore, a small increase in the loan margins compensates the value fall due to the rule.

\subsubsection{Default probabilities}

By (3.11), banks maximize their equity value, they do not necessary minimize their default probability. Because banking regulators are in the business of minimizing the default probability, banks and their regulators might have conflicting interests. For instance, in 2008 during the recent financial crisis 21 large banks in the U.S. and Europe paid total over $\$ 400$ billion dividends which represents around one-third of their 2007 market capitalization of $\$ 1.3$ trillion (Acharya et al. 2009). The dividends 
lowered the banks' capital and, therefore, their default probability increased.

In our model, a new regulation (or similarly a new portfolio constraint) cannot increase the banks' value because the rule sets constraints on their behavior 41 On the other hand, regulation changes can increase or decrease the banks' default probability. Unfortunately, it is not obvious what the effect on the default probability is since banks react to regulation and this can cause positive and negative effects. This is also the case with the Volcker rule.

If trading is profitable then ban on trading lowers the expected earnings and this way also the expected buffer capital level. If also hedging is prevented then earnings risk might increase. Both these effects may increase the default probability. On the other hand, there is also a positive effect: Since Volcker rule prevents trading and, by Table 3.2 , trading earnings have a higher volatility than banking earnings have, the total earnings volatility and this way also the default probability might fall. Thus, the total effect on the default probability depends on the magnitude of the negative and positive effects ${ }^{42}$ Table 3.3 gives the effect of Volcker rule on the banks' default probability over 100 years, expected annual earnings, and earnings volatility. The default probabilities are estimated by Monte Carlo simulation with 10,000 paths. By Table 3.3, the change of the default probability from case $(i)$ (i.e. without the Volcker rule) to cases $(i i)-(i v)$ (ban on alpha bets, hedging, and all trading; both estimated and significant parameters) has correlation of -0.68 with the corresponding expected earnings change and 0.63 with the corresponding earnings volatility change. Thus, the expected earnings seem to drive the default probability as its correlation has a

\footnotetext{
${ }^{41}$ As discussed in subsection 3.4.1 the increase in bank value in case (ii) for banks ABVA, BAC, and STI is due to the negative trading alpha and positive correlation estimates. To avoid this problem, we may assume that in case (ii) and case $(i v)$ we set a new alphaT equal to $\max \left[\alpha_{T}, 0\right]$. Then their bank value in case (ii) would equal their bank value in case (i). We did not implement this in our results.

42 Keppo et al. (2010) consider banks' market risk requirement and, according to their model, the requirement has similar effects on the default probability as the Volcker rule.
} 
higher absolute value.43 This implies that the best way to hedge default risk is to run a profitable business. Note that, by Table 3.2, the Volcker rule prevents several banks to run their most profitable business.

The effect of Volcker rule on the default probability can be analyzed by comparing the default probability in case $(i)$ (without the rule) with cases (ii) (ban on alpha bets) and ( $i v)$ (ban on all the trading). On average the Volcker rule increases the default probability by $0.24 \%$ if only alpha bets are prevented, and by $0.24 \%$ (in the assets-weighted sense) if all the trading is prevented. Thus, if the banks behave optimally according to our model then the negative default effects of trading alpha and hedging are stronger than the positive effect of a lower earnings volatility.

This effect is mainly driven by three banks (FHN, MTB, and WTFC). Their default probabilities rise due to the Volcker rule under all cases, and in this sense their effect is robust. By Table 3.1, all the three banks have statistically significant positive trading alphas and their value would rise if their trading operations were expanded. Therefore, when trading is prevented, their expected profits fall (see column $E(\Delta X)$ in Table 3.3) and this lowers the buffer capital of the three banks, which raises the default probability.

We analyze the robustness of these findings in Table 3.3 in two ways. First, by using the fictitious bank introduced in Subsection 3.4.1 with the hedge fund parameters. We find that the default probability of this bank also rises due to Volcker rule from $89 \%$ to $95 \%$. Second, using the estimated parameters of FHN and MTB banks in Table 3.1, we vary the parameter values to see how the default probability responds to the change of each parameter value. By Table 3.2, the default probabilities of FHN and MTB both rise due to the Volcker rule. Within the range

\footnotetext{
${ }^{43}$ Default probability does not necessarily increase in earnings volatility. By Figures $(d)$ and $(f)$ in Subsection 3.5.6 the dividend barrier rises in the volatility. Therefore, a low earnings volatility also means a low buffer capital which could increase the default probability.
} 
of parameter values in the figures of Table 3.3. FHN has a higher default probability under the Volcker rule as long as its trading alpha is positive and banking volatility is higher than $0.1 \%$. These two parameter scenarios indicate that the rule raises FHN's default probability as long as the bank benefits from trading relative to the banking business. Thus, the effect of Volcker rule on FHN's default probability is quite robust and it is not driven by the banks' unusually high trading alpha (it is enough that the alpha is positive). By Subsection 3.3, MTB's default probability rises due to the Volcker rule as long as the banking proportion is higher than $98.5 \%$, the correlation between trading and banking cash flows is lower than 0.4 , trading volatility is lower than $2.4 \%$, and trading alpha is over $2.2 \%$. Thus, similarly as with FHN, the parameter ranges for the correlation, trading volatility, and the trading alpha imply that as long as there is enough trading value, the Volcker rule raises the default probability. The parameter scenario of the banking book is more complicated. By Figures $(d)$ and $(f)$ in Subsection 3.5.6, the dividend barrier of case $(i i)$ is lower than in case $(i)$ due to the lower earnings volatility of case $(i i)$. When the banking proportion is higher than $98.5 \%$ then, by Figure $(b)$ in Subsection 3.5.6, the dividend barrier is even lower, raising the default probability - especially in case $(i i)$. This explains the rising default probability due to Volcker rule when $\zeta>98.5 \%$.

We doubt the hedging story and its benefits. By Table 3.2 , if the hedging is prevented then the default probability falls by $0.01 \%$ in the assets-weighted sense. This indicates that the banks do not focus on the hedging of their default probability. 


\subsection{Appendix for Chapter III}

\subsubsection{Model under the Objective Measure}

Let us define the market return evolves as the following dynamics under the objective measure $\mathbb{P}$ :

$$
d M(t)=\left(r+\lambda \sigma_{M}\right) M(t) d t+M(t) \sigma_{M} d W_{M}^{\mathbb{P}}(t)
$$

where $W_{M}^{\mathbb{P}}(t)$ is a Wiener process under $\mathbb{P}, \lambda$ is market price of risk and it is constant. We can write this process in terms of $W(t)$, which is a Wiener process under the risk-neutral probability measure, as follows

$$
d M(t)=M(t)\left[r d t+\sigma_{M} d W_{M}(t)\right]
$$

Thus, we have

$$
W_{M}(t)=\lambda t+W_{M}^{\mathbb{P}}(t)
$$

Under the risk-neutral probability,

$$
d A(t)=A(t)\left[\mu_{A} d t+\sigma_{A} d W_{A}(t)\right]
$$

where $W_{A}(t)=\rho_{A M} W_{M}(t)+\sqrt{1-\rho_{A M}^{2}} \tilde{W}_{A}(t), W_{M}(t)$ and $\tilde{W}_{A}(t)$ are independent Wiener processes under the risk-neutral probability measure and $\rho_{A M}$ is the correlation between them. By $(3.24), W_{A}(t)=\rho_{A M}\left[\lambda t+W_{M}^{\mathbb{P}}(t)\right]+\sqrt{1-\rho_{A M}^{2}} \tilde{W}_{A}(t)$ and this gives the following $\mathbb{P}$-dynamics:

$$
d A(t)=A(t)\left[\left(\mu_{A}+\lambda \sigma_{A} \rho_{A M}\right) d t+\sigma_{A} d W_{A}^{\mathbb{P}}(t)\right]
$$

where $W_{A}^{\mathbb{P}}(t)=\rho_{A M} W_{M}^{\mathbb{P}}(t)+\sqrt{1-\rho_{A M}^{2}} \tilde{W}_{A}(t)$.

Similarly, $\rho_{M}$ is the correlation between the market return and net income return. $W_{R}^{\mathbb{Q}}=\lambda t+W_{R}^{\mathbb{P}}$ and $\rho_{S M}$ is the correlation between the market return and net recapitalization return. 
Similarly, the buffer capital ratio dynamics (13a) can be written under $\mathbb{P}$ as follows

$$
\begin{aligned}
X^{\pi}(t)= & X(0)+\int_{0}^{t}\left[\mu_{\theta^{\pi}(u)}-r\left(1-\left(K+X^{\pi}(t)\right)\right)-\sigma_{A} \sigma_{\theta(u)} \rho_{A E}+\sigma_{\theta(t)} \lambda \rho_{M}\right] d u \\
& +\int_{0}^{t} \sigma_{\theta(t)} d W_{E}^{\mathbb{P}}+\int_{0}^{t}\left[\left(\mu_{R}-\sigma_{A} \rho_{R A} \sigma_{R}+\lambda \rho_{S M} \sigma_{R}\right) d u+\sigma_{R} d W_{R}^{\mathbb{P}}(u)\right]-L^{\pi}(t) \\
& -\int_{0}^{t}\left[X^{\pi}(u)+K\right]\left[\left(\mu_{A}-\sigma_{A}^{2}+\lambda \sigma_{A} \rho_{A M}\right) d u+\sigma_{A} d W_{A}^{\mathbb{P}}(u)\right],
\end{aligned}
$$

where the correlations are defined as $\rho_{M}=\operatorname{Corr}\left[\frac{N I_{t}}{A_{t}}, \frac{\Delta M_{t}}{M_{t}}\right], \rho_{A M}=\operatorname{Corr}\left[\frac{\Delta A_{t}}{A_{t}}, \frac{\Delta M_{t}}{M_{t}}\right]$, $\rho_{S M}=\operatorname{Corr}\left[\frac{S_{t}}{A_{t}}, \frac{\Delta M_{t}}{M_{t}}\right]$, and the market price of risk from $\lambda=\frac{E\left[\frac{\Delta M}{M}\right]-r}{\sqrt{\operatorname{Var}\left[\frac{\Delta M}{M}\right] / \Delta t}}$.

\subsubsection{Optimal Trading Strategy}

\section{Unconstrained optimal trading strategy}

Let $\hat{\theta}(x)$ denote an unconstrained optimal trading strategy obtained from $3.17 \mathrm{~b}$ by the first order condition i.e.

$$
\hat{\theta}(x)=-\frac{\zeta \sigma_{B} \rho_{B T}}{(1-\zeta) \sigma_{T}}-\frac{\alpha_{T}}{(1-\zeta) \sigma_{T}^{2}\left(1+\left(\sigma_{R} \rho_{R E}-x \rho_{A E} \sigma_{A}\right) \sigma_{\hat{\theta}(x)}^{-1}\right)} \frac{\partial V^{\zeta}(x)}{\partial x} / \frac{\partial^{2} V^{\zeta}(x)}{\partial x^{2}} .
$$

If $\alpha_{T}=0$ then $\hat{\theta}(x)=-\frac{\zeta \sigma_{B} \rho_{B T}}{(1-\zeta) \sigma_{T}}$ and $\theta^{*}(x)=\max \left\{0, \min \left(-\frac{\zeta \sigma_{B} \rho_{B T}}{(1-\zeta) \sigma_{T}}, 1\right)\right\}$. Now assume $\alpha_{T} \neq 0$.

Rearranging (3.26) we get

$$
V^{\prime \prime}(x)=k_{2}(x ; \hat{\theta}(x)) V^{\prime}(x)
$$

where $k_{2}(x ; \theta(x))=-\frac{\alpha_{T}}{(1-\zeta) \sigma_{T}^{2} B(x ; \theta(x)) \theta(x)+\zeta \sigma_{B} \rho_{B T} \sigma_{T} B(x ; \theta(x))}$ and $B(x ; \theta(x))=1+\left(\sigma_{R} \rho_{R E}-\right.$ $\left.x \rho_{A E} \sigma_{A}\right) \sigma_{\theta(x)}^{-1}$.

Inserting (3.27) into 3.17b and then differentiating w.r.t. $x$. we come to

$$
\begin{aligned}
\lambda V^{\prime}(x)= & \left((1-\zeta)^{2} \hat{\theta}(x) \sigma_{T}^{2} \hat{\theta}^{\prime}(x)+\zeta \sigma_{B} \rho_{B T}(1-\zeta) \sigma_{T} \hat{\theta}^{\prime}(x)\right) k_{2}(x) V^{\prime}(x) \\
& -\frac{1}{2} \sigma_{\theta}^{2}(1-\zeta) \sigma_{T}^{2} \hat{\theta}^{\prime}(x) k_{2}(x) V^{\prime}(x)+(1-\zeta) \alpha_{T} \hat{\theta}^{\prime}(x) V^{\prime}(x) \\
& +\frac{1}{2} \sigma_{\theta}^{2} k_{2}(x) V^{\prime \prime}(x)+\left(r+\zeta \alpha_{B}+(1-\zeta) \hat{\theta}^{\prime}(x) \alpha_{T}\right) V^{\prime \prime}(x)
\end{aligned}
$$


Replacing $V^{\prime \prime}$ by 3.27 into the above equation and solving for $\hat{\theta}^{\prime}(x)$ we get $\theta^{\prime}(x)=\frac{\mu_{A}+\lambda-\left(\sigma_{A}^{2} x-\sigma_{A}\left(\sigma_{R} \rho_{R A}+\sigma_{\theta} \rho_{A E}\right)+\mu_{\theta}+\mu_{R}-x \mu_{A}\right) k_{2}(x)-Q(x)\left(\frac{K_{2}(x)}{\alpha_{T}}+1\right)}{\frac{d \sigma_{\theta}}{d \theta}\left(\sigma_{\theta}+\sigma_{R} \rho_{R E}-x \sigma_{A} \rho_{A E}\right) k_{2}(x)+\frac{Q(x) K_{1}(x)}{\alpha_{T}}+(1-\zeta) \alpha_{T}}$

where

$$
\begin{aligned}
Q(x) & =\frac{1}{2}\left(\sigma_{\theta}^{2}+\sigma_{R}^{2}+2 \sigma_{\theta} \sigma_{R} \rho_{R E}+x^{2} \sigma_{A}^{2}-2 x \sigma_{A}\left(\sigma_{R} \rho_{R A}+\sigma_{\theta} \rho_{A E}\right)\right) k_{2}^{2}(x), \\
K_{1}(x) & =\left((1-\zeta) \sigma_{T}^{2} \theta(x)+\zeta \sigma_{B} \rho_{B T} \sigma_{T}\right) B_{2}(x)+(1-\zeta) \sigma_{T}^{2} B(x) \\
K_{2}(x) & =B_{1}(x)\left((1-\zeta) \sigma_{T}^{2} \theta(x)+\zeta \sigma_{B} \rho_{B T} \sigma_{T}\right), \\
B_{1}(x) & =-\rho_{A E} \sigma_{A} \sigma_{\theta}^{-1} \\
B_{2}(x) & =-\left(\sigma_{R} \rho_{R E}-x \rho_{A E} \sigma_{A}\right) \sigma_{\theta}^{-2} \frac{d \sigma_{\theta}}{d \theta} \\
\frac{d \sigma_{\theta}}{d \theta} & =\sigma_{\theta}^{-1}\left((1-\zeta)^{2} \sigma_{T}^{2} \theta(x)+\zeta(1-\zeta) \sigma_{B} \sigma_{T} \rho_{B T}\right) .
\end{aligned}
$$

Initial unconstrained optimal trading weight $\hat{\theta}(0)$

$\hat{\theta}(0)$ solves the following system of equations:

$$
\left\{\begin{array}{l}
0=\frac{1}{2}\left[\sigma_{\hat{\theta}(0)}^{2}+\sigma_{R}^{2}+2 \sigma_{\hat{\theta}(0)} \sigma_{R} \rho_{R E}\right] V^{\prime \prime}(0)+\left[\mu_{\hat{\theta}(0)}+\mu_{R}\right] V^{\prime}(0), \\
\hat{\theta}(0)=-\frac{\zeta \sigma_{B} \rho_{B T}}{(1-\zeta) \sigma_{T}}-\frac{\alpha_{T}}{(1-\zeta) \sigma_{T}^{2}\left(1+\sigma_{R} \rho_{R E} \sigma_{\hat{\theta}(0)}^{-1}\right)} \frac{V^{\prime}(0)}{V^{\prime \prime}(0)}
\end{array}\right.
$$

The first equation is from (3.17a) and 3.17b), and the second equation is 3.26 at $x=0$.

The second equation is equivalent to:

$$
V^{\prime}(0)=-\frac{(1-\zeta) \sigma_{T}^{2}\left(1+\sigma_{R} \rho_{R E} \sigma_{\hat{\theta}(0)}^{-1}\right) \hat{\theta}(0)+\zeta \sigma_{B} \sigma_{T} \rho_{B T}\left(1+\sigma_{R} \rho_{R E} \sigma_{\hat{\theta}(0)}^{-1}\right)}{\alpha_{T}} V^{\prime \prime}(0),
$$

if $\alpha_{T} \neq 0$. Substituting 3.29 into the first equation in the system and letting 


$$
\begin{aligned}
& \hat{\theta}_{0}=\hat{\theta}(0), \text { we get } \\
& 0=\frac{1}{2}\left[\sigma_{\hat{\theta}_{0}}^{2}+\sigma_{R}^{2}+2 \sigma_{\hat{\theta}_{0}} \sigma_{R} \rho_{R E}\right]-\left[\mu_{\hat{\theta}_{0}}+\mu_{R}\right]\left(1+\sigma_{R} \rho_{R E} \sigma_{\hat{\theta}_{0}}^{-1}\right)\left(\frac{(1-\zeta) \sigma_{T}^{2} \hat{\theta}_{0}+\zeta \sigma_{B} \sigma_{T} \rho_{B T}}{\alpha_{T}}\right),
\end{aligned}
$$

which can be solved for an implied solution $\hat{\theta}_{0}$.

\section{Constrained Optimal Trading strategy $\theta^{*}(x)$}

By (3.28), we get

$$
\hat{\theta}(x)=\hat{\theta}_{0}+\int_{0}^{x} g(y) d y
$$

where

$g(y)=\frac{\mu_{A}+\lambda-\left(\sigma_{A}^{2} y-\sigma_{A}\left(\sigma_{R} \rho_{R A}+\sigma_{\theta} \rho_{A E}\right)+\mu_{\theta}+\mu_{R}-y \mu_{A}\right) k_{2}(y)-Q(y)\left(\frac{K_{2}(y)}{\alpha_{T}}+1\right)}{\frac{d \sigma_{\theta}}{d \theta}\left(\sigma_{\theta}+\sigma_{R} \rho_{R E}-y \sigma_{A} \rho_{A E}\right) k_{2}(y)+\frac{Q(y) K_{1}(y)}{\alpha_{T}}+(1-\zeta) \alpha_{T}}$.

Therefore, constrained optimal trading strategy $\theta^{*}(x)=\max \{0, \min (\hat{\theta}(x), 1)\}$, where

$$
\hat{\theta}(x)= \begin{cases}\hat{\theta}_{0}+\int_{0}^{x} g(y) d y & \text { if } \alpha_{T} \neq 0, \\ -\frac{\zeta \sigma_{B} \rho_{B T}}{(1-\zeta) \sigma_{T}} & \text { if } \alpha_{T}=0,\end{cases}
$$

which can be solved numerically. 


\subsubsection{Model Parameters}

Table 3.1: Sample Banks and Their Model Parameters over 2000 Q1 - 2011 Q4 .

\begin{tabular}{|c|c|c|c|c|c|c|c|}
\hline Bank (Ticker) & Assets, $\mathrm{m} \$$ & $B C, \%$ & $V_{d}, \%$ & $\zeta_{d}, \%$ & $\zeta, \%$ & $u, \%$ & $\delta, \%$ \\
\hline $\begin{array}{l}\text { ALLIANCE BANKSHARES } \\
\text { (ABVA) }\end{array}$ & $\begin{array}{r}411 \\
(503)\end{array}$ & 0.89 & 2.62 & 86.16 & $\mathrm{~N} / \mathrm{A}$ & 0.00 & $\mathrm{~N} / \mathrm{A}$ \\
\hline $\begin{array}{l}\text { BANK OF AMERICA } \\
(\mathrm{BAC})\end{array}$ & $\begin{array}{r}1,211,812 \\
(1,085,799)\end{array}$ & 4.46 & 5.92 & 84.10 & 100.00 & 2.58 & 31.86 \\
\hline $\begin{array}{l}\text { COMMERCE BANCSHARES } \\
(\mathrm{CBSH})\end{array}$ & $\begin{array}{r}14,438 \\
(4,050)\end{array}$ & 3.96 & 17.12 & 98.93 & 75.00 & 2.45 & 4.69 \\
\hline $\begin{array}{l}\text { FIRST HORIZON } \\
(\text { FHN })\end{array}$ & $\begin{array}{r}29,147 \\
(14,441)\end{array}$ & 3.89 & 7.50 & 97.59 & 100.00 & 3.12 & 16.78 \\
\hline $\begin{array}{l}\text { HEARTLAND FINANCIAL } \\
\text { (HTLF) }\end{array}$ & $\begin{array}{r}2,549 \\
(1,623)\end{array}$ & 2.12 & 8.05 & 99.94 & 100.00 & 2.49 & 12.62 \\
\hline $\begin{array}{l}\text { JPMORGAN CHASE } \\
(\text { JPM) }\end{array}$ & $\begin{array}{r}1,190,280 \\
(1,029,168)\end{array}$ & 2.05 & 7.16 & 75.11 & $\mathrm{~N} / \mathrm{A}$ & 0.00 & $\mathrm{~N} / \mathrm{A}$ \\
\hline $\begin{array}{l}\text { M \& T BANK } \\
\text { (MTB) }\end{array}$ & $\begin{array}{r}49,755 \\
(28,978)\end{array}$ & 4.82 & 10.98 & 99.70 & 75.00 & 2.20 & 20.60 \\
\hline $\begin{array}{l}\text { STATE STREET } \\
(\mathrm{STT})\end{array}$ & $\begin{array}{r}108,343 \\
(84,771)\end{array}$ & 2.36 & 13.87 & 96.42 & $\mathrm{~N} / \mathrm{A}$ & 0.00 & $\mathrm{~N} / \mathrm{A}$ \\
\hline $\begin{array}{l}\text { SUNTRUST BANKS } \\
(\mathrm{STI})\end{array}$ & $\begin{array}{r}147,425 \\
(66,854)\end{array}$ & 6.09 & 6.45 & 97.25 & 100.00 & 0.96 & 99.99 \\
\hline $\begin{array}{l}\text { TOMPKINS FINANCIAL } \\
(\mathrm{TMP})\end{array}$ & $\begin{array}{r}2,046 \\
(1,069)\end{array}$ & 2.17 & 15.73 & 98.05 & 100.00 & 2.59 & 11.68 \\
\hline $\begin{array}{l}\text { WELLS FARGO } \\
\text { (WFC) }\end{array}$ & $\begin{array}{r}525,876 \\
(613,018)\end{array}$ & 2.74 & 11.59 & 98.50 & 100.00 & 2.69 & 20.95 \\
\hline $\begin{array}{l}\text { WINTRUST FINANCIAL } \\
\text { (WTFC) }\end{array}$ & $\begin{array}{r}6,688 \\
(6,628)\end{array}$ & 3.29 & 5.45 & 99.96 & 100.00 & 2.09 & 11.97 \\
\hline
\end{tabular}

The sample of twelve U.S. commercial banks over period 2000 Q1 - 2011 Q4. The in-sample period is 2000 Q1 2009 Q4, and the out-of-sample period is 2010 Q1 - 2011 Q4. Assets column is the average total asset size during the whole sample period in terms of million USD. $B C$ denotes the mean buffer capital ratio using the data from 2008 $\mathrm{Q} 1$ - $2009 \mathrm{Q} 4$. The following items were calculated using the in-sample data only. $V_{d}$ is the time-series average of market capitalization divided by total assets (subscript $d$ is for data, distincting from the model estimated value). $\zeta_{d}$ is the time-series average of banking assets divided by total assets. $u$ denotes the model estimated dividend barrier. $\delta$ is computed as an implied value that matches the realized market equity value with the model equity value at the mean buffer capital ratio given in the column $B C$, which is computed with only the statistically significant alphas and correlations (the non-significant alphas and correlations are set to zero). 
Table 3.2: More Model Parameters.

\begin{tabular}{|c|c|c|c|c|c|c|c|c|c|c|c|c|c|c|}
\hline Bank (Ticker) & $\sigma_{B}, \%$ & $\sigma_{T}, \%$ & $\rho_{B T}$ & $\alpha_{B}, \%$ & $\beta_{B}, \%$ & $\alpha_{T}, \%$ & $\beta_{T}, \%$ & $\mu_{A}, \%$ & $\sigma_{A}, \%$ & $\rho_{A E}$ & $\mu_{R}, \%$ & $\sigma_{R}, \%$ & $\rho_{R A}$ & $\rho_{R E}$ \\
\hline $\begin{array}{l}\text { ALLIANCE BANKSHARES } \\
\text { (ABVA) }\end{array}$ & 0.64 & 2.21 & $\begin{array}{r}-0.35 \\
(0.27)\end{array}$ & $\begin{array}{r}-0.99^{* *} \\
(0.38)\end{array}$ & $\begin{array}{r}0.76 \\
(0.89)\end{array}$ & & $\begin{array}{r}0.04 \\
(3.02)\end{array}$ & -3.35 & 10.43 & $\begin{array}{r}0.30 \\
(0.27)\end{array}$ & -0.30 & 0.41 & $\begin{array}{r}0.49 \\
(0.23)\end{array}$ & $\begin{array}{r}-0.48 \\
(0.23)\end{array}$ \\
\hline $\begin{array}{l}\text { BANK OF AMERICA } \\
(\text { BAC) }\end{array}$ & 0.50 & 0.90 & $\begin{array}{r}-0.15 \\
(0.16)\end{array}$ & $\begin{array}{r}0.80^{* *} \\
(0.15)\end{array}$ & $\begin{array}{r}-0.24 \\
(0.47)\end{array}$ & $\begin{array}{r}-1.36^{* *} \\
(0.32)\end{array}$ & $\begin{array}{r}0.02 \\
(0.71)\end{array}$ & 12.57 & 11.07 & $\begin{array}{r}0.03 \\
(0.16)\end{array}$ & 1.05 & 1.85 & $\begin{array}{r}0.60^{* *} \\
(0.10)\end{array}$ & $\begin{array}{l}-0.19 \\
(0.15)\end{array}$ \\
\hline $\begin{array}{l}\text { COMMERCE BANCSHARES } \\
(\mathrm{CBSH})\end{array}$ & 1.08 & 7.45 & $\begin{array}{r}0.00 \\
(0.16)\end{array}$ & $\begin{array}{r}0.28 \\
(0.34)\end{array}$ & $\begin{array}{r}-0.81 \\
(1.00)\end{array}$ & $\begin{array}{r}-6.88^{*} \\
(2.60)\end{array}$ & $\begin{array}{r}0.05 \\
(6.98)\end{array}$ & 5.13 & 5.13 & $\begin{array}{r}-0.01 \\
(0.16)\end{array}$ & 0.56 & 0.90 & $\begin{array}{r}0.21 \\
(0.15)\end{array}$ & $\begin{array}{r}-0.84^{* *} \\
(0.05)\end{array}$ \\
\hline $\begin{array}{l}\text { FIRST HORIZON } \\
(\text { FHN })\end{array}$ & 0.66 & 6.42 & $\begin{array}{r}-0.23 \\
(0.15)\end{array}$ & $\begin{array}{r}-0.31 \\
(0.21)\end{array}$ & $\begin{array}{r}0.14 \\
(0.62)\end{array}$ & $\begin{array}{r}18.83^{* *} \\
(2.24)\end{array}$ & $\begin{array}{r}0.01 \\
(6.02)\end{array}$ & 2.78 & 12.13 & $\begin{array}{r}0.49^{* *} \\
(0.12)\end{array}$ & 0.57 & 1.16 & $\begin{array}{r}-0.22 \\
(0.15)\end{array}$ & $\begin{array}{r}-0.55^{* *} \\
(0.11)\end{array}$ \\
\hline $\begin{array}{l}\text { HEARTLAND FINANCIAL } \\
\text { (HTLF) }\end{array}$ & 0.39 & 23.36 & $\begin{array}{r}-0.02 \\
(0.17)\end{array}$ & $\begin{array}{r}0.59^{* *} \\
(0.13)\end{array}$ & $\begin{array}{r}0.13 \\
(0.38)\end{array}$ & $\begin{array}{r}-21.88^{* *} \\
(4.86)\end{array}$ & $\begin{array}{l}1.03^{* *} \\
(13.54)\end{array}$ & 11.27 & 5.91 & $\begin{array}{r}-0.29 \\
(0.16)\end{array}$ & 0.45 & 0.89 & $\begin{array}{l}0.41^{*} \\
(0.14)\end{array}$ & $\begin{array}{r}-0.46^{* *} \\
(0.14)\end{array}$ \\
\hline $\begin{array}{l}\text { JPMORGAN CHASE } \\
(\text { JPM) }\end{array}$ & 0.92 & 0.75 & $\begin{array}{r}0.12 \\
(0.16)\end{array}$ & $\begin{array}{r}0.53 \\
(0.29)\end{array}$ & $\begin{array}{r}-0.91 \\
(0.85)\end{array}$ & $\begin{array}{r}-1.21^{* *} \\
(0.21)\end{array}$ & $\begin{array}{r}0.01 \\
(0.71)\end{array}$ & 17.07 & 16.31 & $\begin{array}{r}0.65^{* *} \\
(0.09)\end{array}$ & 0.96 & 1.75 & $\begin{array}{r}0.46^{* *} \\
(0.13)\end{array}$ & $\begin{array}{r}0.01 \\
(0.16)\end{array}$ \\
\hline $\begin{array}{l}\text { M \& T BANK } \\
\text { (MTB) }\end{array}$ & 0.32 & 1.96 & $\begin{array}{r}-0.02 \\
(0.16)\end{array}$ & $\begin{array}{r}0.89^{* *} \\
(0.09)\end{array}$ & $\begin{array}{r}0.52 \\
(0.31)\end{array}$ & $\begin{array}{r}2.33^{* *} \\
(0.56)\end{array}$ & $\begin{array}{l}0.06^{*} \\
(1.21)\end{array}$ & 11.43 & 12.69 & $\begin{array}{r}-0.01 \\
(0.16)\end{array}$ & 0.78 & 1.59 & $\begin{array}{r}0.91^{* *} \\
(0.03)\end{array}$ & $\begin{array}{r}-0.20^{*} \\
(0.15)\end{array}$ \\
\hline $\begin{array}{l}\text { STATE STREET } \\
\text { (STT) }\end{array}$ & 1.06 & 3.40 & $\begin{array}{r}-0.17 \\
(0.20)\end{array}$ & $\begin{array}{r}-0.33 \\
(0.44)\end{array}$ & $\begin{array}{r}1.23 \\
(1.41)\end{array}$ & $\begin{array}{r}4.12^{* *} \\
(1.58)\end{array}$ & $\begin{array}{r}0.03 \\
(2.88)\end{array}$ & 23.54 & 36.30 & $\begin{array}{r}0.03 \\
(0.20)\end{array}$ & 0.96 & 1.30 & $\begin{array}{r}-0.11 \\
(0.20)\end{array}$ & $\begin{array}{r}-0.18 \\
(0.20)\end{array}$ \\
\hline $\begin{array}{l}\text { SUNTRUST BANKS } \\
\text { (STI) }\end{array}$ & 0.74 & 4.29 & $\begin{array}{r}-0.24 \\
(0.15)\end{array}$ & $\begin{array}{r}0.66^{* *} \\
(0.23)\end{array}$ & $\begin{array}{r}-0.20 \\
(0.69)\end{array}$ & $\begin{array}{r}-8.06^{* *} \\
(1.59)\end{array}$ & $\begin{array}{r}0.06 \\
(3.97)\end{array}$ & 5.52 & 7.39 & $\begin{array}{r}0.23 \\
(0.15)\end{array}$ & 0.86 & 1.52 & $\begin{array}{r}0.64^{* *} \\
(0.09)\end{array}$ & $\begin{array}{r}-0.33^{*} \\
(0.14)\end{array}$ \\
\hline $\begin{array}{l}\text { TOMPKINS FINANCIAL } \\
\text { (TMP) }\end{array}$ & 0.45 & 1.43 & $\begin{array}{l}0.74^{*} \\
(0.13)\end{array}$ & $\begin{array}{l}1.14^{*} \\
(0.29)\end{array}$ & $\begin{array}{r}-0.23 \\
(0.65)\end{array}$ & $\begin{array}{l}-1.36 \\
(1.17)\end{array}$ & $\begin{array}{r}-0.01 \\
(2.01)\end{array}$ & 12.01 & 6.12 & $\begin{array}{r}-0.32 \\
(0.27)\end{array}$ & -0.03 & 0.18 & $\begin{array}{r}0.47 \\
(0.23)\end{array}$ & $\begin{array}{r}0.05 \\
(0.30)\end{array}$ \\
\hline $\begin{array}{l}\text { WELLS FARGO } \\
\text { (WFC) }\end{array}$ & 0.84 & 2.66 & $\begin{array}{l}0.78^{*} \\
(0.08)\end{array}$ & $\begin{array}{r}0.83^{* *} \\
(0.28)\end{array}$ & $\begin{array}{l}2.99^{*} \\
(0.38)\end{array}$ & $\begin{array}{r}0.23 \\
(0.94)\end{array}$ & $\begin{array}{r}0.07 \\
(2.25)\end{array}$ & 18.35 & 18.97 & $\begin{array}{r}-0.88^{*} \\
(0.05)\end{array}$ & 1.06 & 2.06 & $\begin{array}{r}0.91 \\
(0.03)\end{array}$ & $\begin{array}{r}-0.82 \\
(0.07)\end{array}$ \\
\hline $\begin{array}{l}\text { WINTRUST FINANCIAL } \\
\text { (WTFC) }\end{array}$ & 0.35 & 136.94 & $\begin{array}{r}-0.53^{*} \\
(0.17)\end{array}$ & $\begin{array}{r}0.36^{* *} \\
(0.16)\end{array}$ & $\begin{array}{r}0.56 \\
(0.52)\end{array}$ & $\begin{array}{r}67.58 \\
(65.49)\end{array}$ & $\begin{array}{r}-0.29 \\
(213.53)\end{array}$ & 11.94 & 6.82 & $\begin{array}{r}-0.10 \\
(0.23)\end{array}$ & 0.50 & 0.77 & $\begin{array}{r}0.70^{\text {** }} \\
(0.12)\end{array}$ & $\begin{array}{l}-0.37 \\
(0.20)\end{array}$ \\
\hline
\end{tabular}

All items in Table 3.2 were calculated using the in-sample data only. Each bank's estimated $\sigma_{B}, \sigma_{T}, \sigma_{A}$, and $\sigma_{R}$ are the time-series annualized standard deviation of returns from banking, trading, assets and recapitalization, respectively. $\rho_{B T}, \rho_{A E}, \rho_{R A}$ and $\rho_{R E}$ are the correlations, each between the banking and trading returns, between asset and banking/trading returns, between recapitalization and asset returns, and between banking/trading and recapitalization returns. One asterisk $(*)$ indicates the significance level of $5 \%$, and two (**) indicates 1\%. Each bank's $\alpha_{B}\left(\alpha_{T}\right)$ and $\beta_{B}\left(\beta_{T}\right)$ are the bank's banking (trading) alpha (excess return) and banking (trading) beta coefficient. Standard deviations or errors of the estimates are in the parentheses. 


\subsubsection{Model Value}

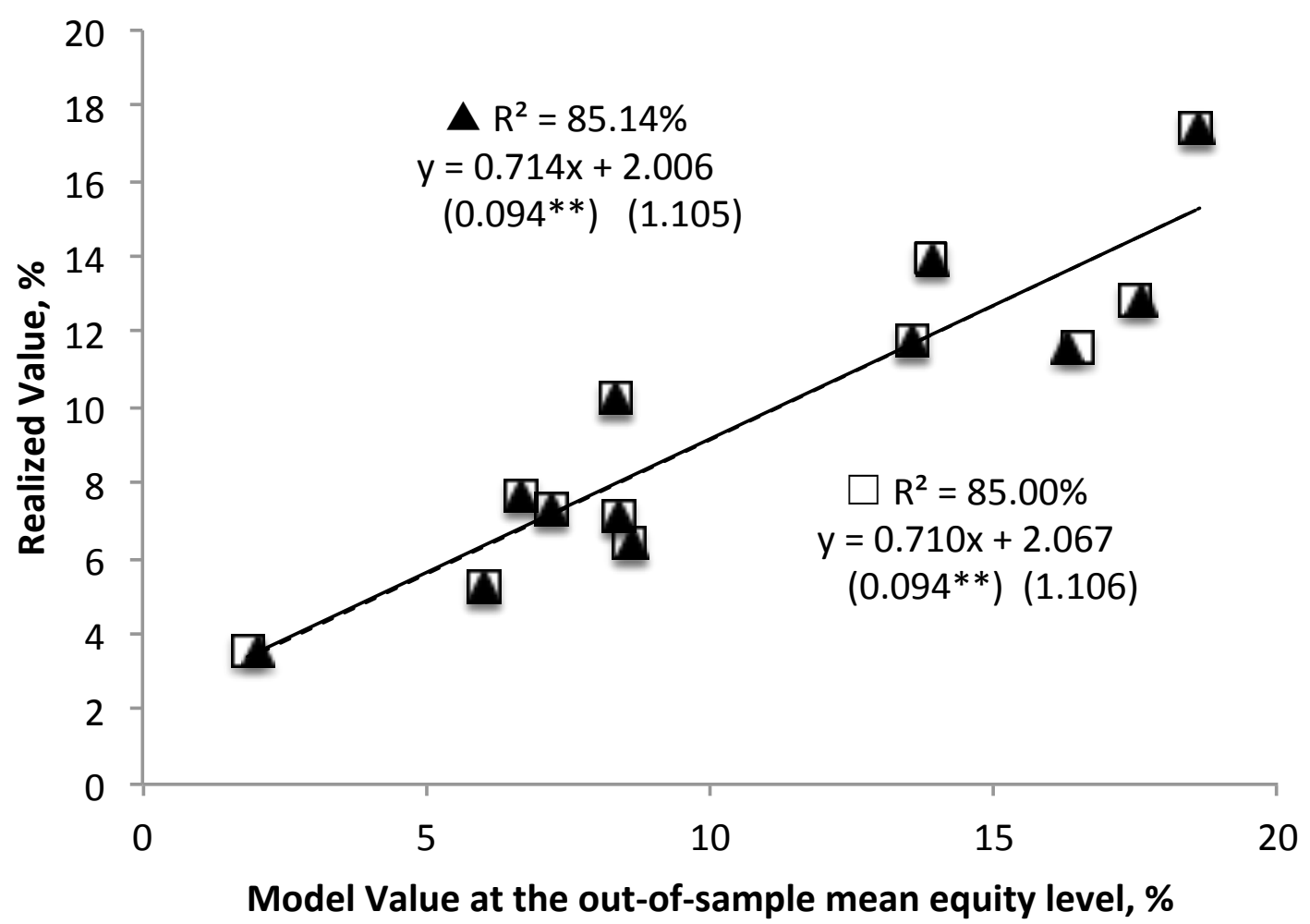

Figure 3.1: Actual vs. model values of banks at the mean out-of-sample equity level. This figure shows realized market equity level during the out-of-sample period 2010 Q1 - 2011 Q4 plotted against the model value function evaluated at the mean out-of-sample equity level. The filled triangles are with the banking and trading alphas and correlations equal to their estimated values while the empty squares are with the statistically significant banking and trading alphas and correlations $\rho_{B T}, \rho_{R E}, \rho_{R A}$ and $\rho_{A E}$ (the non-significant alphas and correlations are zero). Linear regression lines are drawn in the figure. The numbers in the parentheses are the standard deviations of the parameters. One asterisk $\left({ }^{*}\right)$ indicates the significance level of $5 \%$, and two $\left({ }^{* *}\right)$ indicates $1 \%$. 
Table 3.3: Effects of trading. (i) Base case is with the estimated parameters; (ii) is the case with trading alpha $\alpha_{T}=0$; case $(i i i)$ is with $\rho_{B T}=0$, i.e., zero correlation between the banking and trading earnings; case (iv) is with zero $\rho_{B T}$ and $\alpha_{T} . V$ is the model bank equity value in terms of the risk weighted assets. $\Delta V / V$ is the value change relative to the base case value. $\alpha_{B}$ is a (new) banking alpha that gives the same bank equity value as in the base case. $\Delta \alpha_{B}$ is the difference between the base case $\alpha_{B}$ and the new $\alpha_{B}$. DP denotes the default probability during the next 100 years (by Monte Carlo simulation with 10,000 paths and time discretization $\Delta t=1 / 365$ a year). $E(\Delta X)$ and $\operatorname{Std}(\Delta X)$ are the annualized average and standard deviation of $\Delta X$, respectively. $u$ denotes the model estimated dividend barrier.

\begin{tabular}{|c|c|c|c|c|c|c|c|c|c|}
\hline Bank & Cases & $V, \%$ & $\Delta V / V, \%$ & $D P, \%$ & $E(\Delta X), \%$ & $\operatorname{Std}(\Delta X), \%$ & $\alpha_{B}, \%$ & $\Delta \alpha_{B}, \%$ & $u, \%$ \\
\hline \multirow[t]{4}{*}{$\mathrm{BAC}$} & (i) Base case & 5.92 & & 100.00 & -0.68 & 1.67 & 0.80 & & 2.58 \\
\hline & (ii) $\alpha_{T}=0$ & 5.92 & 0.00 & 100.00 & -0.68 & 1.67 & 0.80 & 0.00 & 2.58 \\
\hline & (iii) $\rho_{B T}=0$ & 5.92 & 0.00 & 100.00 & -0.68 & 1.67 & 0.80 & 0.00 & 2.58 \\
\hline & $(i v) \alpha_{T}, \rho_{B T}=0$ & 5.92 & 0.00 & 100.00 & -0.68 & 1.67 & 0.80 & 0.00 & 2.58 \\
\hline \multirow[t]{4}{*}{$\mathrm{CBSH}$} & (i) Base case & 17.12 & & 14.86 & -0.02 & 0.69 & 0.28 & & 2.45 \\
\hline & (ii) $\alpha_{T}=0$ & 17.12 & 0.00 & 14.86 & -0.02 & 0.69 & 0.28 & 0.00 & 2.45 \\
\hline & $(i i i) \rho_{B T}=0$ & 17.12 & 0.00 & 14.86 & -0.02 & 0.69 & 0.28 & 0.00 & 2.45 \\
\hline & (iv) $\alpha_{T}, \rho_{B T}=0$ & 17.12 & 0.00 & 14.86 & -0.02 & 0.69 & 0.28 & 0.00 & 2.45 \\
\hline \multirow[t]{4}{*}{ FHN } & (i) Base case & 7.50 & & 84.67 & -0.08 & 1.09 & -0.31 & & 3.12 \\
\hline & (ii) $\alpha_{T}=0$ & 4.92 & -34.36 & 100.00 & -0.79 & 1.36 & 0.16 & 0.47 & 1.89 \\
\hline & (iii) $\rho_{B T}=0$ & 7.50 & 0.00 & 84.67 & -0.08 & 1.09 & -0.31 & 0.00 & 3.12 \\
\hline & $(i v) \alpha_{T}, \rho_{B T}=0$ & 4.92 & -34.36 & 100.00 & -0.79 & 1.36 & 0.16 & 0.47 & 1.89 \\
\hline \multirow[t]{4}{*}{ HTLF } & (i) Base case & 8.06 & & 68.76 & -0.03 & 0.69 & 0.59 & & 2.49 \\
\hline & (ii) $\alpha_{T}=0$ & 8.06 & 0.00 & 68.76 & -0.03 & 0.69 & 0.59 & 0.00 & 2.49 \\
\hline & (iii) $\rho_{B T}=0$ & 8.06 & 0.00 & 68.76 & -0.03 & 0.69 & 0.59 & 0.00 & 2.49 \\
\hline & $(i v) \alpha_{T}, \rho_{B T}=0$ & 8.06 & 0.00 & 68.76 & -0.03 & 0.69 & 0.59 & 0.00 & 2.49 \\
\hline \multirow[t]{4}{*}{ MTB } & (i) Base case & 10.99 & & 77.62 & -0.08 & 0.92 & 0.89 & & 2.20 \\
\hline & (ii) $\alpha_{T}=0$ & 10.92 & -0.62 & 78.15 & -0.08 & 0.92 & 0.89 & 0.01 & 2.21 \\
\hline & (iii) $\rho_{B T}=0$ & 10.99 & 0.00 & 77.62 & -0.08 & 0.92 & 0.89 & 0.00 & 2.20 \\
\hline & $(i v) \alpha_{T}, \rho_{B T}=0$ & 10.92 & -0.62 & 78.15 & -0.08 & 0.92 & 0.89 & 0.01 & 2.21 \\
\hline \multirow[t]{4}{*}{ STI } & (i) Base case & 6.45 & & 100.00 & -4.05 & 4.31 & 0.66 & & 0.96 \\
\hline & (ii) $\alpha_{T}=0$ & 6.45 & 0.00 & 100.00 & -4.05 & 4.31 & 0.66 & 0.00 & 0.96 \\
\hline & (iii) $\rho_{B T}=0$ & 6.45 & 0.00 & 100.00 & -4.05 & 4.31 & 0.66 & 0.00 & 0.96 \\
\hline & $(i v) \alpha_{T}, \rho_{B T}=0$ & 6.45 & 0.00 & 100.00 & -4.05 & 4.31 & 0.66 & 0.00 & 0.96 \\
\hline \multirow[t]{4}{*}{ TMP } & (i) Base case & 15.76 & & 30.67 & -0.01 & 0.65 & 1.14 & & 2.59 \\
\hline & $(i i) \alpha_{T}=0$ & 15.76 & 0.00 & 30.67 & -0.01 & 0.65 & 1.14 & 0.00 & 2.59 \\
\hline & (iii) $\rho_{B T}=0$ & 15.76 & 0.00 & 30.67 & -0.01 & 0.65 & 1.14 & 0.00 & 2.59 \\
\hline & $(i v) \alpha_{T}, \rho_{B T}=0$ & 15.76 & 0.00 & 30.67 & -0.01 & 0.65 & 1.14 & 0.00 & 2.59 \\
\hline \multirow[t]{4}{*}{ WFC } & (i) Base case & 11.61 & & 70.38 & -0.04 & 0.95 & 0.83 & & 2.69 \\
\hline & $(i i) \alpha_{T}=0$ & 11.61 & 0.00 & 70.38 & -0.04 & 0.95 & 0.82 & 0.00 & 2.66 \\
\hline & (iii) $\rho_{B T}=0$ & 11.61 & 0.00 & 70.38 & -0.04 & 0.95 & 0.82 & -0.01 & 2.66 \\
\hline & $(i v) \alpha_{T}, \rho_{B T}=0$ & 11.61 & 0.00 & 70.38 & -0.04 & 0.95 & 0.82 & 0.00 & 2.66 \\
\hline \multirow[t]{4}{*}{ WTFC } & (i) Base case & 5.45 & & 97.55 & -0.11 & 0.66 & 0.36 & & 2.20 \\
\hline & $(i i) \alpha_{T}=0$ & 5.45 & 0.00 & 97.55 & -0.11 & 0.66 & 0.36 & 0.00 & 2.20 \\
\hline & (iii) $\rho_{B T}=0$ & 5.35 & -1.84 & 99.47 & -0.16 & 0.70 & 0.37 & 0.01 & 2.22 \\
\hline & $(i v) \alpha_{T}, \rho_{B T}=0$ & 5.35 & -1.84 & 99.47 & -0.16 & 0.70 & 0.37 & 0.01 & 2.22 \\
\hline
\end{tabular}




\subsubsection{Buffer Capital}

We illustrate how our model explains cross-sectional variation in the banks' buffer capital ratios (equity capital ratios above the minimum capital level) before the Volcker rule. Figure 3.2 represents the actual maximum capital buffer ratio against the model predicted capital level taken to be the dividend barrier $u$ in Table 3.1. This plot uses banks' maximum capital buffer ratios over 2000 Q1 - 2011 Q4 as the measure of the actual buffer ratios.

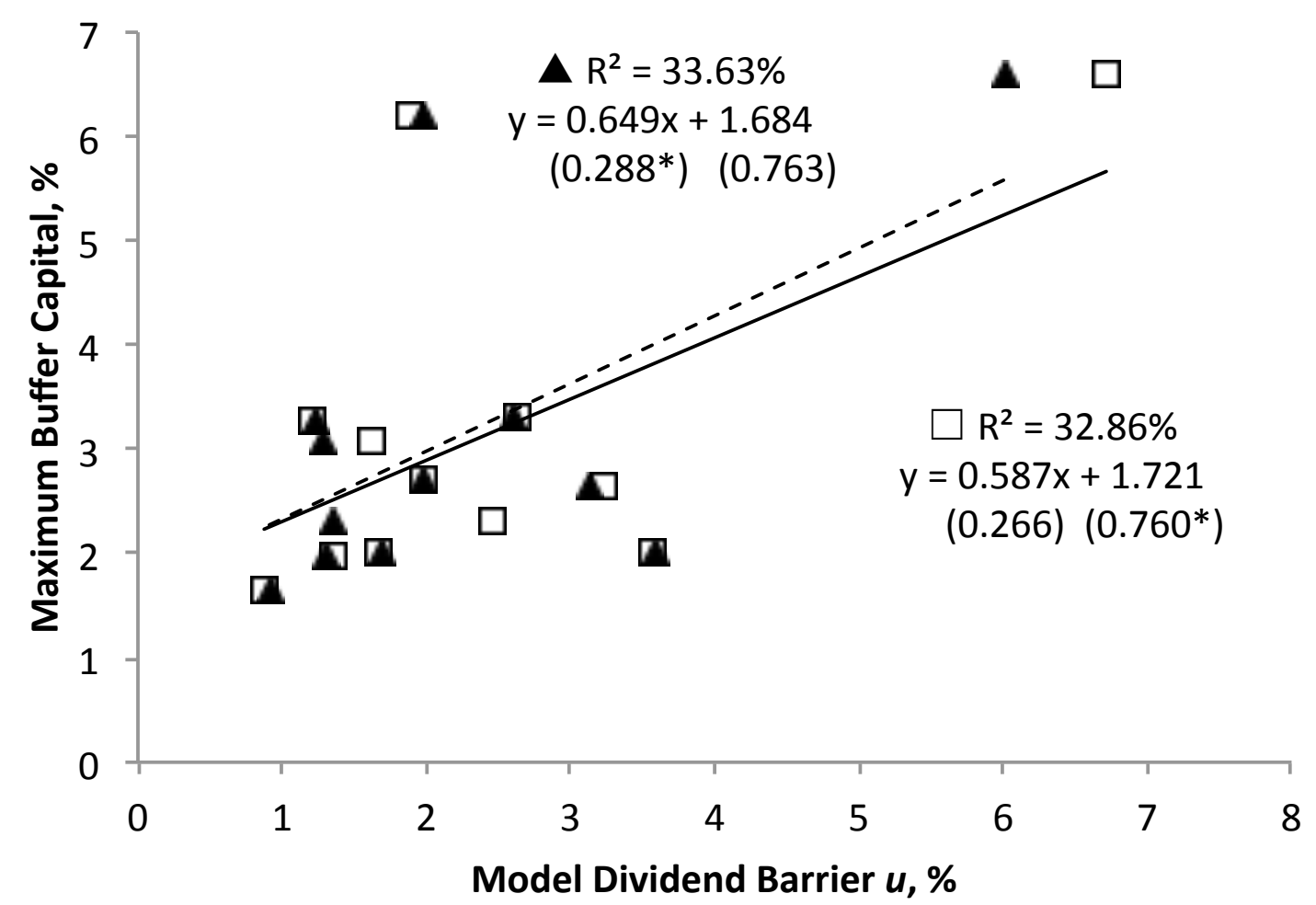

Figure 3.2: Actual vs. model buffer capital ratios for the sample banks. This figure shows maximum buffer capital ratios (during 2000 Q1 - 2011 Q4) plotted against the corresponding model dividend barriers. The filled triangles are with the banking and trading alphas and correlations equal to their estimated values while the empty squares are with the statistically significant banking and trading alphas and correlations $\rho_{B T}, \rho_{R E}, \rho_{R A}$ and $\rho_{A E}$ (the non-significant alphas and correlations are zero). Linear regression lines are drawn in the figure. The numbers in the parentheses are the standard deviations of the parameters. 


\subsubsection{Comparative Statics}

Figure 3.3: Comparative Statics. We use the following median parameter values over all the banks: $\zeta=95 \%, r=2 \%, \sigma_{B}=0.5 \%, \sigma_{T}=2 \%, \rho_{B T}=-0.1, \alpha_{B}=0.1 \%, \alpha_{T}=3 \%, \delta=18 \%$, $\mu_{A}=9 \%, \sigma_{A}=7 \%, \rho_{A E}=-0.01, \mu_{R}=0.5 \%, \sigma_{R}=1 \%, \rho_{R E}=-0.3, \rho_{R A}=0.4$ and $x=1 \%$. Figures below show how the value function $(3.13 d)$ and dividend barrier $u$ change with respect to banking proportion $\zeta$, banking volatility $\sigma_{B}$, trading volatility $\sigma_{T}$, correlation between the banking and trading earnings $\rho_{B T}$, banking alpha $\alpha_{B}$, trading alpha $\alpha_{T}$, risk-free rate $r$, and wedge between debt and equity finance $\delta$, mean asset growth rate $\mu_{A}$, asset volatility $\sigma_{A}$, correlation between net income earnings and assets growth return $\rho_{A E}$, correlation between assets growth return and net recapitalization earnings $\rho_{R A}$, mean net recapitalization rate $\mu_{R}$, net recapitalization volatility $\sigma_{R}$, and correlation between net income earnings and recapitalization earnings $\rho_{R E}$.

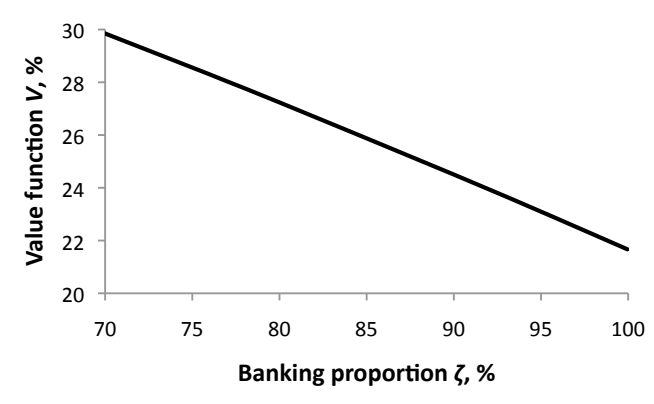

(3.4.1) Value function vs. banking proportion

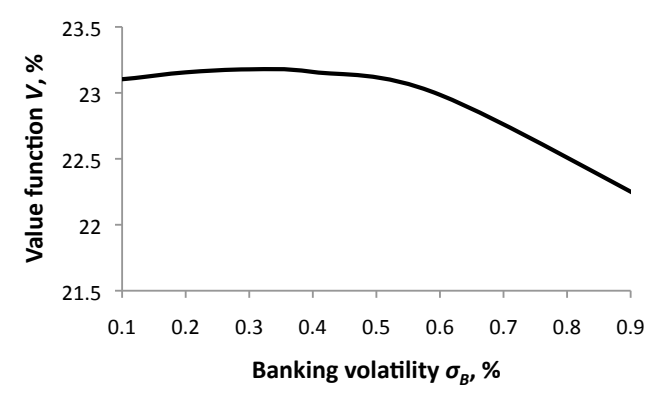

(3.4.3) Value function vs. banking volatility

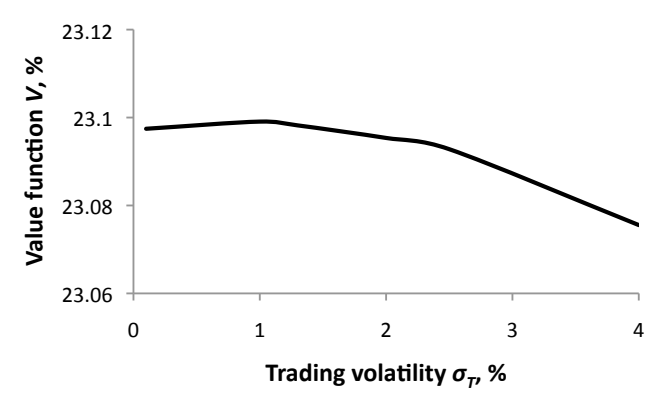

(3.4.5) Value function vs. trading volatility

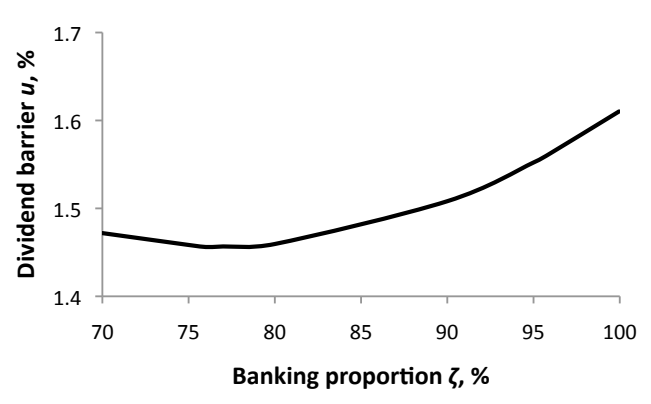

(3.4.2) Dividend barrier vs. banking proportion

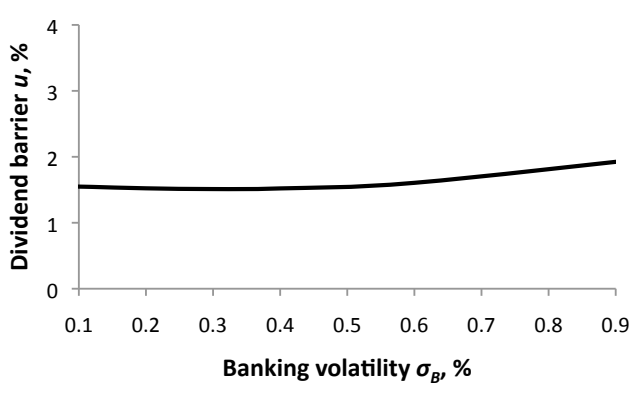

(3.4.4) Dividend barrier vs. banking volatility

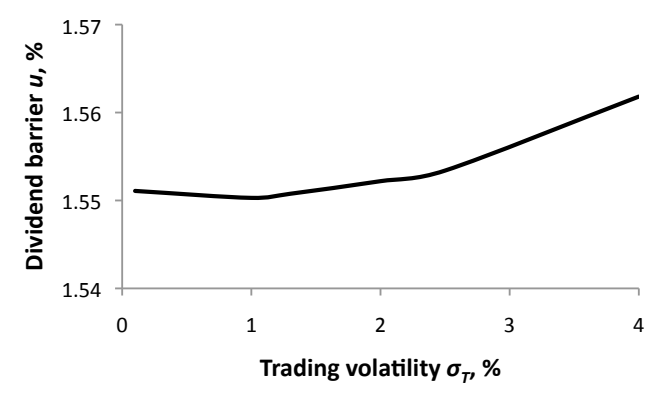

(3.4.6) Dividend barrier vs. trading volatility 


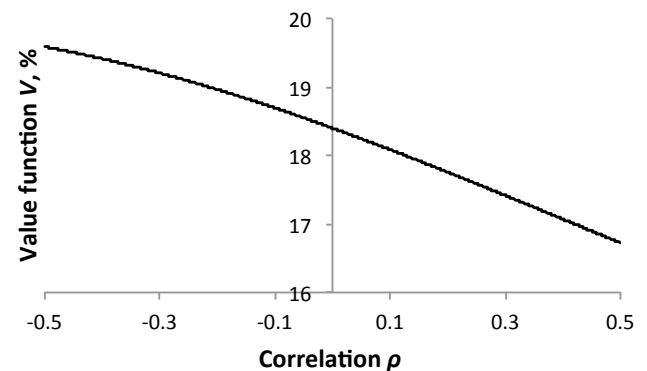

(3.4.7) Value function vs. correlation between banking and trading earnings

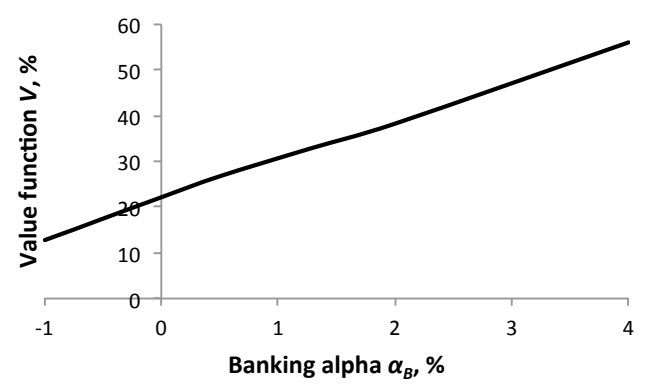

(3.4.9) Value function vs. banking alpha

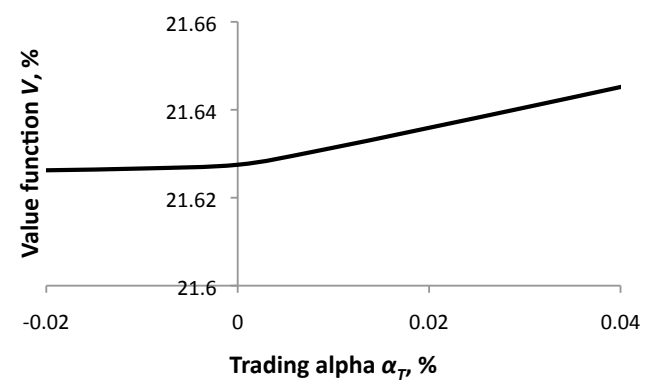

(3.4.11) Value function vs. trading alpha

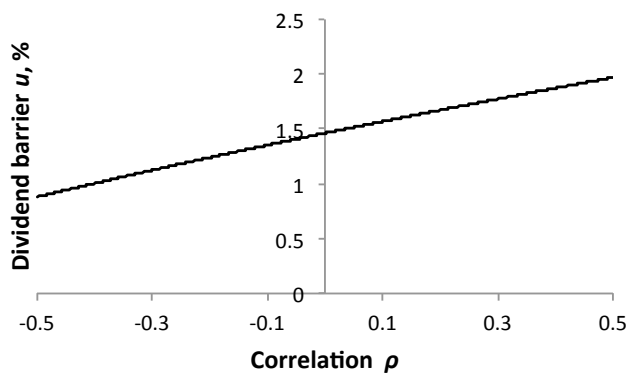

(3.4.8) Dividend barrier vs. correlation between banking and trading earnings

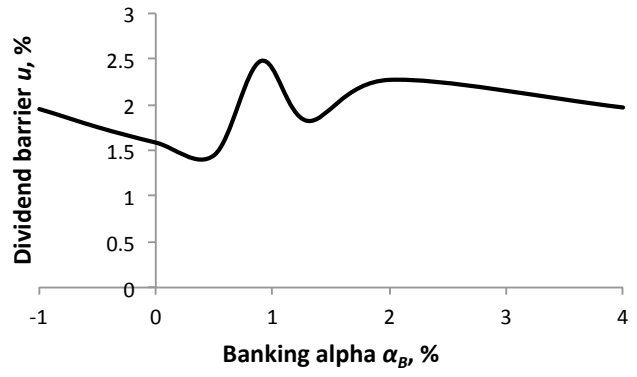

(3.4.10) Dividend barrier vs. banking alpha

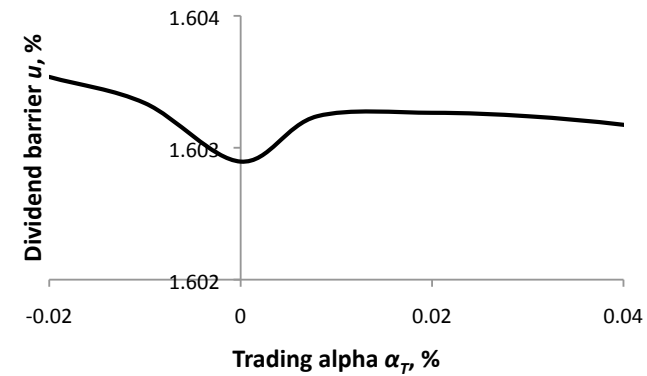

(3.4.12) Dividend barrier vs. trading alpha 


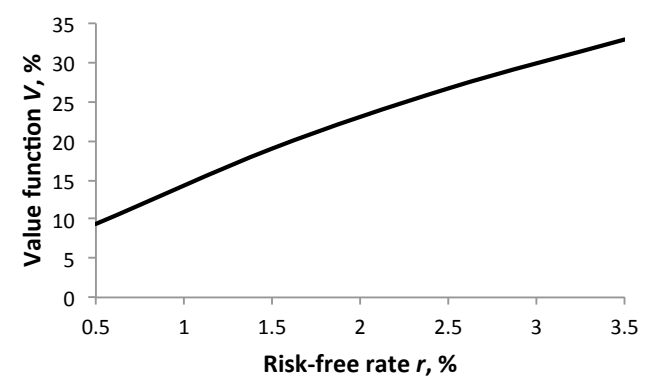

(3.4.13) Value function vs. risk-free rate

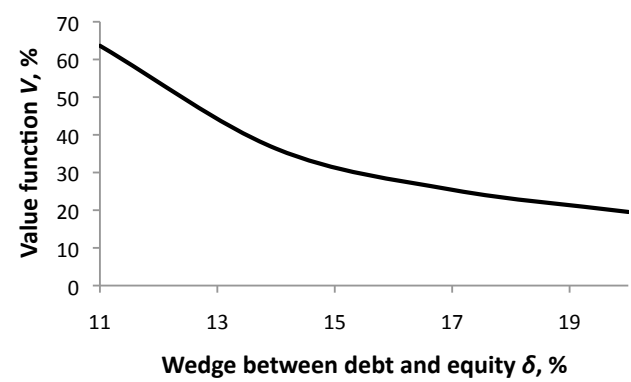

(3.4.15) Value function vs. wedge between debt and equity

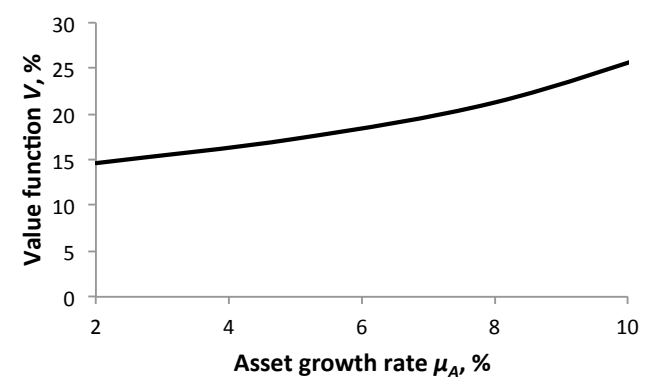

(3.4.17) Value function vs. mean asset growth rate

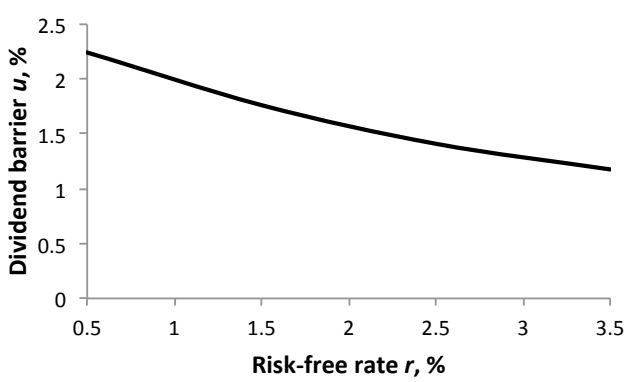

(3.4.14) Dividend barrier vs. risk-free rate

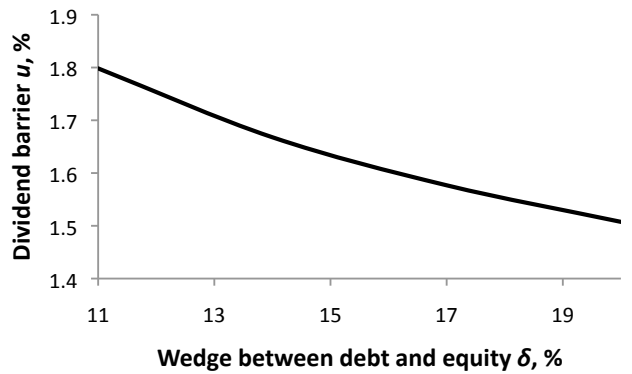

(3.4.16) Dividend barrier vs. wedge between debt and equity

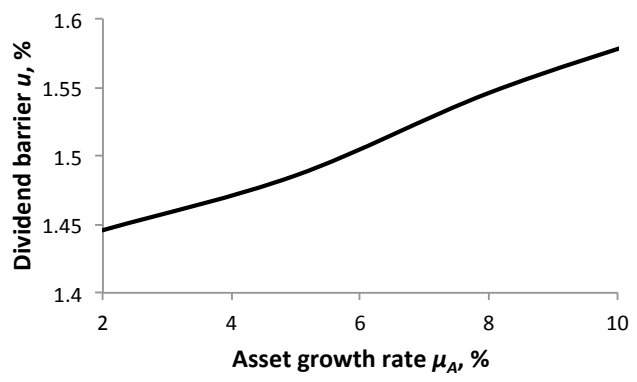

(3.4.18) Dividend barrier vs. mean asset growth rate 


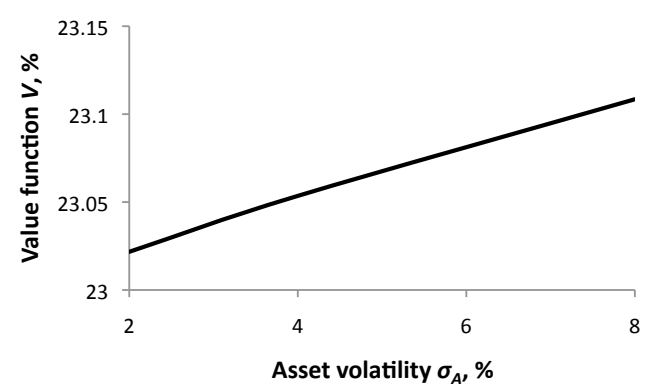

(3.4.19) Value function vs. asset volatility

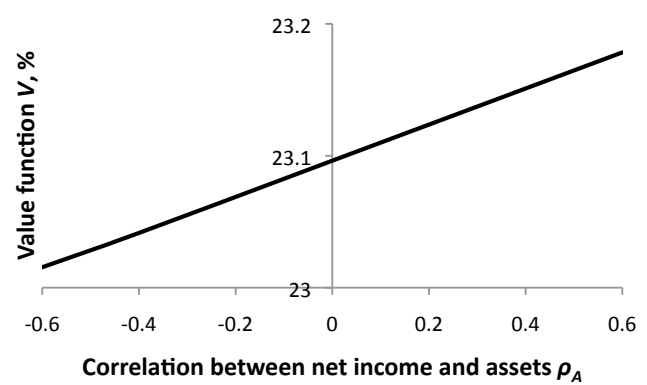

(3.4.21) Value function vs. correlation between net income and assets

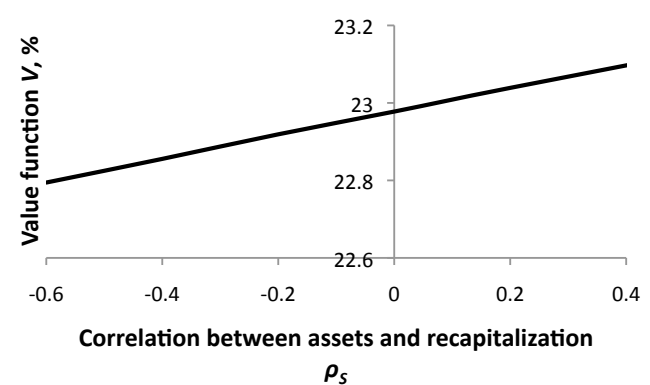

(3.4.23) Value function vs. correlation between assets and recapitalization

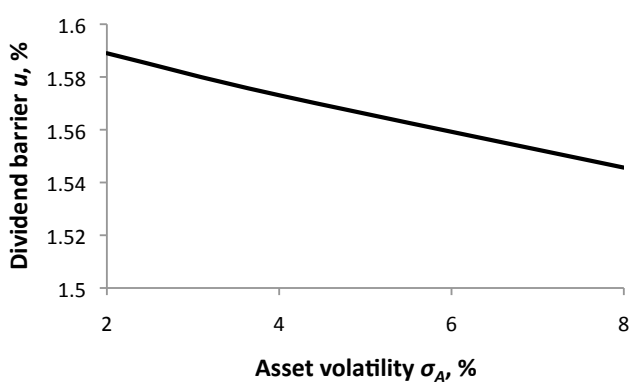

(3.4.20) Dividend barrier vs. asset volatility

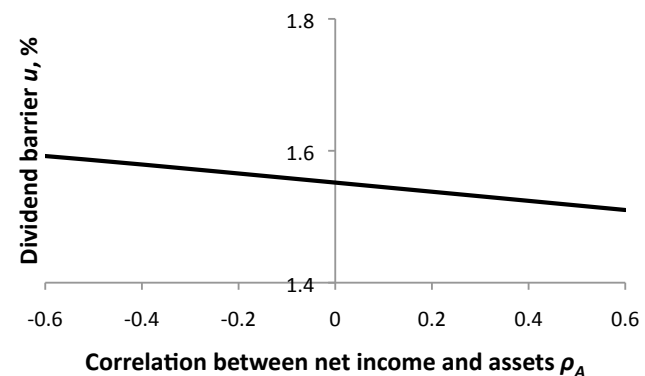

(3.4.22) Dividend barrier vs. correlation between net income and assets

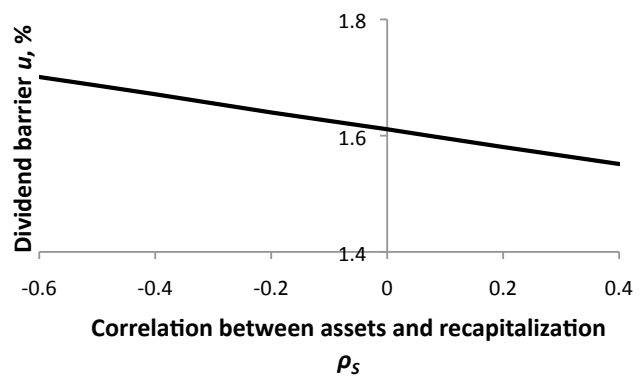

(3.4.24) Dividend barrier vs. correlation between assets and recapitalization 


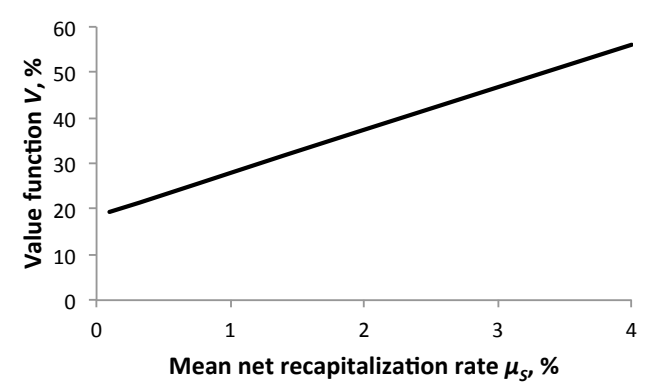

(3.4.25) Value function vs. mean net recapitalization rate

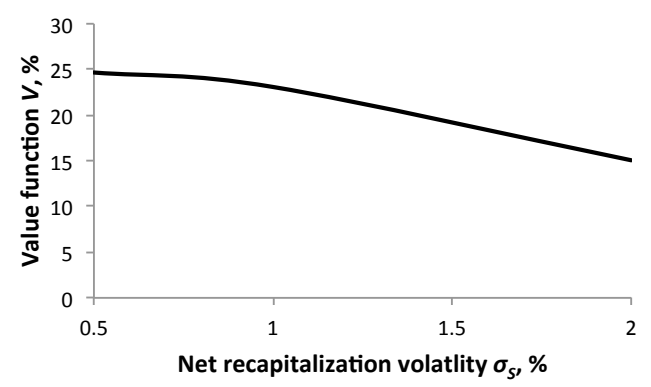

(3.4.27) Value function vs. net recapitalization volatility

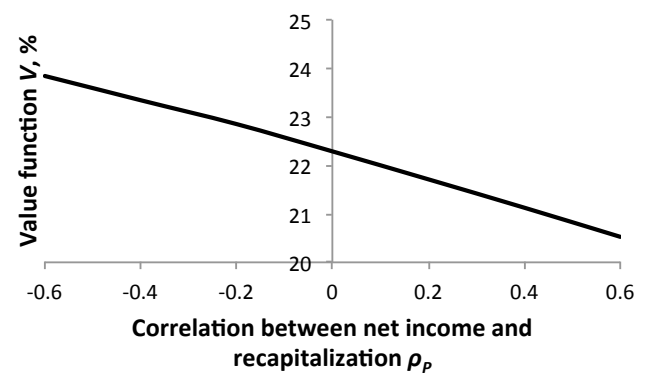

(3.4.29) Value function vs. correlation between net income and recapitalization

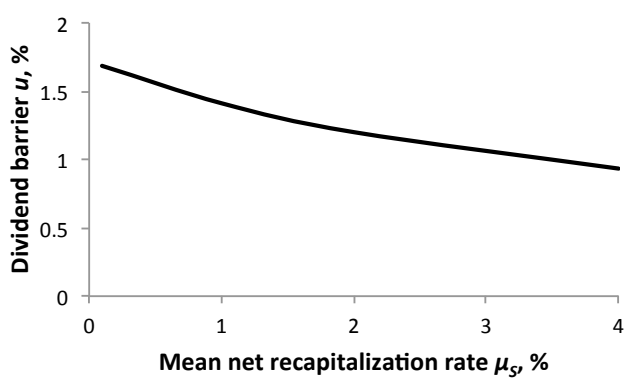

(3.4.26) Dividend barrier vs. mean net recapitalization rate

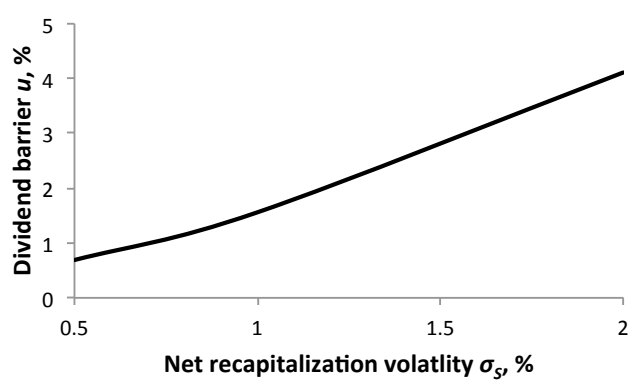

(3.4.28) Dividend barrier vs. net recapitalization volatility

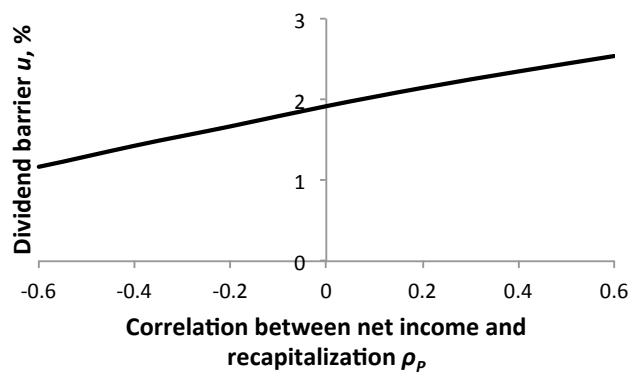

(3.4.30) Dividend barrier vs. correlation between net income and recapitalization 


\subsubsection{Default Probability}

Figure 3.4: Default probability changes with varying model parameters for Bank FHN. We analyze two banks (FHN and WFC) and how their default probability changes with respect to model parameters. We consider two cases: case $(i)$ is without the Volcker rule and case $(i i)$ is under the Volcker rule (no alpha bets). The first bank is FHN and we use its estimated parameters in Table 3.2. Figures below show how the default probability changes with respect to banking proportion $\zeta$, risk-free rate $r$, banking volatility $\sigma_{B}$, trading volatility $\sigma_{T}$, banking alpha $\alpha_{B}$, trading alpha $\alpha_{T}$, correlation between the banking and trading earnings $\rho_{B T}$, correlation between net income earnings and net recapitalization earnings $\rho_{R E}$, correlation between assets and net income earnings $\rho_{A E}$, correlation between net recapitalization earnings and assets $\rho_{R A}$, assets growth rate $\mu_{A}$, net recapitalization returns on assets $\mu_{R}$, assets volatility $\sigma_{A}$, net recapitalization volatility $\sigma_{R}$, wedge between debt and equity finance $\delta$.

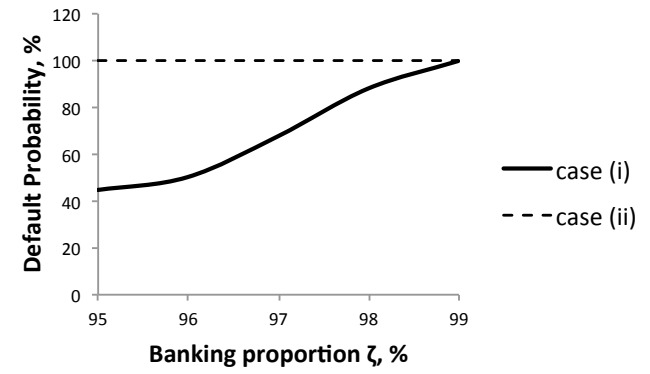

(3.5.1) Default probability vs. banking proportion

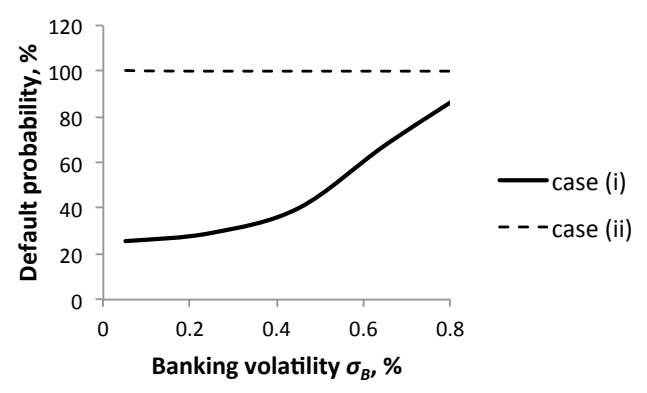

(3.5.3) Default probability vs. banking volatility

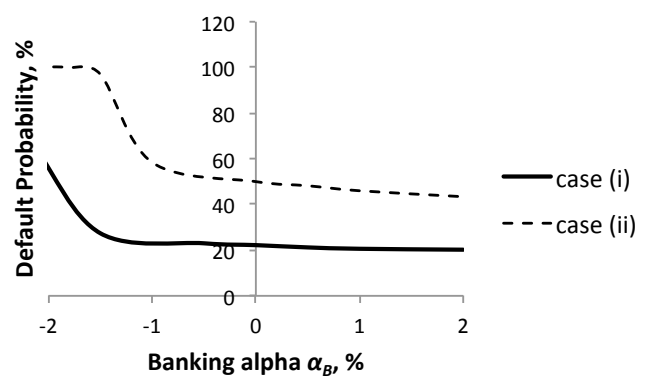

(3.5.5) Default probability vs. banking alpha

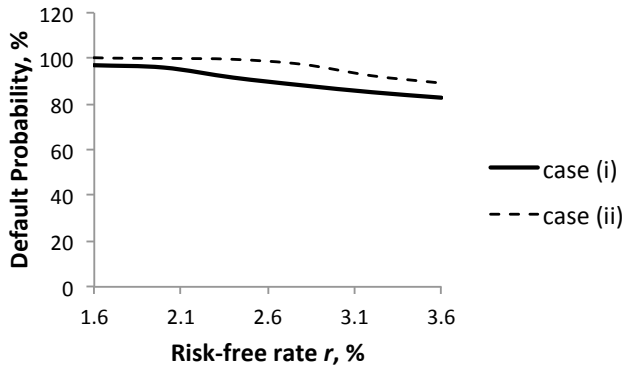

(3.5.2) Default probability vs. adjusted risk-free rate

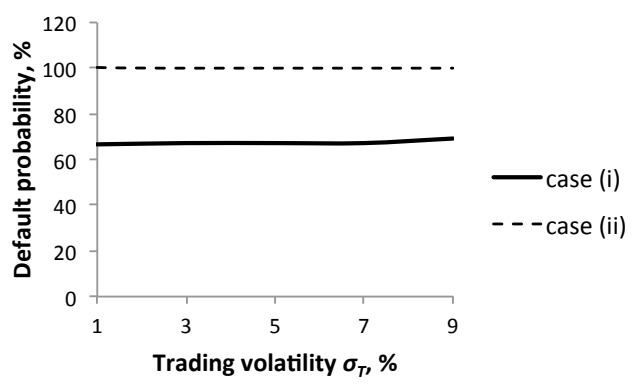

(3.5.4) Default probability vs. trading volatility

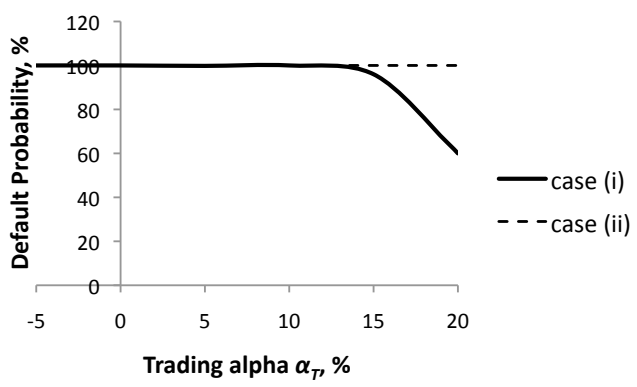

(3.5.6) Default probability vs. trading alpha 


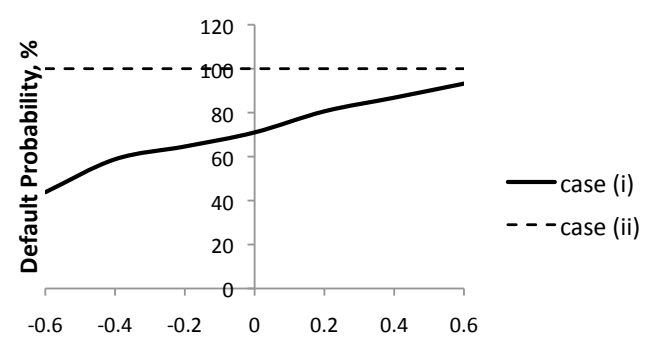

Correlation between banking and trading $\rho$

(3.5.7) Default probability vs. correlation between banking and trading returns

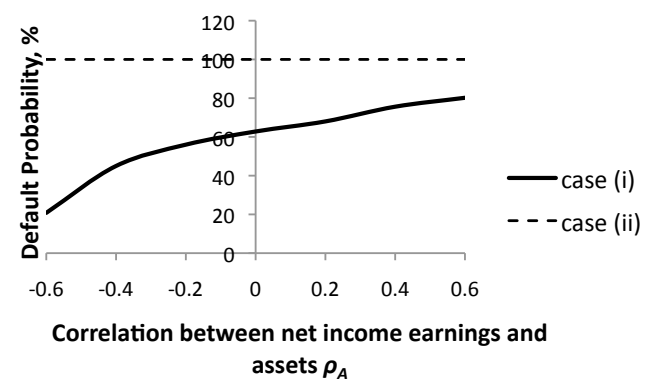

(3.5.9) Default probability vs. correlation between income and asset returns

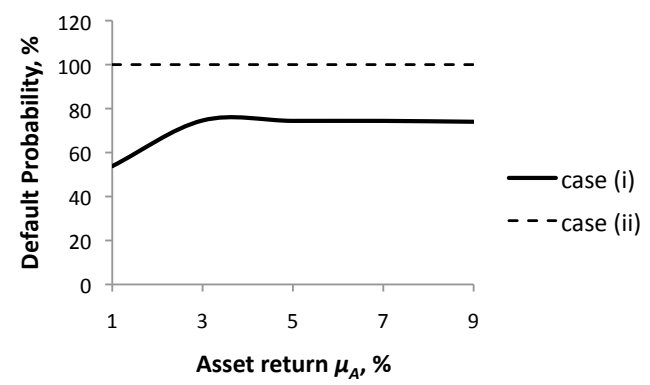

(3.5.11) Default probability vs. mean asset returns

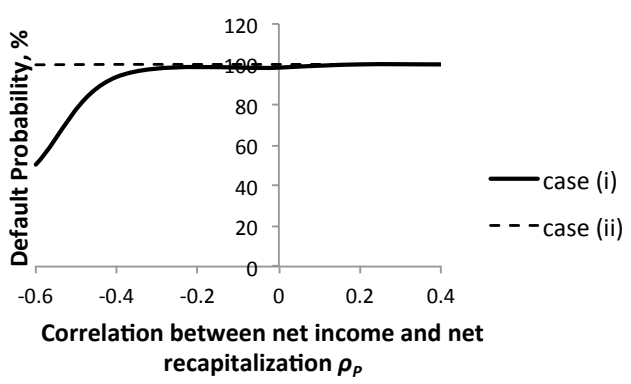

(3.5.8) Default probability vs. correlation between recapitalization and income returns

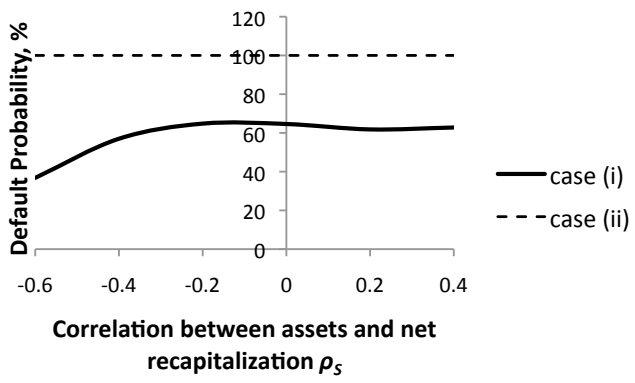

(3.5.10) Default probability vs. correlation between asset and recapitalization returns

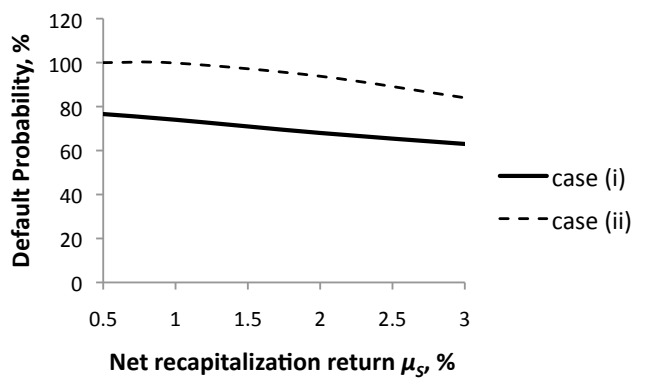

(3.5.12) Default probability vs. mean return on recapitalization 


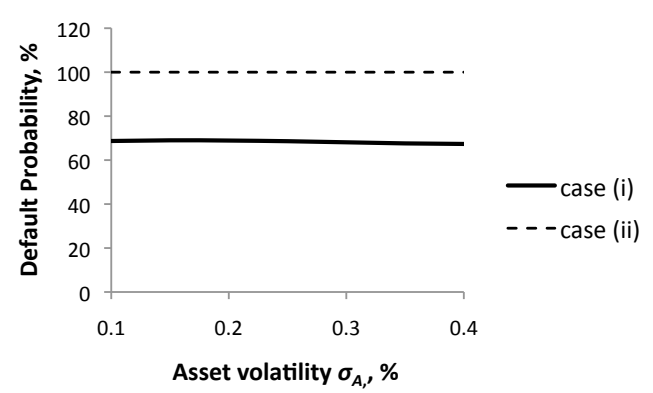

(3.5.13) Default probability vs. assets volatility

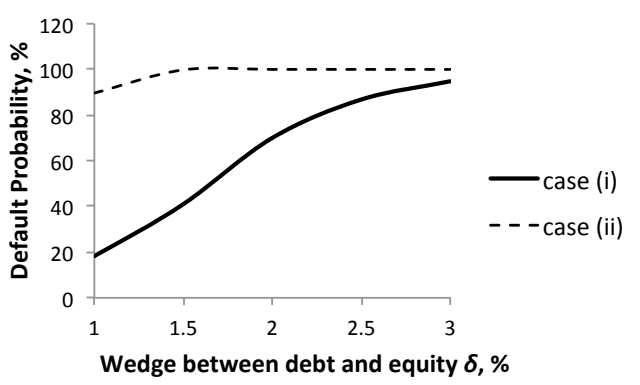

(3.5.15) Default probability vs. wedge between debt and equity

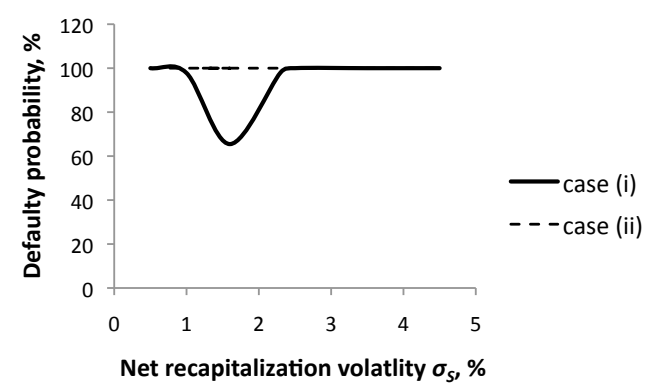

(3.5.14) Default probability vs. net recapitalization volatility

Figure 3.5: Default probability changes with varying model parameters for Bank WFC. The second bank is WFC and we use its estimated parameters in Table 3.2. Figures below show how the default probability changes with respect to banking proportion $\zeta$, risk-free rate $r$, banking volatility $\sigma_{B}$, trading volatility $\sigma_{T}$, banking alpha $\alpha_{B}$, trading alpha $\alpha_{T}$, correlation between the banking and trading earnings $\rho_{B T}$, correlation between net income earnings and net recapitalization earnings $\rho_{R E}$, correlation between assets and net income earnings $\rho_{A E}$, correlation between net recapitalization earnings and assets $\rho_{R A}$, assets growth rate $\mu_{A}$, net recapitalization returns on assets $\mu_{R}$, assets volatility $\sigma_{A}$, net recapitalization volatility $\sigma_{R}$, wedge between debt and equity finance $\delta$.

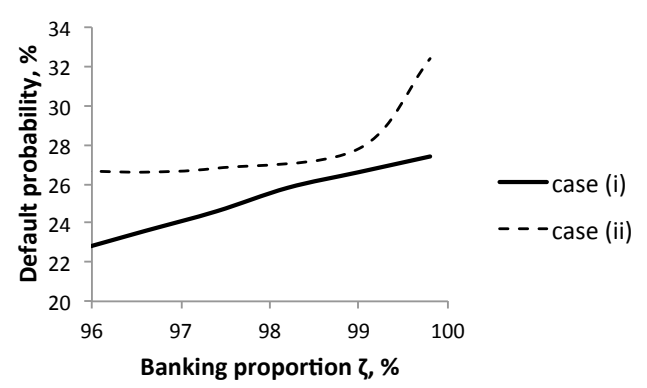

(3.6.1) Default probability vs. banking proportion

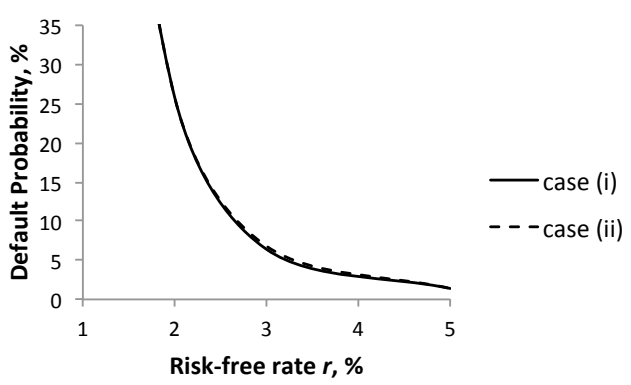

(3.6.2) Default probability vs. adjusted risk-free rate 


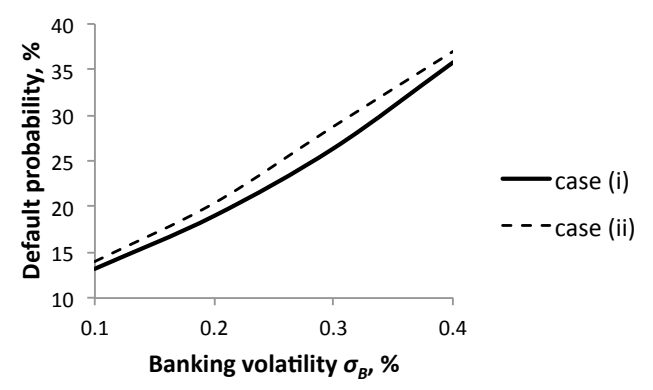

(3.6.3) Default probability vs. banking volatility

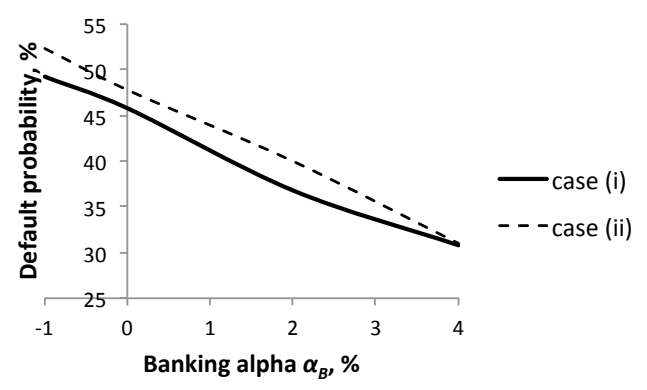

(3.6.5) Default probability vs. banking alpha

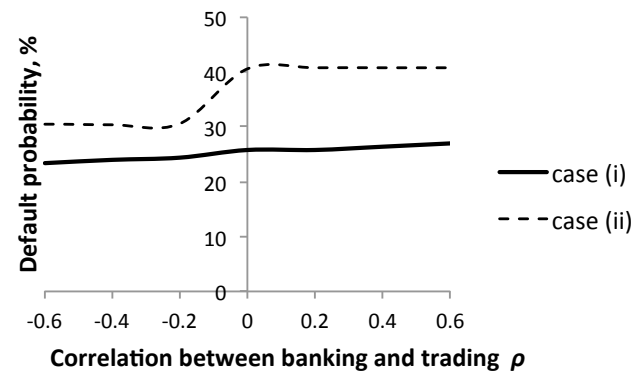

(3.6.7) Default probability vs. correlation between banking and trading returns

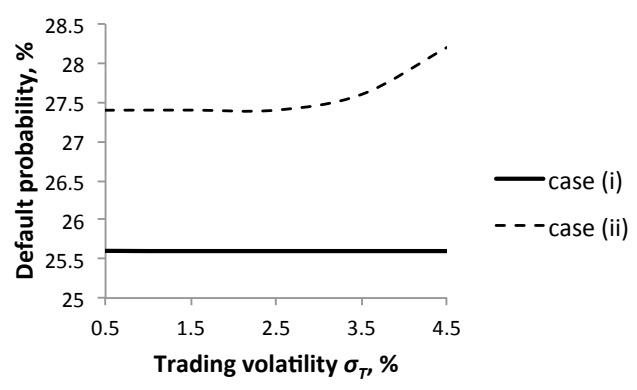

(3.6.4) Default probability vs. trading volatility

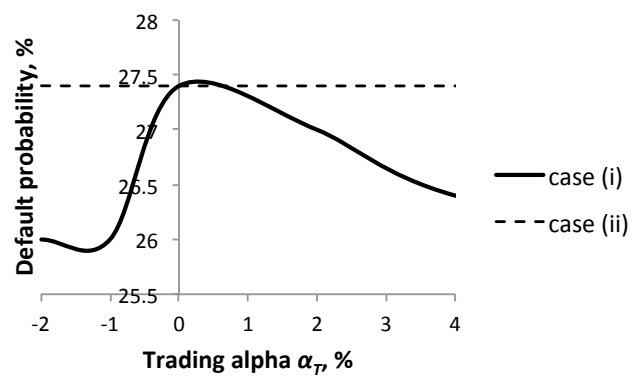

(3.6.6) Default probability vs. trading alpha

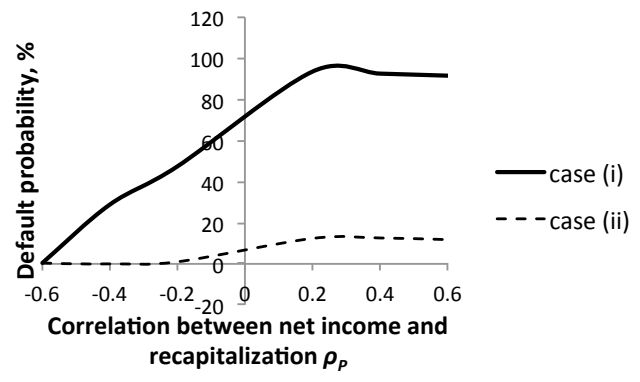

(3.6.8) Default probability vs. correlation between recapitalization and income returns 


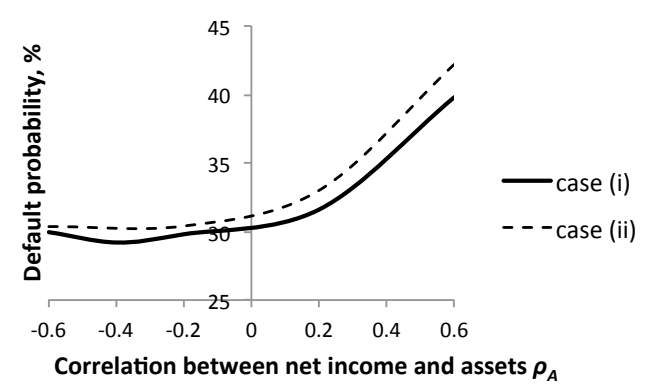

(3.6.9) Default probability vs. correlation between income and asset returns

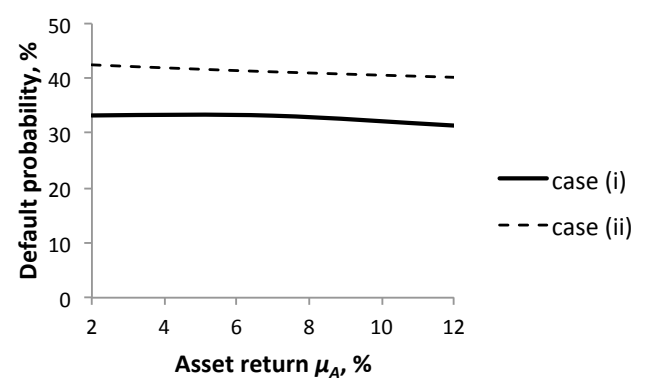

(3.6.11) Default probability vs. mean asset returns

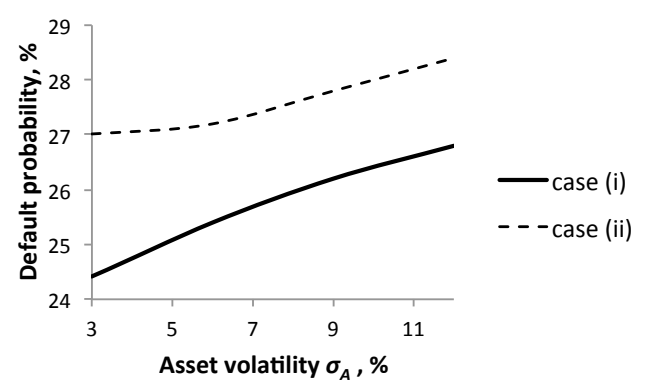

(3.6.13) Default probability vs. assets volatility

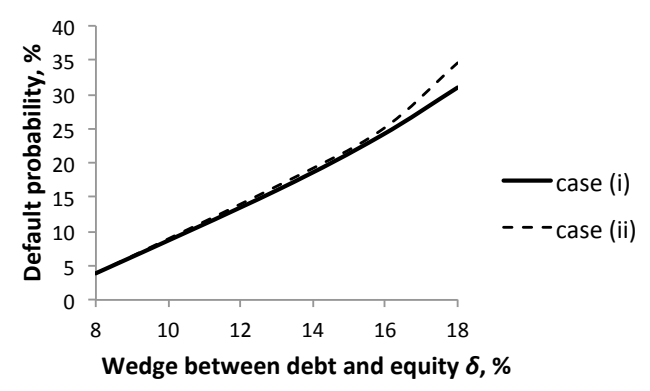

(3.6.15) Default probability vs. wedge between debt and equity

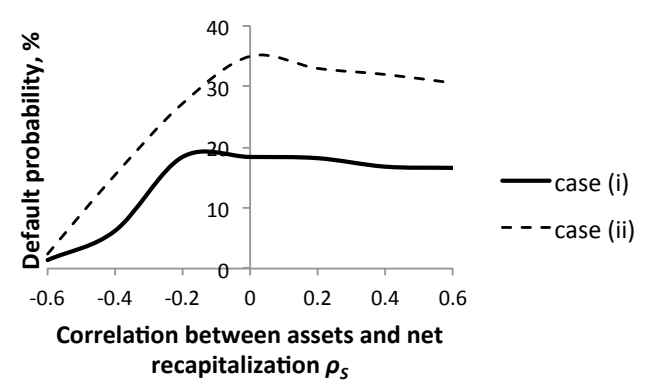

(3.6.10) Default probability vs. correlation between asset and recapitalization returns

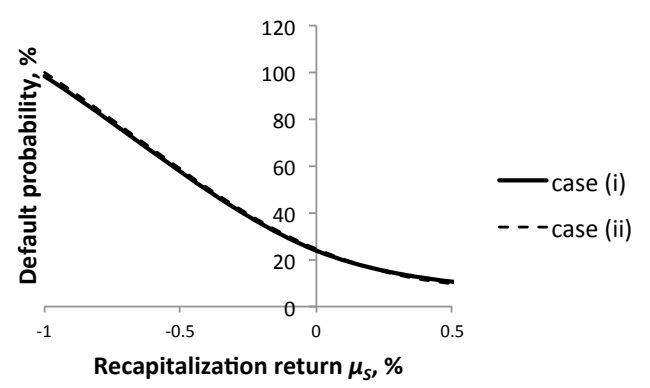

(3.6.12) Default probability vs. mean return on recapitalization

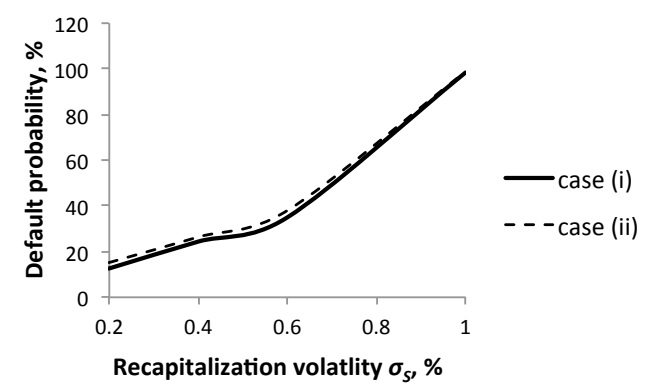

(3.6.14) Default probability vs. net recapitalization volatility 


\section{CHAPTER IV}

\section{Conclusion}

Our goal of this study is to develop a framework with which we are able to measure and analyze the impact of Volcker rule on banks' market equity value and default probability. We have developed two models in which a bank aims to maximize its expected future dividends i.e. the bank's market equity value. The models divide banks' trading into alpha bets and hedging of basic banking cash flows. We assume that the Volcker rule can be implemented and that it bans alpha bets or all trading. We have shown that if the alpha of a bank's trading strategies and the correlation between its trading and banking cash flows are both zero then it is optimal for the bank not to trade at all.

Further, we calibrate the models to a sample of twelve U.S. banks. We use these banks because for them required accounting data for our analysis is available in the Compustat Database. Our empirical results with the limited accounting data indicate that the equity value of the banks would fall on average by about $1 \%$ (in the assets-weighted sense) due to the Volcker rule, this fall could be compensated by raising loan margins by about 1 basis point, and that the rule would increase the banks' default probability on average. The default probability rises because the rule cuts the banks' profitable operations. As a robustness check, we have confirmed 
that the decreased equity value and increased default probability in the results of our sample banks are consistent with the case of a bank with hedge fund parameter estimates.

Our analysis is based on the pre-Volcker rule situation under which several banks may have had profitable or unprofitable trading due to certain economic conditions. We do not know if the trading profits are sustainable and how they are generated (could be partly due to market making). However, we have shown that the rule can raise the default probability of a bank even under a small trading alpha. We ignore implementation costs and risks of the regulation. These important issues are considered in other papers. However, even under our stylized model that assumes that the rule can be implemented without costs, its benefits are unclear.

The Volcker rule may have unintended consequences such as increasing default probability of a bank and therefore harming the stability of the U.S. financial system. Those need to be analyzed and measured. 


\section{Bibliography}

Acharya, V. V., N. Kulkarni, and M. Richardson (2010). Capital, contingent capital, and liquidity requirements. In M. V. V. A. Acharya, Thomas Cooley, T. Cooley, M. Richardson, and I. Walter (Eds.), Regulating Wall Street: The Dodd-Frank Act and the New Architecture of Global Finance, Chapter 6, pp. 143-180. John Wiley \& Sons, Inc.

Acharya, V. V., H. S. Shin, and I. Gujral (2009). Bank dividends in the crisis: A failure of governance. www.voxeu.org/article/.

Agarwal, S., D. Lucca, A. Seru, and F. Trebbi (2012). Inconsistent regulators: Evidence from banking. NBER Working Papers 17736, National Bureau of Economic Research, Inc.

Ang, A., S. Gorovyy, and G. B. van Inwegen (2011). Hedge fund leverage. Journal of Financial Economics 102(1), 102 - 126.

Barth, J. R., G. J. Caprio, and R. Levine (2004). Bank regulation and supervision: what works best? Journal of Financial Intermediation 13(2), 205-248.

Basel Commitee on Banking Supervision (1996a). Amendment to the capital accord to incorporate market risk. Technical report, Bank for International Settlements.

Basel Commitee on Banking Supervision (1996b). Overview of the amendment to the 
capital accord to incorporate market risk. Technical report, Bank for International Settlements.

Basel Commitee on Banking Supervision (1996c). Supervisory framework for the use of ëbacktestingí in conjunction with the internal models approach to market risk capital requirements. Technical report, Bank for International Settlements.

Bhattacharya, S., A. W. A. Boot, and A. V. Thakor (1998). The economics of bank regulation. Journal of Money, Credit and Banking 30(4), 745-70.

Bjork, T. (2009). Arbitrage Theory in Continuous Time. Oxford Finance Series. Oxford University Press, USA.

Brunnermeier, M., A. Crockett, C. Goodhart, A. Persaud, and H. Shin (2009). The Fundamental Principles of Financial Regulation. London: Centre for Economic Policy Research.

Campbell, J. Y., T. Ramadorai, and B. Ranish (2012). How do regulators influence mortgage risk: Evidence from an emerging market. NBER Working Papers 18394, National Bureau of Economic Research, Inc.

Carhart, M. M. (1997). On persistence in mutual fund performance. The Journal of Finance 52(1), 57-82.

Chatterjee, R. R. (2011). Dictionaries fail: The Volcker rules reliance on definitions renders it ineffective and a new solution is needed to adequately regulate proprietary trading. Brigham Young University International Law and Management Review 8(33), 33-62.

Chen, J., H. Hong, M. Huang, and J. D. Kubik (2004, September). Does fund size 
erode mutual fund performance? the role of liquidity and organization. American Economic Review 94(5), 1276-1302.

Chow, J. T. and J. Surti (2011). Making banks safer: Can Volcker and Vickers do it? SSRN eLibrary.

Cremers, K. J. M. and A. Petajisto (2009). How active is your fund manager? a new measure that predicts performance. Review of Financial Studies 22(9), 3329-3365.

Dangl, T. and A. Lehar (2004). Value-at-risk vs. building block regulation in banking. Journal of Financial Intermediation 13(2), 96-131.

Daniel, K., M. Grinblatt, S. Titman, and R. Wermers (1997). Measuring mutual fund performance with characteristic-based benchmarks. The Journal of Finance 52(3), $1035-1058$.

Decamps, J.-P., J.-C. Rochet, and B. Roger (2004). The three pillars of Basel II: optimizing the mix. Journal of Financial Intermediation 13(2), 132-155.

DeYoung, R. and K. P. Roland (2001). Product mix and earnings volatility at commercial banks: Evidence from a degree of total leverage model. Journal of Financial Intermediation 10(1), 54-84.

Duffie, J. D. (2012). Market making under the proposed Volcker rule. SSRN eLibrary.

Dumas, B. (1991). Super contact and related optimality conditions. Journal of Economic Dynamics and Control 15(4), 675-685.

Estrella, A. (2004). The cyclical behavior of optimal bank capital. Journal of Banking $\&$ Finance 28(6), 1469-1498. 
Fabozzi, F. J., R. J. Shiller, and R. S. Tunaru (2010). Property derivatives for managing european real-estate risk. European Financial Management 16(1), 826.

Fleming, W. and H. Soner (2005). Controlled Markov Processes and Viscosity Solutions. Stochastic Modelling And Applied Probability. Springer.

Froot, K. A. and J. C. Stein (1998). Risk management, capital budgeting, and capital structure policy for financial institutions: an integrated approach. Journal of Financial Economics $47(1), 55-82$.

Getmansky, M., A. W. Lo, and I. Makarov (2004). An econometric model of serial correlation and illiquidity in hedge fund returns. Journal of Financial Economics, 529-609.

Haldane, A. G. and P. Alessandri (2009). Banking on the state. BIS Review.

Hart, O. and L. Zingales (2011). A new capital regulation for large financial institutions. American Law and Economics Review 13(2), 453-490.

Heid, F., D. Porath, and S. Stolz (2004). Does capital regulation matter for bank behaviour? evidence for german savings banks. Discussion paper series 2: Banking and financial studies, Deutsche Bundesbank, Research Centre.

Hellmann, T. F., K. C. Murdock, and J. E. Stiglitz (2000). Liberalization, moral hazard in banking, and prudential regulation: Are capital requirements enough? American Economic Review 90(1), 147-165.

Højgaard, B. and M. Taksar (1999). Controlling risk exposure and dividends payout schemes:insurance company example. Mathematical Finance 9(2), 153-182. 
Højgaard, B. and M. Taksar (2004). Optimal dynamic portfolio selection for a corporation with controllable risk and dividend distribution policy. Quantitative Finance 4(3), 315-327.

Holmstrom, B. and J. Tirole (1997). Financial intermediation, loanable funds, and the real sector. The Quarterly Journal of Economics 112(3), 663-91.

Kashyap, A., R. Rajan, and J. Stein (2008). The global roots of the current financial crisis and its implications for regulation. Working paper, University of Chicago.

Keppo, J., L. Kofman, and X. Meng (2010). Unintended consequences of the market risk requirement in banking regulation. Journal of Economic Dynamics and Control 34(10), 2192-2214.

Konczal, M. (2012). Explainer: Why do we need a volcker rule?

Kosowski, R., N. Y. Naik, and M. Teo (2007, April). Do hedge funds deliver alpha? a bayesian and bootstrap analysis. Journal of Financial Economics 84(1), 229-264.

Kushner, H. J. and P. G. Dupuis (2000). Numerical Methods for Stochastic Control Problems in Continuous Time (Stochastic Modelling and Applied Probability). Springer.

Liikanen, E. (2012). High-level expert group on reforming the structure of the eu banking sector: Final report. Technical report, EU.

Mehran, H. and A. Thakor (2011). Bank capital and value in the cross-section. Review of Financial Studies 24(4), 1019-1067.

Miles, D., J. Yang, and G. Marcheggiano (2012). Optimal bank capital. The Economic Journal. 
Milne, A. and D. Robertson (1996). Firm behaviour under the threat of liquidation. Journal of Economic Dynamics and Control 20(8), 1427-1449.

Milne, A. K. (2004). The inventory perspective on bank capital. SSRN eLibrary.

Milne, A. K. and A. E. Whalley (2001). Bank capital regulation and incentives for risk-taking. SSRN eLibrary.

Morrison, A. D. and L. White (2005). Crises and capital requirements in banking. American Economic Review 95(5), 1548-1572.

Peura, S. and J. Keppo (2006). Optimal bank capital with costly recapitalization. Journal of Business 79(4), 2163-2202.

Repullo, R. (2004). Capital requirements, market power, and risk-taking in banking. Journal of Financial Intermediation 13(2), 156-182.

Stiroh, K. J. (2004). Diversification in banking: Is noninterest income the answer? Journal of Money, Credit and Banking 36(5), 853-82.

Stiroh, K. J. (2006). A portfolio view of banking with interest and noninterest activities. Journal of Money, Credit and Banking 38(5), 1351-1361.

Stiroh, K. J. and A. Rumble (2006). The dark side of diversification: The case of us financial holding companies. Journal of Banking \& Finance 30(8), 2131-2161.

Verdier, P.-H. (2012). U.S. implementation of Basel II: Lessons for informal international law-making. In R. W. Joost Pauwelyn and J. Wouters (Eds.), Informal International Lawmaking. Oxford University Press.

Vickers, J. (2011). Vickers report: Final report. Technical report, Independent Commission on Banking. 
Wermers, R. (2003). Are mutual fund shareholders compensated for active management bets?

Whitehead, C. K. (2011). The Volcker rule and evolving financial markets. Harvard Business Law Review 1(1), 39-73. 